Sentence First, ARguments After: MeChanisms of MorPhosyntaX ACQUisition

\author{
A Dissertation \\ submitted to the Faculty of the \\ Graduate School of Arts and Sciences \\ of Georgetown University \\ in partial fulfillment of the requirements for the \\ degree of \\ Doctor of Philosophy \\ in Linguistics
}

By

Heidi Rose Getz, M.S.

Washington, DC

June 29, 2018 
Copyright (ㄷ 2018 by Heidi Rose Getz

All Rights Reserved 


\section{SENTENCE FirST, ARGUMENTS AFter: MeChANISMS OF MORPHOSYNTAX ACQUISITION}

Heidi Rose Getz, M.S.

Thesis Advisor: Elissa L. Newport, Ph.D.

ABSTRACT

Natural languages contain complex grammatical patterns. For example, in German, finite verbs occur second in main clauses while non-finite verbs occur last, as in dein Brüder möchte in den Zoo gehen ("Your brother wants to go to the zoo"). Children easily acquire this type of morphosyntactic contingency (Poeppel \& Wexler, 1993; Deprez \& Pierce, 1994). There is extensive debate in the literature over the nature of children's linguistic representations, but there are considerably fewer mechanistic ideas about how knowledge is actually acquired. Regarding German, one approach might be to learn the position of prosodically prominent open-class words ("verbs go $2^{\text {nd }}$ or last") and then fill in the morphological details. Alternatively, one could work in the opposite direction, learning the position of closed-class morphemes ("-te goes $2^{\text {nd }}$ and -en goes last") and fitting open-class items into the resulting structure. This second approach is counterintuitive, but I will argue that it is the one learners take.

Previous research suggests that learners focus distributional analysis on closedclass items because of their distinctive perceptual properties (Braine, 1963; Morgan, Meier, \& Newport, 1987; Shi, Werker \& Morgan, 1999; Valian \& Coulson, 1988). The Anchoring Hypothesis (Valian \& Coulson, 1988) posits that, because these items tend to occur at grammatically important points in the sentence (e.g., phrase edges), focusing on them helps learners acquire grammatical structure. Here I ask how learners use closed- 
class items to acquire complex morphosyntactic patterns such as the verb form/position contingency in German. Experiments 1-4 refute concerns that morphosyntactic contingencies like those in German are too complex to learn distributionally. Experiments 5-8 explore the mechanisms underlying learning, showing that adults and children analyze closed-class items as predictive of the presence and position of open-class items, but not the reverse. In these experiments, subtle mathematical distinctions in learners' input had significant effects on learning, illuminating the biased computations underlying anchored distributional analysis. Taken together, results suggest that learners organize knowledge of language patterns relative to a small set of closed-class items-just as patterns are represented in modern syntactic theory (Rizzi \& Cinque, 2016). 
"Let the jury consider their verdict," the King said, for about the twentieth time that day.

"No, no!" said the Queen. "Sentence first—verdict afterwards."

"Stuff and nonsense!" said Alice loudly. "The idea of having the sentence first!"

—Lewis Carroll, Alice in Wonderland 


\section{ACKNOWLEDGMENTS}

This research was supported by the Feldstein-Veron Fund for Cognitive Science, Georgetown University, NIH grant Ro1HDo37082 to Elissa Newport, and by the Center for Brain Plasticity and Recovery.

This dissertation was made possible through the support of many people. First and foremost, I am enormously grateful to my advisor, Elissa Newport. What a privilege it has been to be guided by her insight, clarity of thought, and general brilliance for five years. I thank her for all of the ideas, support, encouragement, and inspiration she has provided—she has shaped not just my research but also me. David Lightfoot, too, has been a continual source of insight and encouragement ever since my first semester in graduate school, and I thank him for the many valuable discussions we have had since then. I am also grateful to Virginia Valian and Ruth Kramer for serving on my committee and contributing helpful, thoughtful, and thought-provoking comments and discussion.

For assistance with data collection, I thank Newport lab managers Jaclyn Horowitz, Sarah Furlong and Rebecca Rennert; undergraduate research assistants Alannah Connolly, Claire Nenninger, and Kathleen Coughlin; the DC area schools and daycares who allowed us to conduct research at their facilities, especially the Washington International School and the Arlington YMCA; and the children and adults who participated in these studies.

The title of this dissertation was a gift from Lila Gleitman. I thank Lila (and Lewis Carroll) for this contribution, which I explain on page 9. 
The Interdisciplinary Ph.D. Concentration in Cognitive Science has transformed Cognitive Science at Georgetown, and I want to thank Lissa and David for building this wonderful community. I could not imagine a better environment for interdisciplinary work. Thanks to everyone involved in the Concentration for many stimulating and productive discussions, especially Alix Fetch, Katie Schuler, Bryce Huebner, Shannon Mooney, and Jake Farrell.

For friendship, support, inspiration, motivation, and snacks, a million thanks to Alix Fetch as well as to Adrienne Isaac-I really don't know what I would have done without you.

To my parents, thank you for teaching me to love and cherish learning. I am forever grateful for the education that you worked so hard to give me-it led me straight here. A million thanks to the rest of my family for their unending love and support, and most especially to Andy, for whom thanks could never be enough. 


\section{TABLE OF CONTENTS}

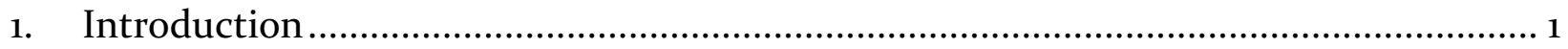

1.1. Theories of morphosyntax acquisition.................................................. 1

1.2. Two approaches to the acquisition of morphosyntactic patterns ...................5

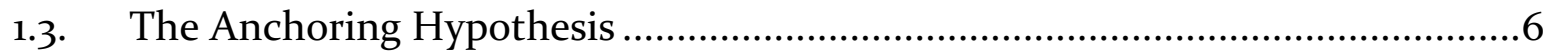

1.4. Closed-class items in linguistic theory ...................................................

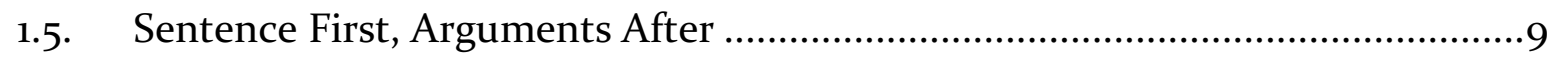

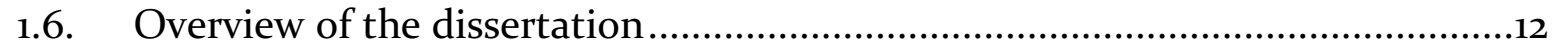

2. Learnability of Complex Morphosyntactic Patterns ............................................. 14

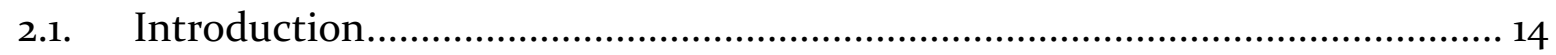

2.2. Experiment 1: Miniature $V_{2}$ language with closed-class morphology ............. 18

2.3. Experiments 2-4: Miniature V2 language with altered morphology................36

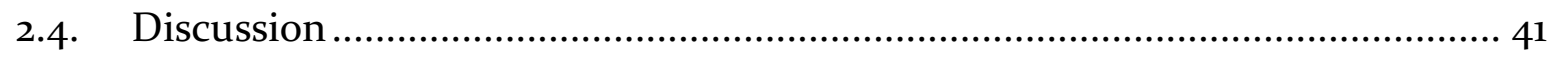

3. Computational Mechanisms of Anchored Distributional Analysis ..........................47

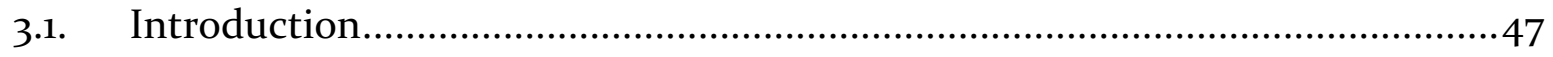

3.2. Experiment 5: Predictive dependency language $(\mathrm{X} \rightarrow \mathrm{Y})$.............................. 53

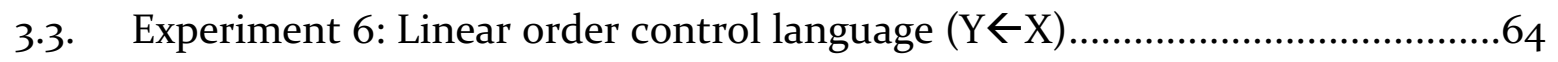

3.4. Experiment 7: Prosody control language $(\mathrm{X} \rightarrow \mathrm{Y})$......................................71

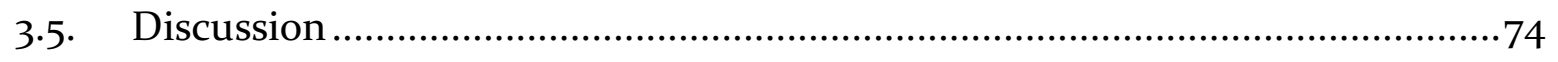

4. Computational Mechanisms for Acquiring a Complex Morphosyntactic Pattern ........77

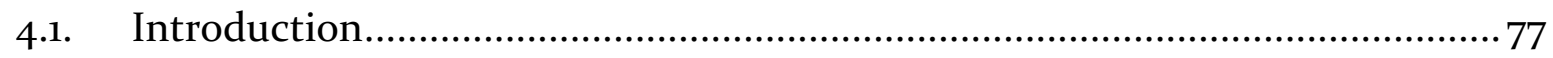

4.2. Experiment 8: Form/position contingency language .................................86

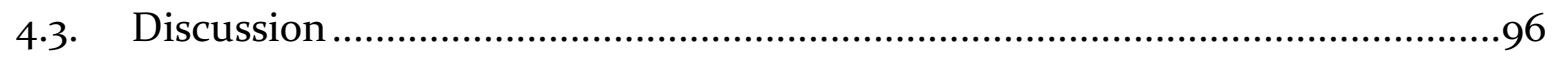

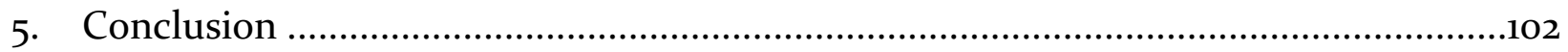

5.1. Summary of the dissertation ............................................................102

5.2. Implications for theories of language acquisition ................................... 104

5.3. Predictions for cross-linguistic variation ............................................107

5.4. Outstanding questions ....................................................................... 110

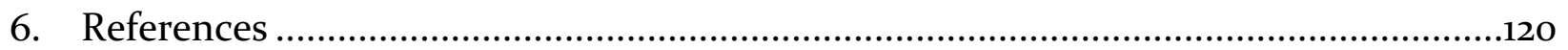




\section{LIST OF FIGURES}

Figure 2.1: Videos used for language exposure in Experiments 1-4….........................23

Figure 2.2: Results of Experiment 1 (miniature V2 language with closed-class morphology), by test item type ...........................................................30

Figure 2.3: Results of Experiment 1 (miniature V2 language with closed-class morphology), by construction

Figure 2.4: Results of Experiments 2-4 (miniature V2 languages with altered morphology), by test item type...........................................................39

Figure 3.1: Results of Experiment 5 (predictive dependency language) ....................... 61

Figure 3.2: $\quad$ Results of Experiment 6 (predictive dependency language, linear

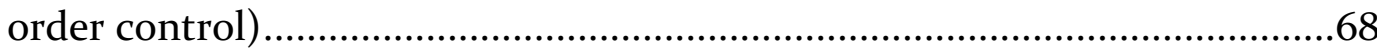

Figure 3.3: Results of Experiment 7 (predictive dependency language, prosody control).

Figure 4.1: Results of Experiment 8 (form/position contingency language) .94

Figure 4.2: Individual results for Experiment 8 (form/position contingency language) 


\section{LIST OF TABLES}

Table 2.1: $\quad$ Syntax of the miniature V2 language used in Experiments 1-4 …................ 19

Table 2.2: Vocabulary of the miniature V2 language used in Experiments 1-4 ….........20

Table 2.3: $\quad$ Morphology of the miniature V2 language used in Experiments 1-4............21

Table 2.4: Test design for Experiments 1-4 .........................................................28

Table 3.1: Vocabulary of the predictive dependency language used in

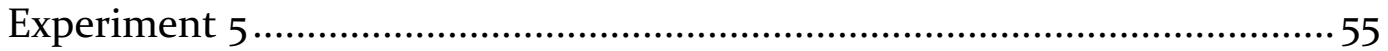

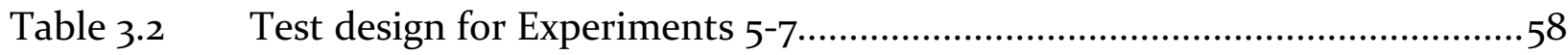

Table 3.3: $\quad$ Results of Experiment 5 (predictive dependency language) ......................6o

Table 3.4: Results of Experiment 6 (predictive dependency language, linear

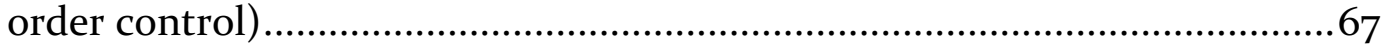

Table 3.5: $\quad$ Results of Experiment 7 (predictive dependency language, prosody

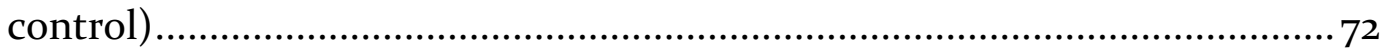

Table 4.1: Design of the form/position contingency language used in

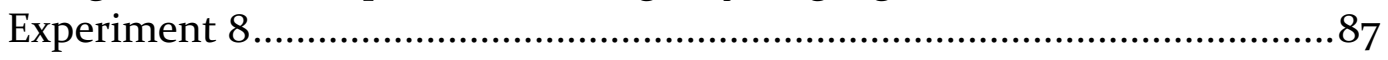

Table 4.2: Results of Experiment 8 (form/position contingency language) .................93 


\section{INTRODUCTION}

1.1. Theories of morphosyntax acquisition

Research on language acquisition has yielded a fine-grained understanding of what this process looks like from the outside. It is clear that any child, no matter their intelligence, can acquire any language of the world with ease; and we know quite a bit about the developmental trajectory along which this knowledge emerges. In the domain of morphosyntax, for example, we know that babies can perceive the perceptual differences between open-class items (content words such as nouns and verbs) and closed-class items (function words such as determiners, pronouns, and tense markers) ${ }^{1}$ soon after birth (Shi, Werker, \& Morgan, 1999). By their first birthday, babies notice when the closed-class items in sentences are removed or altered (Shafer, Shucard, Shucard, \& Gerken, 1998; Shi, Werker, \& Cutler, 2006). Within months, babies also appear to know something about the distribution of closed-class items in a sentence, such as the types of of open-class items that tend to occur nearby (Höhle et al., 2004; Shi \& Melançon, 2010; Zhang, Shi, \& Li, 2015). Knowledge of more complex morphosyntactic patterns begins to emerge soon afterwards (Legendre, Barrière, Goyet, \& Nazzi, 2010; Nazzi, Barrière, Goyet, Kresh, \& Legendre, 2011; Santelmann \& Jusczyk, 1998; Soderstrom, White, Conwell, \& Morgan, 2007). Although children's first sentences generally lack closed-class items

${ }^{1}$ The term 'functional items' or 'function words' refers to elements that carry grammatical structure as opposed to lexical content. The grammatical categories to which these words belong do not readily accept new members, hence these words belong to a 'closed class.' These terms are often used interchangeably. I adopt the terminology of closed and open classes because these terms more readily apply to the miniature language experiments that I conducted. 
(except when these words are perceptually like content words; Slobin, 1966), when children do begin producing these items, they generally put them in the right place (Clahsen, Eisenbeiss, \& Penke, 1996; Clahsen, Penke, \& Parodi, 1993; Déprez \& Pierce, 1993; Déprez \& Pierce, 1994; Haan, 1987; Haegeman, 1995; Jordens, 1990; Pierce, 1992; Poeppel \& Wexler, 1993; Rohrbacher \& Vainikka, 1994; Verrips \& Weissenborn, 1992; Westergaard, 2008).

With all of this data, researchers have developed detailed and contrasting theories of children's linguistic representations. Researchers have debated whether these representations are syntactic (Bloom, 1970a; Valian, 1986) or semantic (Bowerman, 1978; Goldin-Meadow, 1979), abstract (Fisher, 2002; Valian, Solt, \& Stewart, 2009; Yang, 2013) or item-based (Ambridge \& Lieven, 2011, 2015; Bannard, Lieven, \& Tomasello, 2009; Braine, 1976; Tomasello, 2000), present from birth (Crain \& Nakayama, 1987; Crain \& Thornton, 1998; Hyams, 1994, 1996; Rizzi, 1994; Santelmann et al., 2002; Wexler, 1994, 1998) or maturationally triggered (Borer \& Wexler, 1987; Guilfoyle \& Noonan, 1992; Radford, 1990; Vainikka, 1993).

In contrast to this range of theories about children's representations, we have considerably fewer mechanistic ideas about how knowledge is acquired. Languages vary, and a child must first learn that grammatical patterns exist in a particular language before she can represent knowledge of them. Theories claiming that children map sentence strings to an innate Universal Grammar beg the question, since one must actually spell out how learners accomplish this mapping in order for the theory to be explanatory 
(Ambridge, Pine, \& Lieven, 2014; Getz, 2018; Lightfoot, 1995). On this point, there have been very few proposals.

The dearth of mechanistic theories perhaps reflects the difficulty of constructing them in this domain. In biology, one can isolate mechanisms by systematically removing variables that one suspects are involved in the process of interest, and seeing what happens; but of course one cannot ethically do that with children acquiring language. One can take advantage of 'natural experiments' in which some feature of children's environment is atypical (Gleitman, 1990; Newport, 1990), but such studies have inherent limits and do not allow direct manipulation or control over relevant variables.

A methodology that does allow precise control, and which has yielded quite a bit of mechanistic insight, is the miniature language paradigm. In these studies, researchers devise made-up languages, teach them to learners, and measure learners' knowledge on a test. This type of experiment allows precise control over the structure of the input language and the information that is present in the learning environment. An important insight from studies using this method is that humans_-including babies-are capable of extracting information about language structure from the statistical patterns of their input (Aslin, Saffran, \& Newport, 1998; Saffran, Aslin, \& Newport, 1996; Saffran, Newport, \& Aslin, 1996). Contrary to the dominant view of earlier acquisition theory (Pinker, 1984), it turns out that learners can acquire quite a bit of grammatical knowledge-including abstract categories (Reeder, Newport, \& Aslin, 2013) and representations of phrase structure (Thompson \& Newport, 2007)—without semantic meaning, by analyzing the distribution of various linguistic elements (cf. Maratsos \& Chalkley, 1980). 
The mechanism of statistical learning could, in principle, account for the acquisition of a wide range of grammatical patterns. However, research has mainly focused on lower-level patterns such as word segmentation, with a few exceptions (Reeder et al., 2013; Schuler, Yang \& Newport 2016; Wonnacott, Newport \& Tanenhaus 2008; Thompson \& Newport, 2007). The grammatical patterns of natural languages can be quite complex, and work on statistical learning has not yet asked how children acquire these more complex patterns. For example, consider the German sentence (1.1) from the Simone corpus (MacWhinney, 200o; Miller, 1979). There are two verbs in this sentence. One (möchte) appears second and is marked morphologically as finite (with the suffix te); the second (rauchen) appears sentence-finally and is marked morphologically as nonfinite (with the suffix -en). Across different constructions in German, this correlation between syntax (verb position) and morphology (verb inflection) holds, such that finite verbs are generally second in main clauses and non-finite verbs are final.

(1.1) Maxe möchte nur eine Zigarette rauchen Max wants just a cigarette to-smoke 'Max just wants to smoke a cigarette'

Morphosyntactic contingencies like this are quite common in the world's languages, and children acquire them with ease, placing verbs according to finiteness by the age of 2 (Déprez \& Pierce, 1994; Poeppel \& Wexler, 1993). In certain parts of the field, particularly those informed by linguistic theory, there is widespread skepticism that these complex patterns could ever be acquired from statistical information. For example, Poeppel and Wexler (ibid.) note that "it is extremely difficult to see how such complex 
syntactic computations could be learned" (p. 30) and conclude that children who know such patterns must be representing them in an innate linguistic tree.

Of course, the learnability of grammatical structure is an empirical issue. Furthermore, as Poeppel and Wexler themselves acknowledge, saying that children encode knowledge of morphosyntactic patterns using innate representations does not explain how children learn that German has this morphosyntactic pattern in the first place. The goal of the present research is to begin to shed light on the mechanisms by which children do this.

1.2. Two approaches to the acquisition of morphosyntactic patterns

What kinds of computational mechanisms could learners use to identify complex morphosyntactic patterns? Consider a contingency between the verb's position and its morphology as in the German example above. We know that there are perceptual differences between closed-class and open-class items in all languages (Shi, Morgan, \& Allopenna, 1998) and that babies are sensitive to this distinction (Shi et al., 1999). Thus, one approach would be to focus on the words that sound most prominent-the openclass words-and learn their distribution (Gleitman \& Wanner, 1984). In the case of German that would mean learning that verbs can occur second (in main clauses) or last. Then, children could examine the type of morphology that is present on verbs in each position. Focusing on open-class items would seem, intuitively, like the right approach, especially since children's first sentences consist overwhelmingly of these words. In principle, however, there is another approach one could take. Babies could focus on the seemingly less prominent words-the closed-class items-and build the 
sentence up from there. In the case of German, they would learn that the suffix -te goes on whatever is second while the suffix -en occurs on whatever is last. Although this approach may seem counter-intuitive, focusing on closed-class items would reveal quite a bit about the grammar of a language. Function words such as prepositions and determiners tend to occur at the edges of phrases (Clark \& Clark, 1977; Kimball, 1973), so they form a potential clue to the phrase structure of the sentence that adult learners take advantage of (Morgan, Meier, \& Newport, 1987). The high frequency of closed-class items in general could make them useful as markers relative to which learners could encode the position of other items ("first after X"; Braine, 1963; Valian \& Coulson, 1988). And they have a peculiar asymmetry in their distribution (Saffran, 2001): closed-class items always depend on open-class items, but not the other way around. For example, in English if there is a determiner, there will always (eventually) be a noun, but nouns can occur with or without determiners. ${ }^{2}$ These special characteristics of the distribution of closed-class items mean that focusing on them would be a very efficient way of tackling morphosyntax acquisition.

\subsection{The Anchoring Hypothesis}

The theory that learners begin distributional analysis by focusing on closed-class items was termed the Anchoring Hypothesis by Valian and Coulson (1988). The idea is

${ }^{2}$ In some languages, the relationship is bidirectional. For example, determiners are obligatory in French, so determiners always occur with nouns and nouns always occur with determiners. The asymmetry across languages is that closed-class items always predict open-class items, whereas open-class items only sometimes predict closed-class ones. Therefore, it is always more efficient to focus on closed-class items. See Chapter 3 and footnote 9 for further discussion. 
that learners focus on closed-class items because of their distinctive perceptual properties, and that because these items occur in grammatically important parts of the sentence (e.g. phrase edges), this helps learners find the dependencies inside and among phrases. The theory, initially supported by studies of miniature language learning with adults (Morgan et al., 1987; Valian \& Coulson, 1988) and older children (Braine, 1963), gained additional empirical support when it was discovered that babies, too, use closedclass items to find and categorize new words (Shi et al., 2006; Shi \& Lepage, 2008; Zhang et al., 2015). Similar ideas have been proposed in the acquisition of form/position contingencies as in German (Clahsen, Eisenbeiss, \& Penke, 1996; Clahsen \& Penke, 1992).

Anchored distributional analysis does seem like a promising approach for the acquisition of morphosyntactic contingencies. However, at present we lack a mechanistic understanding of how anchored distributional analysis actually works. Once learners have noticed closed-class items, what do they do with them? Do closed-class items point out other grammatical units which learners can then analyze? Or do learners actually analyze closed-class items? What computations are actually done, that is, what is the math that learners do with closed-class items or their neighbors to uncover patterns of language structure? All of these are open questions.

\subsection{Closed-class items in linguistic theory}

The computations that learners perform when analyzing language input will ultimately shape how they represent the language. In linguistic theory, the basic structure of linguistic representations has been well defined, and so we do know where the learner needs to end up. For example, adults' linguistic representations are highly abstract (that 
is, reflecting generalization over specific exemplars and not consisting only of the exemplars themselves) and hierarchically structured. Another property of adults' linguistic representations, discovered more recently, relates to the role of functional categories (see Rizzi \& Cinque, 2016 for discussion and historical context). Increasingly, linguists have argued that properties of closed-class items determine the behavior of other words in the sentence. This extends beyond the presence of certain open-class categories to their actual positions in the sentence. Returning to the German example, linguists capture the contingency between finiteness and verb position by positing that finite and non-finite morphemes are represented in different positions in the sentence. If there is finite morphology, there will be a verb and that verb will occur in the "finite" position (second position in main clauses). In this way, the presence and location of verbs is determined by the kind of morphology that occurs in the sentence.

Why do closed-class items have this special role in sentence structure? One answer is that humans have an innate Universal Grammar, which specifies a central role for functional categories. An alternative is that this property arises from some aspect of the learning process. There is other evidence that learning biases can shape the structure of natural language in this way (Culbertson \& Newport, 2017; Hudson Kam \& Newport, 2009; Newport, 1990). Thus, an important question addressed in this dissertation is whether the learning mechanism responsible for acquiring morphosyntactic patterns can also help account for this structural universal. 


\subsection{Sentence First, Arguments After}

The goal of this dissertation is to examine the learning mechanisms underlying the acquisition of morphosyntactic dependencies. The question is how learners use closedclass items to acquire other language patterns, and how these analyses shape the nature of learners' representations. The answer, I will argue, is that learners analyze closed-class items as predictive of other language patterns. This leads to early detection of simple predictive dependencies ("if Determiner, then Noun") as well as to the acquisition of more complex patterns such as finite/non-finite verb placement. On my hypothesis, the reason learners preferentially analyze closed-class items as predictive is not because they know in advance that this would be the most efficient way to acquire sentence structure. Rather, it is because closed-class items have a cluster of properties that make them highly noticeable to the human brain (e.g., high frequency and distinctive phonology). As a result, representations of these items are available to learners early on as units around which to organize knowledge of sentences. Put simply, the hypothesis is that learners construct representations of sentences out of closed-class items, and fill in the other words-the sentence's arguments-after. ${ }^{3}$

${ }^{3}$ My thanks to Lila Gleitman for suggesting the title of my dissertation: 'Sentence First, Arguments After'. It comes from a passage in Alice and Wonderland where Alice is attending a farce trial of a hare who has allegedly stolen a pan of tarts. The Queen declares that the trial procedure will be "Sentence first, verdict after!" - the absurd idea being that the hare will be sentenced before he ever hears the arguments against him. Lila had the idea for this title quite some time ago but could never use it herself because she and Eric Wanner have argued exactly the opposite (Gleitman \& Wanner, 1982, 1984). That is, they have suggested that children focus on content words (arguments) first, and fill in details of sentence structure later on. When Lila heard what I was proposing, she told me I could have her title. 
The experiments in this dissertation were designed to test the basic claims of the hypothesis : (i) learners can acquire morphosyntactic patterns without representing, in advance, the language's underlying structure (Chapter 2), and (ii) learners acquire such patterns by analyzing closed-class items as predictive of the presence (Chapter 3 ) and also the position (Chapter 4) of open-class items. In order to test these basic claims, we conducted a series of carefully controlled experiments using miniature languages (see section 1.1 for justification of this methodology). These languages are designed to be as simple as possible while retaining whatever properties are critical for asking a specific research question. By design, they lack much of the complexity of real natural languages (otherwise people could not learn them in such a short time). These experiments allowed us to demonstrate empirically that the proposed learning mechanism actually exists, and to begin to explore the range of phenomena that it can handle. It now remains for future work to develop and refine the proposal in order to understand how children draw on this mechanism in the acquisition of real natural languages.

For example, one important question that arises immediately concerns the relevance of this learning mechanism for languages with few closed-class items. All languages have at least some closed-class items : even Mandarin Chinese, the classic example of a language with minimal grammatical inflection, has demonstratives, prepositions, copulas, modals, noun classifiers, verb and noun particles, and sentencefinal pragmatic particles. The closed-class items in Chinese have the same types of correlated cues to class membership as the closed-class items in English and Turkish (Shi, Morgan, \& Allopenna, 1998). However, languages do vary in the number and type of 
closed-class items they contain, and in the degree to which such items are involved in other syntactic patterns. The hypothesized learning mechanism will naturally play a larger role in languages that contain more closed-class items. These are the same languages where the mechanism would be most useful, since it is meant primarily to account for the acquisition of morphosyntactic patterns (and if there is no morphology, then there cannot be any morphosyntactic patterns, so the learners of such languages do not need the mechanism anyway). In languages with fewer closed-class items, where the grammatical patterns are generally syntactic rather than morphosyntactic, other learning mechanisms will presumably play a relatively greater role. I return to this issue in Chapter 2, where I show that learners analyze the same syntactic patterns differently when closed-class items are not present.

A variety of other questions remain. For example, the proposal will need to eventually account for how learners handle items that "sound" like closed-class items but behave somewhat differently, such as prepositions (which may be analyzed as lexical categories) and pronouns (which do not structurally depend on open-class items in the same way that other types of closed-class items do). It was not possible to address these important questions in this dissertation; the focus instead was necessarily on establishing empirical support for the general proposal. However, I will return to these and other issues in the General Discussion where I point out promising areas for future research. 
1.6. Overview of the dissertation

In Chapter 2 (Experiments 1-4) I motivate a pattern-learning approach to morphosyntax acquisition and address concerns about learnability. It has been claimed that complex patterns are too difficult to learn unless learners can, in advance, represent the full linguistic structure of the language. I demonstrate that adults can in fact learn complex grammatical patterns in a miniature language without full knowledge of the language's grammar. Learning of this language was best when the syntactic patterns correlated with a morphological one, illustrating that anchoring to closed-class items is an important feature of this pattern-learning mechanism.

In Chapter 3 (Experiments 5-7) I begin to examine the computational mechanisms underlying anchored distributional analysis. I ask what types of analyses adult learners do with closed-class and open-class items, and whether any of these computations are privileged over others. Results reveal that closed-class items have a privileged status in learners' computations as given terms, such that learners more readily acquire relationships in which closed-class items predict open-class ones than the other way around.

In Chapter 4 (Experiment 8), I ask whether the computational mechanism discovered in Chapter 3 can account for the acquisition of the more complex patterns studied in Chapter 2. I also ask whether this mechanism is available to child learners. The answer to both questions is yes: child learners acquire a verb form/position contingency by encoding the position of closed-class items, rather than the position of open-class 
items, taking a counter-intuitive—but fruitful—approach to the acquisition of morphosyntactic knowledge.

Finally, in Chapter 5, I briefly summarize implications for theories of language acquisition, raise several important questions about how this learning mechanism might apply in the context of the acquisition of real languages, and point out promising avenues for future research. 


\section{LEARNABILITY OF COMPLEX MORPHOSYNTACTIC PATTERNS}

\subsection{Introduction}

Complex word-order patterns in natural languages pose a challenge for the language learner. For example, in German, embedded clauses have SOV word order while main clauses always have the verb second and allow any topicalized constituent (either subjects or non-subjects) to be first. This is called V2 word order. In addition, the verb's inflection varies with its position: verbs that are morphologically inflected for finiteness generally occur second in main clauses (V2), while nonfinite verbs are last (Vfinal). ${ }^{4}$

Adults' knowledge of this complex set of patterns can be elegantly represented as a transformational grammar. The idea is that German's underlying word order is SOV, and V2 sentences are generated from that structure via two movement operations. One operation (Fronting) moves a Subject or non-Subject to first position, and a second operation (Verb Movement) raises the verb from final to second position. The correlation between Fronting and Verb Movement, and the relationship of between the verb's position and morphological finiteness, can be captured by stating restrictions on when certain syntactic operations can occur.

${ }^{4}$ This form/position contingency is not perfect. Finite verbs can also occur last (as in subordinate clauses) or first (imperatives and questions). In the literature on the acquisition of $\mathrm{V}_{\mathbf{2}}$ languages, however, sentence-final finite verbs in the speech of young children (age $\sim 1-3$ ) are generally interpreted as verb placement errors. This interpretation reflects the assumption that children have not yet acquired embedded clauses (there is no other evidence that they have acquired embedded clauses by this point; they do not produce complementizers, for example). Furthermore, these "errors" are extremely rare (see below), suggesting that children learning V2 languages treat second position as the location for finite verbs-despite occasional exposure to sentences where the finite verb is elsewhere. 
Children acquire the patterns of V2 word order remarkably early. For example, toddlers learning German and other V2 languages correctly place finite verbs second and non-finite verbs last, use either $V_{2}$ or Vfinal when subjects are first, and use only V2 when objects or adverbs are first (Boser 1992, Poeppel and Wexler 1993, Haegeman 1995). Based on this evidence, many linguists have concluded that toddlers represent an abstract, adultlike transformational grammar. Note, however, that the actual data comprises statistical contingencies among surface patterns (verb form, verb position, and the category of sentence-initial words), while the inference is that toddlers represent these patterns in an abstract way.

Suppose toddlers do use an abstract transformational grammar to represent patterns such as verb placement. How do they learn which particular operations are relevant for a specific language? Poeppel and Wexler (1993) noted that this question was unanswered, and twenty-five years later this is still true. The mechanism cannot be, for example, parameter setting: $V_{2}$ patterns manifest variably in different languages, and learners of languages like Norwegian—where V2 works differently with certain lexical items—do not overgeneralize (Westergaard, 2009). Instead, children must use inputdriven learning procedures to learn, step by step, how V2 works in their particular language. They must first learn that certain patterns exist in their language in order to represent them in an abstract tree, raising the possibility that perhaps these superficial patterns are—at least initially—all the child knows.

In that case, knowledge would be of the following nature. Instead of representing an abstract transformational grammar, the child would know a set of relatively concrete 
surface patterns: that verbs may be second or final, and that second-position verbs take one set of endings, while final-position verbs take a different set; that subjects may be first, and when they are, the verb may be second or final; and that non-subjects may be first as well, but the verb is always second. Note that the child need not actually know what the patterns mean (e.g., that the verb endings encode the notions of 'finiteness' or 'non-finiteness') in order to place words in the correct position, nor do they need to represent an underlying structure with two movement rules. In other words, it is possible in principle to know these distributional patterns of German without actually representing them in an abstract way.

If this approach is right, then toddlers' knowledge of $V_{2}$ languages may reflect knowledge of concrete distributional patterns, and not adultlike representations. This possibility has not been seriously considered in the generative literature. To the contrary, a widespread assumption is that acquisition of complex patterns is simply not possible without full linguistic representations. Poeppel and Wexler (1993), for example, note that "it is extremely difficult to see how such complex syntactic computations could be learned," concluding not only that children represent a transformational grammar but that the components of this grammar (e.g., verb movement) must be innate.

However, the learnability of complex syntactic patterns is an empirical issue, and that is the focus of this chapter. I explore the hypothesis that learners acquire linguistic contingencies by identifying and correlating concrete patterns of word order and word form. Although this approach emphasizes input-driven learning, it does not claim that learners search for patterns in an unconstrained way. Rather than identifying and 
correlating all possible patterns in the language—an approach that might seem possible in principle but which would seem at odds with the relatively limited variation in natural languages-I explore the possibility that learners "anchor" their analyses to closed-class items, as they have been shown to do in the acquisition of grammatical categories and phrase structure (Valian \& Coulson, 1988; Morgan, Meier \& Newport, 1987; Braine, 1963). This would lead learners to find patterns that correlate with closed-class morphology, such as V2 word order, without requiring them to search all possible portions of the sentence.

This pattern-learning approach is different in important ways from a constructivist approach (e.g., Freudenthal et al. 2007). Constructivist learning models posit that children memorize sentence templates but do not acquire any independent knowledge of the patterns inside them. In contrast, I suggest that the child does learn patterns, though she may not initially represent them in an abstract adultlike way.

The aim of this chapter is to ask empirically whether a pattern-learning approach of this kind is viable. Our first question, motivated by the learnability concerns of Poeppel and Wexler (1993) and many others, was whether a complex cluster of patterns can be learned in the laboratory at all, given minimal semantic and pragmatic information and relatively little exposure to the language. A second question was whether it is possible to learn those distributional patterns without full hierarchical linguistic representations. We addressed these two questions in Experiment 1. Then, in Experiments 2-4, we began to explore constraints on this pattern learning mechanism by asking whether the availability of a salient closed-class anchor on V2 affects learners' ability to acquire V2 patterns. 
2.2. Experiment 1: Miniature V2 language with closed-class morphology

We created a miniature language with the classic V2 patterns: the verb's form depended on its position, initial Subjects allowed V2 or Vfinal, and initial Objects/Adverbs required V2. These are the patterns that Poeppel and Wexler (1993), among others, cite as too complex to learn without innate representations. The aim of Experiment 1 was to determine whether these patterns could be acquired by learners in the lab, with minimal semantic and pragmatic information and relatively brief exposure to the language. A second aim was to find out whether full knowledge of the language's structure is required in order to learn these patterns.

\subsubsection{Experiment 1 method}

\subsubsection{Participants}

Eight students at Georgetown University (age 18-20, mean 18.6) received \$10 to participate in this study. Potential participants were screened via email. Individuals who reported exposure to any $V_{2}$ language, or reported having taken a course on language acquisition or language structure (e.g., Syntax), were not invited to participate.

\subsubsection{Description of the language}

The syntax of our language, summarized in Table 2.1, was the same for all four experiments in this chapter. The basic sentence structure was S-Adv-O-V. We formed complex sentences by applying two rules: (1) front a non-verb (S, Adv, or O) and (2) place the verb 2nd. These constraints allow sentences with initial Subjects to have either Vfinal or V2, while sentences with initial Objects or Adverbs require V2. 
Table 2.1: Syntax of the miniature V2 language used in Experiments 1-4.

\begin{tabular}{|c|c|c|c|c|c|c|c|}
\hline \multirow[b]{2}{*}{ Basic structures (12) } & \multicolumn{2}{|c|}{ "Moved" words } & \multicolumn{4}{|c|}{ "Unmoved" words } & \multirow{2}{*}{$\frac{\text { Types }}{6}$} \\
\hline & & & S & Adv & $\mathrm{O}$ & $\mathrm{V}$ & \\
\hline & & & S & & $\mathrm{O}$ & $\mathrm{V}$ & 6 \\
\hline \multirow[t]{5}{*}{ Complex structures (26) } & $\mathrm{S}$ & $\mathrm{V}$ & & Adv & $\mathrm{O}$ & & 4 \\
\hline & $\mathrm{S}$ & $\mathrm{V}$ & & & $\mathrm{O}$ & & 4 \\
\hline & $\mathrm{O}$ & $\mathrm{V}$ & S & Adv & & & 5 \\
\hline & $\mathrm{O}$ & $\mathrm{V}$ & S & & & & 5 \\
\hline & Adv & $\mathrm{V}$ & S & & $\mathrm{O}$ & & 8 \\
\hline
\end{tabular}

Note. Complex sentences were derived by moving a non-verb $1^{\text {st }}$ and moving the verb $2^{\text {nd }}$. The morphology of the language depended on the experiment (see Table 2.4).

While the syntax of this language includes the fundamental characteristics of a natural V2 language, it is kept simple for learning in large part because of the small vocabulary used in the language. The lexical items in the language's tiny vocabulary (Table 2.2) included three nouns, two verbs, and two adverbs. Each lexical category included a mixture of mono- and bisyllabic words, all bearing initial stress and ending with a closed final syllable. The distribution of lexical categories in sentences is determined by the syntax of the language and was the same for all experiments in this chapter. The language also contains a meaningless verb inflection. The distribution and class type of the inflection category varied across experiments (Table 2.3). In Experiment 1, the inflection category was closed class: it contained a single short, unstressed, phonologically reduced, prosodically weak form ("kuh"). This form occurred as a suffix on 
second-position verbs only and did not occur on final-position verbs. In this condition, the inflection is analogous to finite morphology in German, where main clause verbs with finite morphology are generally second and not final (this miniature language does not have embedded clauses, which is the context where finite verbs can be final in German). All natural V2 languages have, at minimum, closed-class finite morphology. Experiment 1 therefore asked whether people can learn V2 word order patterns under typologically natural conditions.

Table 2.2. Vocabulary of the miniature V2 language used in Experiments 1-4.

\begin{tabular}{|c|c|c|}
\hline Category & Word & Meaning \\
\hline \multirow[t]{3}{*}{ Noun } & flugit & bee \\
\hline & daffin & giraffe \\
\hline & mawg & lion \\
\hline \multirow[t]{2}{*}{ Verb } & zemper & hug \\
\hline & $\operatorname{nim}$ & head-butt \\
\hline \multirow[t]{2}{*}{ Adverb } & spad & slowly \\
\hline & lapal & twice \\
\hline Inflection & see Table 2.3 & none \\
\hline
\end{tabular}


Table 2.3: Morphology of the miniature V2 language used in Experiments 1-4.

\begin{tabular}{|c|c|c|c|c|}
\hline \multicolumn{2}{|c|}{ Experiment } & \multirow{2}{*}{$\frac{\mathrm{V}_{2}}{\text { "zemperkuh" }}$} & \multirow{2}{*}{$\frac{\text { Vfinal }}{\text { "zemper" }}$} & \multirow{2}{*}{$\begin{array}{l}\text { Description } \\
V_{2} \text { is marked with the suffix kuh } \\
\text { (the inflection is short, high } \\
\text { frequency, and prosodically } \\
\text { reduced) }\end{array}$} \\
\hline 1 & $\mathrm{~V}_{2}+\mathrm{CC}$ & & & \\
\hline 2 & $\mathrm{~V} 2+\mathrm{OC}$ & "zemper lapal" & “zemper” & $\begin{array}{l}\mathrm{V}_{2} \text { is followed by tombur, zup, or } \\
\text { lapal (these words are similar in } \\
\text { length and frequency to the other } \\
\text { open-class words in the language) }\end{array}$ \\
\hline 3 & $V_{2}-\varnothing$ & “zemper” & “zemper” & No inflection \\
\hline 4 & Vfinal+CC & “zemper” & “zemperkuh” & Vfinal is marked with the suffix $k u h$ \\
\hline
\end{tabular}

Note. The language's morphology differed depending on the experiment. In Experiment 1 $\left(\mathrm{V}_{2}+\mathrm{CC}\right)$, verbs in second position $\left(\mathrm{V}_{2}\right)$ had the suffix kuh while verbs in final position (VFinal) were uninflected; in Experiment 2 (V2+OC), V2 was followed by tombur, zub or lapal while Vfinal was uninflected; in Experiment 3 (V2-ø), neither V2 nor Vfinal had any inflection; and in Experiment 4 (Vfinal+CC), Vfinal was followed by tombur, zup, or lapal. Only the morphology in Experiment 1 is typical of natural V2 languages.

\subsubsection{Materials}

We generated a 38 -sentence exposure set by selecting 4 to 8 sentence types for each of the seven sentence structures in Table 2.1. Twenty six of these sentences (68\%) were complex $\left(\mathrm{V}_{2}\right)$ sentences, while the remaining $32 \%(12 / 38)$ had basic sentence structure (Vfinal). Subject-initial sentences were a slight majority $(53 \%) .{ }^{5}$ When selecting sentence strings, care was taken to ensure that the distribution of lexical items was even, both across and within sentence structures. For each sentence structure, sentence types

${ }^{5}$ We arrived at this distribution of type frequencies after extensive piloting. Preliminary results suggested that participants failed to extend a generalized "fronting" rule to adverbs when the AVSO structure had the same token frequency as the others. Note that there are twice as many Object-initial structures as Adverb-initial structures. 
were selected such that half used one verb and half used the other; each of the three nouns appeared as subject and object at least once with each verb; and, for sentences containing adverbs, each adverb occurred equally often with each verb. Sentence sound files were synthesized in MacInTalk using a female voice from InfoVox iVox (Sharon). Words were separated by 150 msec of silence.

During exposure, each sentence was paired with a video from an existing corpus of miniature language stimuli (Austin, 2010). In each video, one puppet approached a second puppet and performed a transitive action (Figure 2.1). The Agent and Patient of the action were always the syntactic subject and object of the sentence, respectively. Our miniature language contained adverbs, so we also created modified versions of the videos in which the action took place "twice" or "slowly". The "twice" videos were created by applying iMovie's Rewind function, then duplicating the video, such that the Agent appeared to perform the action, return to a standing position, and then re-perform the action. The "slow" videos were created by applying iMovie's "slow motion" function ( $25 \%$ slower). 


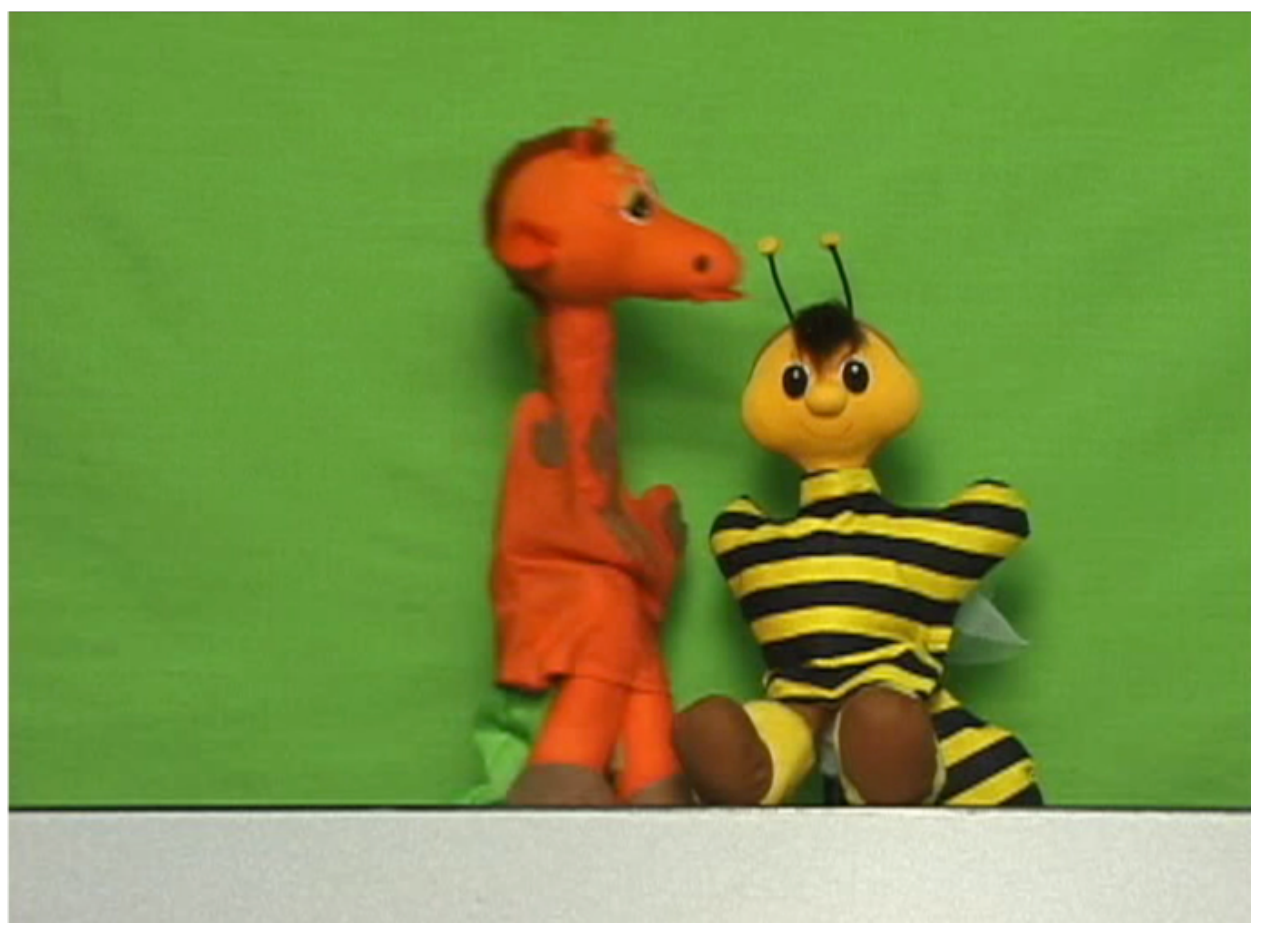

Figure 2.1: Videos used for language exposure in Experiments 1-4. Participants listened to sentences while watching movies of two puppets participating in a transitive action. Here, the giraffe approaches the bee and proceeds to hug it (from Austin 2010).

\subsubsection{Procedure}

The procedures were adapted from Austin (2010). Participants were told that they would be learning a made-up language called SillySpeak by playing a computer game. The game was programmed in PsiTurk, a platform for conducting online experiments through Mechanical Turk (Gureckis et al., 2016) because earlier versions of this experiment were run through Mechanical Turk. Written instructions were provided on the screen. The experimenter was not present for any portion of the exposure or test phase. The entire experiment took approximately 30 minutes. 
The experiment began with a Vocabulary Training Phase which provided explicit training of noun names. An image of one puppet was displayed on the screen. Written instructions prompted participants to click the picture to hear the puppet's name and to repeat it aloud. At the end of this and all subsequent blocks, a "refresher" screen displayed images of all three puppets. Participants were invited to listen to and repeat the puppets' names again if they could not remember them.

Next, participants entered the four-block Exposure Phase. On each trial, participants listened to a sentence from the language and were instructed to repeat it. Each sentence was accompanied by a video of two puppets participating in a transitive action (e.g., "lion headbutts bee slowly"). In the first block, only Basic sentences were presented. ${ }^{6}$ Of the 12 Basic sentence types, half occurred once and half occurred twice in this block (in random order), such that participants heard a total of 18 Basic sentences in the first block. In subsequent blocks, a mixture of six Basic and 30 Complex sentences were presented, such that each sentence type occurred a total of three times across the entire exposure phase. The order of sentences was randomized within each block for each participant. Each exposure block concluded with the "refresher" screen to ensure that participants had ample opportunities to review the three puppets' names. The entire exposure phase took approximately 30 minutes.

\footnotetext{
${ }^{6}$ Pilot experiments suggested that beginning exposure with a block of Basic structures led to better learning overall. We suspect this provides a stable word order to aid in learning vocabulary and categorizing lexical items, particularly Adverbs and Verbs, which might be misperceived as belonging to a single 'predicate' category.
} 
Finally, participants entered the Test Phase (see below). Participants were informed that there would be two new puppets, a Dog and an Elephant, who would each try to say what was happening in the video. The participant's job was to decide who said the best sentence in SillySpeak. The Test Phase appeared identical to the Exposure Phase except that images of the two new puppets appeared below the movie, and a star appeared underneath each of the two images. Participants clicked each image to hear the two sentence alternatives. They indicated their choice by clicking the star underneath the puppet who said the best sentence.

\subsubsection{Test}

We designed a two-alternative forced-choice (2AFC) test to measure knowledge of the language's V2 patterns and, separately, knowledge of the language's generative rules. Although the patterns are generated by the rules, learners could in principle acquire knowledge of rules and patterns separately. That is, the fact that verbs are second when Objects are first is an empirical fact that can be observed through distributional analysis. Learning this fact does not require knowing the position from which the Object moved (or even that there was movement at all).

On each of the 58 test trials, participants heard an grammatical sentence and a sentence containing an error (see below). Ungrammatical sentences were paired with a correct alternative containing the same lexical items. The grammatical choice occurred first or second equally often, in random order. The different error types were evenly distributed throughout the test. 
There were four types of test items, distinguished by the kind of error present in the ungrammatical foil (Table 2.4). Three types of items measured knowledge of the language's distributional patterns. On the Verb Position items, the ungrammatical sentence contained a verb in 1st or 3rd position, while the grammatical choice contained a verb that was 2nd or final. On items testing Inflection, ungrammatical sentences contained an incorrectly inflected verb. Either the verb was in second position and bare, or it was in final position and inflected. Grammatical choices contained a verb in the same position as the foil, but correctly inflected. On items testing the Fronting Restriction-the defining word-order pattern of V2 languages—-the ungrammatical sentence had an initial Object or Adverb and a verb that was second and bare; final and inflected; or final and bare. This third type contrast was most important. Rejecting these sentences requires knowing that even though the verb is correctly inflected for its position, the sentence is ungrammatical because initial Objects and Adverbs require V2. If participants perform well on the tests of Verb Position, Inflection, and Initial Non-Subjects, we can conclude that they have acquired the language's distributional patterns. However, as we pointed out earlier, this would not necessarily indicate that participants have acquired the language's entire grammar. Acquiring the full structure of the language would mean that they represented a basic (underlying) sentence structure and the two rules used to derive complex sentences. To find out whether subjects represented the language in this abstract way, we created two additional types of test items. On $\underline{B a s i c}$ Structure items, the ungrammatical sentence was Subject-initial and verb-final (as in the actual basic structure of the language), but the order of the medial 
constituents was scrambled. On the Complex Rules items, ungrammatical sentences contained an initial Subject, Object, or Adverb followed by an inflected verb in second position, but again the order of the remaining constituents was scrambled.

There are a variety of ways to succeed on the Basic Structure and Complex Rules test items. Most importantly, if participants fully represent the language's transformational grammar, they should recognize that the ungrammatical foils cannot be generated by the rules of the language. However, there is other, less abstract knowledge that they could also draw on. Participants could succeed by rejecting ungrammatical bigrams, since each of the foils contained a bigram that never appeared in their input. They could also succeed by simply memorizing the seven sentence structures as unique constructions. Success on this test therefore would not reveal what kinds of representations are required to learn a V2 language. However, failure on this test-if it accompanies successful learning of the patterns of verb position, verb form, and fronting non-Subjects—-would be informative: this would reveal that V2 patterns are learnable without full linguistic representations. 
Table 2.4: Test design for Experiments 1-4.

\begin{tabular}{|c|c|c|c|}
\hline Item type & Error & Foil structure & Correct structure \\
\hline \multirow[t]{8}{*}{ Verb position } & ${ }^{*} \mathrm{~V}_{1}-\mathrm{ka}$ & ${ }^{*} \mathrm{Vka}-\mathrm{S}-\mathrm{O}$ & S-Vka-O \\
\hline & & *Vka-S-A-O & S-Vka-A-O \\
\hline & ${ }^{*} V_{2}-\varnothing$ & *Vø-S-O & $\mathrm{S}-\mathrm{O}-\mathrm{V} \varnothing$ \\
\hline & & ${ }^{*} \mathrm{Vø}-\mathrm{S}-\mathrm{A}-\mathrm{O}$ & S-A-O-Vø \\
\hline & ${ }^{*} V_{3}-\mathrm{ka}$ & ${ }^{*} \mathrm{~S}-\mathrm{A}-\mathrm{Vk} \mathrm{k}-\mathrm{O}$ & S-Vka-A-O \\
\hline & & ${ }^{*} \mathrm{O}-\mathrm{S}-\mathrm{Vka}-\mathrm{Adv}$ & O-Vka-S-A \\
\hline & & ${ }^{*} \mathrm{Adv}-\mathrm{S}-\mathrm{Vka}-\mathrm{O}$ & Adv-Vka-S-O \\
\hline & ${ }^{*} V_{3}-\varnothing$ & *S-A-Vø-O & $\mathrm{S}-\mathrm{A}-\mathrm{O}-\mathrm{V} \varnothing$ \\
\hline \multirow[t]{8}{*}{ Inflection } & $* V_{2}-\varnothing$ & ${ }^{*} \mathrm{~S}-\mathrm{Vø}-\mathrm{O}$ & S-Vka-O \\
\hline & & ${ }^{*} \mathrm{~S}-\mathrm{Vø}-\mathrm{O}$ & $\mathrm{S}-\mathrm{O}-\mathrm{V} \varnothing$ \\
\hline & & *S-Vø-A-O & S-Vka-Adv-O \\
\hline & & ${ }^{*} \mathrm{~S}-\mathrm{Vø}-\mathrm{A}-\mathrm{O}$ & S-Adv-O-Vø \\
\hline & *VFin-ka & ${ }^{*} \mathrm{~S}-\mathrm{O}-\mathrm{Vka}$ & $\mathrm{S}-\mathrm{O}-\mathrm{V} \varnothing$ \\
\hline & & *S-O-Vka & $\mathrm{S}-\mathrm{O}-\mathrm{Vø}$ \\
\hline & & ${ }^{*} \mathrm{~S}-\mathrm{A}-\mathrm{O}-\mathrm{Vka}$ & S-Adv-O-Vø \\
\hline & & ${ }^{*} \mathrm{~S}-\mathrm{A}-\mathrm{O}-\mathrm{Vka}$ & S-Adv-O-Vø \\
\hline \multirow{9}{*}{$\begin{array}{l}\text { Initial } \\
\text { non-Subjects }\end{array}$} & ${ }^{*} \mathrm{XP}+\mathrm{V}_{2}-\varnothing$ & ${ }^{*} \mathrm{O}-\mathrm{Vø}-\mathrm{S}$ & O-Vka-S \\
\hline & & ${ }^{*} \mathrm{O}-\mathrm{V} \varnothing-\mathrm{S}-\mathrm{A}$ & O-Vka-S-A \\
\hline & & ${ }^{*} \mathrm{Adv}-\mathrm{V} \varnothing-\mathrm{S}-\mathrm{O}$ & Adv-Vka-S-O \\
\hline & ${ }^{*} \mathrm{XP}+\mathrm{VFin}-\varnothing$ & ${ }^{*} \mathrm{O}-\mathrm{S}-\mathrm{V} \varnothing$ & O-Vka-S \\
\hline & & ${ }^{*} \mathrm{O}-\mathrm{S}-\mathrm{A}-\mathrm{V} \varnothing$ & O-Vka-S-A \\
\hline & & ${ }^{*} \mathrm{Adv}-\mathrm{S}-\mathrm{O}-\mathrm{V} \varnothing$ & Adv-Vka-S-O \\
\hline & ${ }^{*} \mathrm{XP}+$ VFin-ka & ${ }^{*} \mathrm{O}-\mathrm{S}-\mathrm{Vka}$ & O-Vka-S \\
\hline & & ${ }^{*} \mathrm{O}-\mathrm{S}-\mathrm{A}-\mathrm{Vka}$ & O-Vka-S-A \\
\hline & & ${ }^{*} \mathrm{Adv}-\mathrm{S}-\mathrm{O}-\mathrm{Vka}$ & Adv-Vka-S-O \\
\hline \multirow[t]{4}{*}{ Rules } & Incorrect order (basic) & ${ }^{*} \mathrm{~S}-\mathrm{O}-\mathrm{Adv}-\mathrm{V}$ & S-Adv-O-V \\
\hline & Incorrect order (complex) & ${ }^{*}$ S-Vka-O-Adv & S-Vka-Adv-O \\
\hline & & ${ }^{*} \mathrm{O}-\mathrm{Vka}-\mathrm{Adv}-\mathrm{S}$ & O-Vka-S-A \\
\hline & & ${ }^{*} A d v-V k a-O-S$ & Adv-Vka-S-O \\
\hline
\end{tabular}

Note. The table lists the pairs of sentence structures that appeared as alternatives on the $2 \mathrm{AFC}$ test. Each contrast (e.g. ${ }^{*} \mathrm{Vka}-\mathrm{S}-\mathrm{O}$ vs. S-Vka-O) was tested twice, once with each of the two verbs. 


\subsubsection{Experiment 1 results}

Accuracy on the $2 \mathrm{AFC}$ test was measured as the proportion of times participants chose the grammatical alternative. Results for the concrete patterns of V2 word order are presented first, followed by the results for the transformational rules of the language; both sets of results appear in Figure 2.2.

\subsubsection{Successful acquisition of $V_{2}$ patterns}

The patterns of $V_{2}$ word order-verb position, inflection, and fronting restrictions-were readily acquired. On Verb Position trials, participants reliably chose grammatical V2 or Vfinal sentences over sentences where the verb occurred 1 st or $3^{\text {rd }}$ (63\% correct). On Inflection trials, learners reliably preferred sentences where the verb was correctly inflected for its position (i.e., second and inflected or final and bare; $75 \%$ correct). The most complex aspect of the language concerned the restrictions on fronting: initial Subjects allowed either V2 (inflected) or Vfinal (uninflected), while initial Objects or Adverbs required V2 (inflected). Participants in our study preferred sentences with initial Objects or Adverbs to have inflected V2 over sentences ( $78 \%$ correct), indicating that they acquired this restriction as well. 


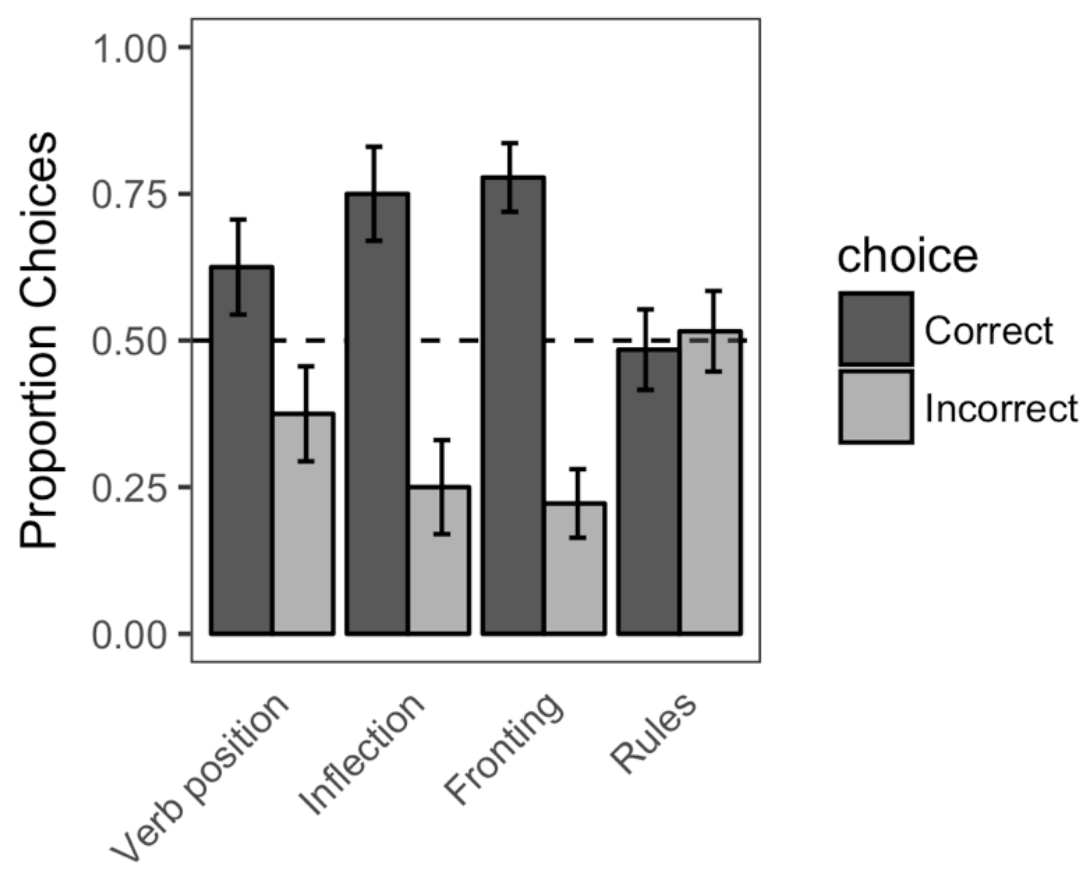

Test item type

Figure 2.2: Results of Experiment 1 (miniature V2 language with closed-class

morphology), by test item type. Choice of a correct structure (darker bars) or an incorrect alternative on a 2AFC test. Different items tested knowledge of V2 patterns and generative rules.

The previous results showed that in general, learners did acquire V2 patterns. Our methodology also allowed us to ask how productive this knowledge is, by testing knowledge across multiple constructions. It is generally not possible to measure knowledge this carefully when conducting research on children acquiring real $V_{2}$ languages, since one's dataset is limited to the sentences that children actually produce (that is, it is difficult to directly test whether they find certain constructions ungrammatical). We tested each V2 pattern in a variety of different ways (Figure 2.3). Overall, learners' knowledge of V2 patterns is remarkably productive across the constructions that we tested. This was of particular interest for the Fronting items, since 
participants could succeed on some of these items based on the verb's inflection and not necessarily through knowledge of the fronting rule. However, learners preferred correct fronting constructions over foils of all types, even those where the verb was final and uninflected. On those items, the verb was correctly inflected for its position, so choosing the correct item requires knowing that only one of the two verb positions is grammatical when an Object or Adverb occurs first. Consistent performance across these constructions indicates that participants knew the verb needed to be both second and inflected when Objects or Adverbs are first.

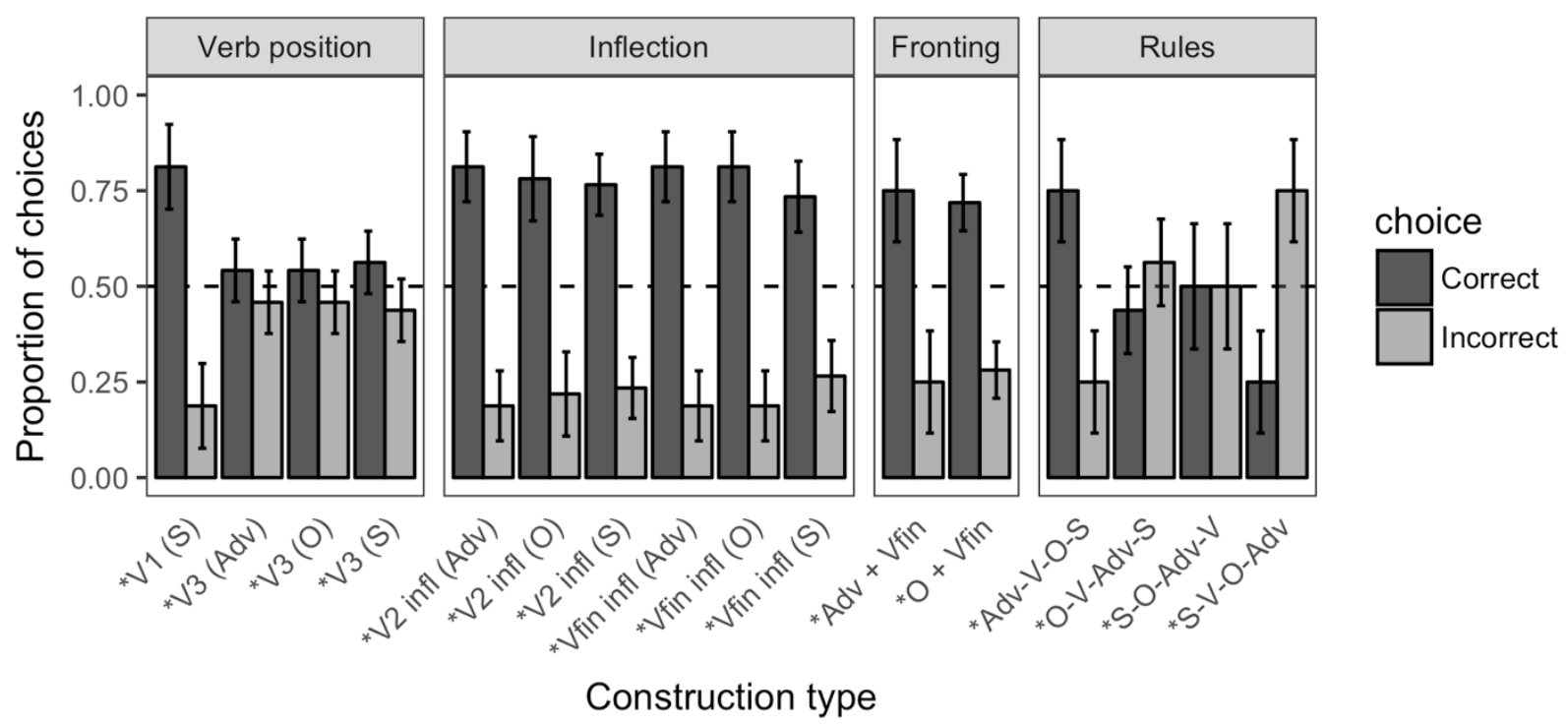

Figure 2.3: Results of Experiment 1 (miniature V2 language with closed-class morphology), by construction. The construction's initial category is noted in parentheses. On items testing V2 patterns, performance was remarkably consistent across constructions, except that participants struggled to reject $V_{3}$ sentences. However, on items testing the language's rules, performance was inconsistent and—overall—at chance. 
The one exception to participants' generally robust knowledge of $V_{2}$ patterns was that they struggled to reject $V_{3}$ sentences, whether they had initial Subjects, Objects, or Adverbs. These results suggest that participants may have encoded the verb's possible positions as medial or final rather than second or final.

2.2.2.2. Failure to learn word order and rules

The results reported so far demonstrated excellent learning of $V_{2}$ patterns. For many linguists, children's knowledge of these same patterns is considered evidence that they represent the generative rules of the language. We tested this claim empirically by analyzing performance on the Rules test items. As described in section 2.2.1.5 (and see also Table 2.4), these items were designed to tease apart knowledge of the language's patterns from knowledge of the language's generative rules. On each trial, participants heard a pair of sentences which were both consistent with the language's V2 patterns: in both sentences the verb was either second or final, the verb was correctly inflected, and if a non-Subject was first, the verb was second. However, one sentence could be generated by the language's transformational rules and one could not. For example, S-Vka-Adv-O is formed from the basic structure S-Adv-O-V by fronting S and placing the verb $2^{\text {nd }}$. On the Rules test, S-Vka-Adv-O appeared with the ungrammatical foil *S-Vka-O-Adv, which cannot be derived from the basic structure unless there is an additional movement rule that changes the relative order of $\mathrm{O}$ and $\mathrm{Adv}$. Thus, performance on this test reveals whether participants represent complex sentences as derived from a basic structure via two movement rules. 
In stark contrast to results for $\mathrm{V}_{2}$ patterns, participants performed poorly on these tes items, and did not differentiate sentences that could be generated by the language's grammar from sentences that could not ( $48 \%$ correct). Furthermore, performance was inconsistent across constructions (Figure 2.3). This evidence is not consistent with knowledge of abstract movement rules. Rather, the results indicate that participants were able to acquire the V2 patterns of the language without representing the language's generative rules.

In principle, there is an alternative explanation. Perhaps learners did represent the language in terms of generative rules, and they simply acquired the wrong basic structure, the wrong movement rules, or an extra movement rule. This would predict a certain pattern of performance on the Rules test. If learners are representing the language in terms of a deterministic grammar, they should perform systematically: for each construction, performance should be either significantly above or significantly below chance, depending on which of the two alternatives can be generated by their grammar. Furthermore, performance should be coherent, such that one could write a grammar that describes all and only the set of sentences that they prefer on the test. Neither prediction appears consistent with the data (Figure 2.3; see also Table 2.4 for the specific structures tested). First, participants are different from chance on only two of the four Rules Test construction types. Second, there does not appear to be a grammatically coherent pattern with regard to which constructions they perform well on. For example, participants apparently prefer *S-V-O-Adv to the correct alternative S-V-Adv-O. Does this mean that they acquired the incorrect ordering of $\mathrm{Adv}$ and $\mathrm{O}$ in the basic structure (i.e., participants 
are incorrectly representing the basic structure as *S-O-Adv-V)? No: participants would have preferred that incorrect structure when we tested it against the correct basic structure, whereas in reality they showed no preference. In addition, it is not clear why learners did not prefer O-Vka-S-A to *O-Vka-A-S but did prefer Adv-V-S-O to *Adv-V-OS. If learners had acquired an extra rule (such as "move anything") they should have performed similarly on these two test items. In general, learners' performance gives us little reason to attribute to them representations of a generative grammar. The more plausible explanation seems to be that they have learned patterns without representing the language's underlying rules.

\subsubsection{Experiment 1 discussion}

After approximately 20 minutes of exposure to a miniature $V_{2}$ language, adult participants acquired the fundamental patterns of V2 word order. In children, this accomplishment has been argued to require knowledge of the full structure of the language. However, careful testing of our participants revealed that they did not actually represent the language's generative rules. When test sentences were matched for verb position, verb inflection, and initial category (i.e., when both choices had correct $V_{2}$ patterns), participants did not distinguish between sentences that could be generated by the language's grammar and sentences that could only be generated by a grammar with an additional movement rule. These results demonstrate that it is possible to learn $\mathrm{V}_{\mathbf{2}}$ patterns without having full linguistic representations. Learning these surface patterns may actually be easier than learning other more "basic" properties of the language such as 
word order. In the Discussion section for this chapter (Section 2.4) we discuss implications of these results for child language acquisition.

This experiment demonstrated that it is possible to learn morphosyntactic patterns in a miniature language without representing the language's underlying generative rules. The next question is what learning mechanisms enable people to do this. Earlier, we suggested that learners might anchor distributional analysis to closed-class morphology because the high frequency and distinctive properties of that morphology draws learners' attention early on. Natural V2 languages always mark finite verbs morphologically, and since it is finite verbs that are $2^{\text {nd }}$ in main clauses, this makes a closed-class anchor available on V2 which would allow learners to acquire the syntactic patterns in this way. The language we used in Experiment 1 also had this feature. In Experiments 2-4, we asked whether this feature is necessary for the acquisition of $\mathrm{V}_{2}$ patterns. We manipulated the distribution and class type of the inflection-reducing its salience, removing it entirely or using it to mark final-position verbs rather than $\mathrm{V}_{2}$-and measured changes in learning. If learners can still acquire $V_{2}$ patterns under these conditions, this would suggest that people do not need a salient closed class (CC) anchor to acquire the syntactic patterns, pointing to a relatively unconstrained learning mechanism. Alternatively, one or more of our manipulations might result in decreased learning relative to Experiment 1, suggesting that the salient CC anchor is indeed necessary for acquisition of $V_{2}$ patterns. That in turn would suggest that certain typological patterns, such as the existence of CC morphology in V2 languages, arise at 
least in part due to the nature of humans' language learning mechanisms. This is a possibility we will further explore in the General Discussion.

2.3. Experiments 2-4: Miniature V2 language with altered morphology

The syntax of the languages used in Experiments 2-4 was identical to that of Experiment 1. What we manipulated was the morphology (Table 2.3). In Experiment 1, second-position verbs were marked with a closed-class verbal inflection $\left(\mathrm{V}_{2}+\mathrm{CC}\right)$. This language is like natural V2 languages, which always have closed-class morphology on (at minimum) V2. In Experiment 2, we reduced the salience of the V2 inflection category by making it an open class $\left(\mathrm{V}_{2}+\mathrm{OC}\right)$. Instead of carrying the phonologically weak, highly frequent suffix ka, second-position verbs were now followed by one of three phonologically heavy lexical items (tombur, lapal, and zup). In Experiment 3, we removed the inflection category altogether $\left(\mathrm{V}_{2}-\varnothing\right)$. The syntax of the language stayed the same, but there was no longer a correlated morphological pattern. Finally, in Experiment 4, we re-introduced the closed-class inflection category but used it on final-position verbs rather than $V_{2}$ (Vfinal+CC). This way, the salient CC anchor is present only in basic, verbfinal sentences and does not occur with initial Objects or Adverbs. All of these are uncommon in natural $V_{2}$ languages, and our design allows us to ask whether this is because they remove a necessary cue.

Our main interest was in seeing if learners could still acquire V2 patterns when the morphology was disrupted in these ways. We were particularly interested in learning outcomes for the fronting restrictions. If learners in Experiments 2-4 can acquire these patterns without salient V2 morphology, that would mean they must have some 
mechanism for tracking the distribution of open-class categories (Objects, Adverbs, and Subjects) relative to other open-class categories (Verbs). These results would inform our understanding of the range of adults' pattern learning mechanisms, but they would not yield any insight into why languages with V2 syntax universally have V2 morphology. Alternatively, learning in Experiments 2-4 might be reduced relative to Experiment 1, indicating that the pattern learning mechanism is sensitive to the presence and/or distribution of morphology. That would suggest that natural V2 languages have V2 morphology at least in part because $V_{2}$ syntax cannot be acquired without it. We will explore this idea in the discussion.

\subsubsection{Experiments 2-4 method}

\subsubsection{Participants}

24 adults age 18-26 from the Georgetown University community received $\$ 10$ in exchange for participating in this experiment.

\subsubsection{Design}

Except for the salience and distribution of $V_{2}$ morphology, the design, materials, and procedures were identical to Experiment 1.

\subsubsection{Experiments 2-4 results}

The three manipulations in Experiments 2-4 each had different effects on different aspects of learning (Figure 2.4). For verb position, learning was equivalent to Experiment $1(64 \%)$ when the $\mathrm{V}_{2}$ inflection was open-class ( $\left.\mathrm{V}_{2}+\mathrm{OC}: 62 \%\right)$ and when there was no inflection in the language (V2-ø: 64\%). When Vfinal carried a closed-class inflection, participants learned verb position somewhat better ( $71 \%$ correct). These results indicate 
that the availability of a V2 anchor does not affect how well learners acquire the possible positions of the verb.

In contrast, learning of the Inflection pattern, which was excellent in Experiment 1 (76\%), was reduced in the experiment with open-class V2 morphology (69\%) but excellent in the language with closed-class morphology on Vfinal (82\%). These results indicate that learning a correlation between a verb's form and its position is easiest when the verb carries closed-class morphology in at least one of those positions, but it does not matter which position it is.

The most important pattern of interest in the altered-morphology experiments is Fronting. This is the defining syntactic pattern of $V_{2}$ languages, and what differentiates the "V2 word order" languages from languages like English, where the verb generally is second but the order of the other words is fixed (in the order SVO). Here, we saw learning outcomes decrease systematically as a function of the salience of $V_{2}$ inflection. Relative to Experiment 1, where accuracy was $73 \%$ on these items, learning decreased when the $\mathrm{V}_{\mathbf{2}}$ inflection was open-class $(60 \%)$ and even more when there was no inflection in the language (54\%). When there was inflectional morphology but it occurred on Vfinal rather than $\mathrm{V}_{2}$, learners failed entirely to learn the crucial fronting pattern (44\% correct). These results indicate that learners struggled to acquire the Fronting pattern in our miniature language when there was no closed-class morphology on $\mathrm{V}_{2}$. 

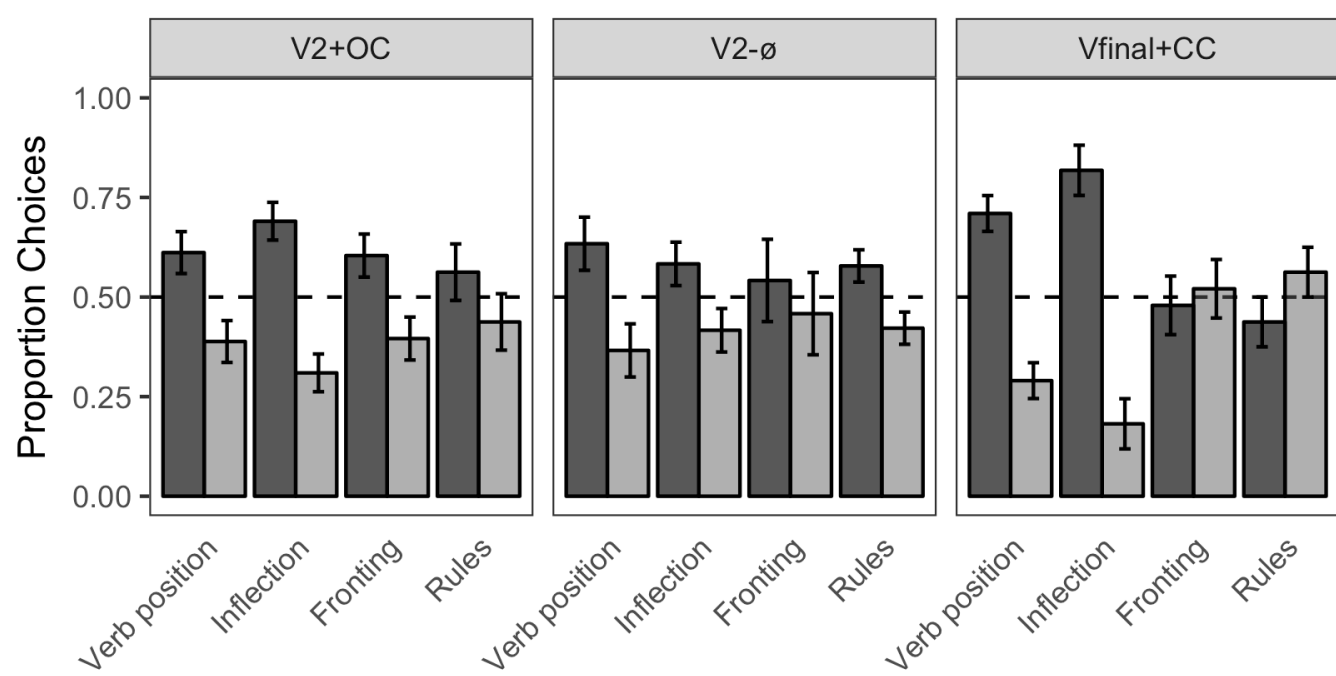

choice

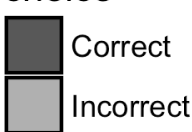

Test item type

Figure 2.4: Results of Experiments 2-4 (miniature V2 languages with altered morphology), by test item type. Choice of a correct structure (darker bars) or an incorrect alternative on the 2AFC test. Learning of V2 patterns, especially the crucial Fronting pattern, was reduced relative to Experiment 1. Learners in the conditions without closed-class morphology (V2+OC and V2-ø) likely succeeded on the Rules test by rejecting ungrammatical bigrams.

As before, we also measured performance on our Rules test, where learners chose between sentences that could be generated by the language's grammar and those that could not. On these items, where learners in Experiment 1 failed ( $48 \%$ correct), learning was also poor in the language where closed-class morphology appeared on Vfinal (44\%) correct. The conditions without closed-class morphology did relatively better on these items, though not significantly different from chance $\left(\mathrm{V}_{2}+\mathrm{OC}: 56 \%\right.$ correct, $\mathrm{t}(7)=0.88$, $\mathrm{p}=.41 ; \mathrm{V} 2-\varnothing: 58 \%$ correct, $\mathrm{t}(7)=1.93, \mathrm{p}=.09)$. Given the results for $\mathrm{V}_{2}$ patterns, the trend toward significance in the $\mathrm{V}_{2}-\varnothing$ condition seems unlikely to reflect knowledge of the language's generative rules. A more likely explanation is that when learners cannot 
anchor distributional analyses to the positions of the sentence with closed-class morphology, they instead focus on learning the linear order of the language. In a language with complex word order like this one, a linear-order approach will not be very productive, but it might ultimately allow learners to reject sentences with unattested bigrams (e.g. *S-V-O-Adv, and all of the other incorrect alternatives on the Rules test items).

\subsubsection{Experiments 2-4 discussion}

In Experiments 2-4, where we reduced the salience of the V2 anchor or moved to sentence-final position, learners failed to acquire all of the V2 patterns. They particularly struggled with the syntactic contingency between initial non-Subjects and V2, which is in principle learnable from the distribution of open-class items in the sentence. This result illuminates the nature of human pattern-learning mechanisms, demonstrating sensitivity to a closed-class anchor even for contingencies that are unrelated to morphology.

In contrast to learning outcomes for $\mathrm{V}_{2}$ patterns, portions of the language's linear order were learned only in languages without a salient closed-class anchor. This suggests that the presence of an anchor shifts, rather than expands, learners' distributional analyses. When there is no closed-class morphology, learners may tend to perform linear analyses, resulting in better acquisition of word order. When closed-class morphology does exist, learners' attention is drawn away from basic word order toward the salient closed-class item, resulting in better acquisition of correlated syntactic patterns. 


\subsection{Discussion}

Using a miniature language learning paradigm, we explored a pattern learning approach to the acquisition of $\mathrm{V}_{2}$ word order. Experiment 1 demonstrated the feasibility of this approach, showing that distributional patterns can be learned without full linguistic representations. Experiments 2-4 showed that this pattern learning mechanism is successful only when there is closed-class morphology on $V_{2}$, as in natural $V_{2}$ languages. These results demonstrate that widespread skepticism in the generative literature over whether children could possibly learn patterns such as verb movement is unfounded. V2 patterns are not too complex to learn, as long as there is a salient closedclass anchor on second-position verbs as in natural V2 languages.

\subsubsection{Implications for child language acquisition}

What are the implications of our results for child language acquisition? Children are very young when they master $\mathrm{V}_{2}$ patterns, and they have more limited memory and processing abilities than our adult learners. However, evidence increasingly suggests that when child and adult learners are exposed to languages with predictable patterns, they learn using similar mechanisms (Aslin, Saffran, \& Newport, 1998; Reeder, Newport, \& Aslin, 2013; Saffran, Newport, \& Aslin, 1996; Schuler, Lukens, Reeder, Newport, \& Aslin, in preparation). ${ }^{7}$ it seems to us entirely feasible that children, like our adult learners, could

${ }^{7} \mathrm{~A}$ popular position in the generative acquisition literature is that researchers should assume "continuity" between the cognitive mechanisms available to adults and those available to children, otherwise one must specify how new cognitive mechanisms become available. This is usually noted as part of an argument for innate linguistic representations. Those who favor this assumption might consider, alternatively, that powerful statistical learning mechanisms might be what is continuously available throughout development. Indeed, that is what current evidence 
acquire concrete linguistic patterns before representing an abstract transformational grammar. At the very least, this possibility must be considered when evaluating the source of children's grammatical knowledge; we see no justification for dismissing it $a$ priori.

For children learning real languages, one way to distinguish knowledge of patterns from knowledge of generative rules would be to examine errors. In fact, the types of constructions that our adult participants erroneously accepted are also attested in the literature on children acquiring natural $V_{2}$ languages. Our participants failed to reject complex sentences in which the third and fourth words-whose order should be the same as in the basic sentence structure-were scrambled (subjects accepted *SVOA in addition to SVAO when both verbs were correctly inflected). We interpreted this as evidence that they did not represent the complex sentences as derived from a basic structure. Interestingly, the same kind of error has been attested for children learning a variety of V2 languages including Dutch (Schlichting 1996), Norwegian (Westergaard 2008) and Swedish (Waldman 2011, Santelmann 1995). Our participants also did not prefer V2 over $\mathrm{V}_{3}$ structures (e.g., they accepted both *SAVO and SVAO when the verb was correctly inflected in both choices). Again, this error has been attested in children learning V2 languages (Santelmann, 1995). Waldman (2011) notes that English-learning children make a similar kind of "V3" error in WH-questions as in What you can do?. The similar types of errors made by our participants and by children acquiring natural $V_{2}$ languages are at

suggests. From that perspective, if syntactic patterns are learnable by adults, there is good reason to think they should be learnable by children as well. 
least consistent with the hypothesis that children, too, represent patterns and not necessarily transformational rules.

2.4.2. V2 patterns are acquired through anchored learning

Consistent with the Anchoring Hypothesis, we found successful learning only when the language had V2 morphology, as in natural V2 languages. This suggests that the V2 anchor served as a cue to the existence of syntactic patterns, shifting learners' attention toward the patterning of open-class words at the front of the sentence. When the $\mathrm{V}_{2}$ anchor was less salient $\left(\mathrm{V}_{\mathbf{2}}+\mathrm{OC}\right)$ or was absent entirely $\left(\mathrm{V}_{\mathbf{2}}-\varnothing\right)$, learners were less likely to pay attention to this portion of the sentence. Moving the anchor to the opposite end of the sentence (Vfinal+CC) had the same effect. This last condition is important because it shows that having closed-class verbal morphology in general does not help learners acquire V2 patterns. In principle, one might have expected this to help. The verb form/position correlation (bare V2 and inflected Vfinal) could have highlighted the fact that there are two positions for the verb, which might then cue learners to track the distribution of other categories relative to the placement of the verb, enabling them to acquire the fronting restrictions. However, this was not what we observed. When Vfinal was inflected, learners did not acquire the fronting restrictions at all, performing even worse than the condition without any closed-class morphology at all (V2-ø). Apparently, learning V2 patterns requires, at minimum, closed-class morphology on finite verbs-not merely verbal morphology in general.

The results are also consistent with the further possibility that anchoring to the closed-class anchor kuh led learners to organize knowledge relative to that anchor. That 
is, learners might have learned that "kuh occurs on V2, and V2+kuh occurs after Objects, Adverbs, and Subjects". That knowledge would enable them to reject sentences where kuh occurred last, or where Objects or Adverbs occurred first but without V2+kuh. Children acquiring real V2 languages could take the same approach, that is, they could learn that one set of endings ("finite") occurs on V2 and after any XP, while a second set of endings ("non-finite") occurs on Vfinal, after Objects. This approach was unavailable in our control conditions, however, because either there was no closed-class anchor or because the anchor's presence did not correlate with the V2 patterns (because it occurred in basic, verb-final sentences). The possibility that anchoring leads learners to represent language patterns in terms of the distribution of closed-class items is intriguing because it dovetails with the types of representations posited in modern syntactic theory. Linguists have increasingly argued that the behavior of open-class categories reflects the features of the closed-class categories (i.e., the functional categories) in the sentence. In this way, language patterns are represented in terms of restrictions on closed-class items. In ongoing research, we are asking whether a learning mechanism that anchors distributional analysis to closed-class items ends up with representations that are structured in this way.

One interesting prediction of this approach concerns language change. If salient closed-class morphology is required for learning V2 patterns, loss of morphology in a V2 language should eventually be accompanied by loss of V2 patterns. In fact, work on language change suggests that English lost verb movement in exactly this way (Lightfoot, 2006). In Old and Middle English, main verbs appeared in two distinct positions, and a 
robust system of verbal morphology correlated with this alternation as in German. Simplification of English morphology due to contact with Scandinavian languages led, in a period of a few hundred years, to the loss of the positional alternation. In Modern English, most verbs occur exclusively after the subject; only a few verbs can actually occur in multiple positions (modals, auxiliaries, and notably the copula be, which unlike other main verbs has a rich inflectional paradigm).

2.4.3. Scaling up to hierarchically structured representations

On our approach, learners do not initially represent complex sentences as derived from a basic structure. Instead, they learn the properties of complex sentences-their patterns-independently, and only later represent their relationship to the basic structure. If learners do not initially represent a relationship between basic and complex structures, how do they learn that one exists? One possibility is that knowledge of the relationship among sentence structures emerges with increased exposure to different sentence types. Support for this possibility comes from a miniature language study by Thompson and Newport (2007). In that study, learners were exposed to a phrasestructure language with the basic word order $(\mathrm{AB})(\mathrm{CD})(\mathrm{EF})$ where each letter represents a form-class category. Acquisition of phrase structure was facilitated when learners were exposed to complex sentences where phrases had been repeated, deleted, and/or reordered, for example $(\mathrm{CD})(\mathrm{EF})(\mathrm{AB})(\mathrm{AB})$. Of relevance here, learners were able to acquire the basic word order of the language even when $95 \%$ of the sentences in their input had been permuted in this way. Learning was significantly better than in a control condition where learners had the same amount of exposure to the basic sentence type, but where 
the permutations in complex sentences did not respect phrasal groupings. These results suggest that basic word order can be learned from exposure to sentences that have been transformed in a systematic way.

\subsubsection{Conclusion}

Languages vary widely in the patterns they use to express grammatical relations. Here, we showed that adult learners can identify and correlate these concrete distributional patterns without representing the full structure of the language. This learning mechanism is sensitive to the presence and distribution of closed-class morphology, suggesting that it is suitably constrained for the acquisition of natural language patterns. These results raise the possibility that children acquiring natural languages might also begin by learning patterns, without necessarily representing them in an adultlike linguistic tree, a possibility we are investigating in ongoing work. If children, too, can learn complex linguistic patterns, this may be an important mechanism enabling learners to acquire the morphosyntax of different languages. 


\section{COMPUTATIONAL MeChanisms OF ANCHORED Distributional ANALYSIS}

\subsection{Introduction}

One means of marking grammatical structure in natural languages is through the use of functional or closed-class items. For example, English marks definiteness with the article the, which always occurs before its noun. There is wide variation in the distribution of functional items across languages: in contrast to English, definiteness in Amharic is marked as a suffix on lexical items in a particular structural position and can attach to nouns, adjectives, numerals, or even verbs depending on sentence structure (Kramer, 2010). The distribution of closed-class items is always predictable in certain ways, but learners must do a substantial amount of distributional analysis in order to learn the particular patterning of closed-class items in their language. The goal of the present chapter is to explore the computational mechanisms that enable language learners to do this.

We already know that closed-class items draw special attention from language learners. Infants can identify them on the basis of distinctive phonological, prosodic and distributional properties such as their short duration, light syllable structure, and high frequency (Shi, Morgan, \& Allopenna, 1998; Shi, Werker, \& Morgan, 1999). Children can recognize familiar closed-class items before their first birthday (Shafer, Shucard, Shucard, \& Gerken, 1998; Shi, Werker, \& Cutler, 2006) and gradually begin to represent information about their distribution over the next year (Gerken \& McIntosh, 1993; Santelmann \& Jusczyk, 1998; Legendre et al., 2010; Shi \& Melançon, 2010). Research with adults and older children has shown that closed-class items help learners segment words, 
form grammatical categories, and acquire grammatical structure (Braine, 1963; Morgan, Meier, \& Newport, 1987; Valian \& Coulson, 1988). All of these authors have argued that learners' attention to closed-class items serves to focus attention on certain grammatically important parts of the sentence (e.g., phrase boundaries, where these items tend to occur), facilitating the acquisition of grammatical structure (Valian and Coulson call this the Anchoring Hypothesis).

However, it is not yet clear what computational mechanisms underlie learners' distributional analyses, once they have noticed closed-class items. The broader literature on statistical learning has not focused particularly on closed-class items; and there are only a few studies that identify specific statistical computations that learners might draw on. These studies have revealed, for example, that learners compute transitional probabilities between adjacent syllables to find word boundaries (Aslin, Saffran, \& Newport, 1998; Saffran, Newport, \& Aslin, 1996; Saffran, Aslin, \& Newport, 1996) and between word classes to acquire grammatical phrases (Thompson \& Newport, 2007). More recent work has examined the computations underlying the acquisition of grammatical categories (Reeder, Newport, \& Aslin, 2013) and productive rules (Schuler, Yang, \& Newport, 2016). Despite this progress, we are only beginning to identify the computational mechanisms underlying many aspects of language acquisition. It thus remains a mystery how learners manage to sort out patterns as complicated as (for example) Amharic definiteness. It is clear that the distributional analyses of language learners - especially young learners — are quite different from those of a computer. Although young children readily acquire consistent statistical patterns, they perform 
quite differently when exposed to language input that is probabilistic or inconsistent; in these situations, instead of mirroring the statistical structure of their input, children modify the language to be more regular (Culbertson \& Newport, 2015; Hudson Kam \& Newport, 2005, 2009).

This evidence indicates that there must be constraints on the nature of children's distributional learning mechanisms. One possibility is that learners are constrained by innate representations of language: perhaps they only search for and acquire patterns that can be encoded with these representations. However, it is not clear how innate knowledge would constrain learners' analyses in any concrete sense. Learners cannot begin to link a specific linguistic form such as 'the' to a highly abstract innate category such as Determiner until they have already determined the form's patterns of occurrence. At that point, distributional analysis is already complete. A second, alternative possibility is that learners do not perform all logically possible computations during distributional analysis, but instead privilege some types of computations over others. For example, learners may be biased to compute predictive statistics (such as conditional probability) over non-predictive statistics (such as co-occurrence frequency) (Aslin et al., 1998; Saffran et al., 1996; Schuler, Reeder, Newport, \& Aslin, 2017; Thompson \& Newport, 2007), a bias that would position them well for acquiring predictive dependencies in natural languages.

Interestingly, certain predictive statistics may be more useful than others. Saffran (2001) pointed out that predictive dependencies within grammatical phrases are unidirectional: for example, a determiner is always (eventually) followed by a noun, whereas a noun may or may not be preceded by a determiner. Saffran's observation led 
her to explore the possibility that unidirectional predictive structure facilitates the acquisition of phrase structure. There is, however, an additional and important point concerning the distribution of closed-class versus open-class items in natural languages. In a dependency between two open-class categories A and B, there is no way to know in advance which category predicts the other: A could predict B, or B could predict A. The learner must consider both possibilities. However, dependencies between closed-class and open-class categories, such as determiners (D) and nouns (N), are different. A closedclass category like $\mathrm{D}$ always predicts an open-class category like $\mathrm{N}$, but $\mathrm{N}$ does not always predict $\mathrm{D}$. That is, closed-class items are always predictive of, and not necessarily predicted by, open-class ones. ${ }^{8}$ In a sense, the distribution of closed-class items determines the distribution of open-class ones. Nouns in English occur wherever determiners do, and verbs occur wherever tense morphology does, because determiners and tense morphology each depend on the presence of certain open class lexical items.

This point is especially interesting in light of the recent emphasis in syntactic theory on the role of functional categories in sentence structure (see Rizzi \& Cinque, 2016 for discussion and historical context). Increasingly, linguists have argued that properties

${ }^{8}$ In some cases, open-class items do predict closed-class ones, making the relationship bidirectional. For example, in French, all non-proper nouns require determiners. Thus, a learner could in principle compute how often nouns are accompanied by determiners, and this would sometimes reveal a predictive pattern (as in French) and sometimes not (as in English). In contrast, computing how often determiners are accompanied by nouns will always reveal a predictive pattern, regardless of the language being learned. Thus, analyzing closed-class items as predictive of open-class items is the most efficient way to uncover patterns, even though other types of analyses would in some cases also be informative. One interesting implication of the results of this dissertation, especially the results of Chapter 4, is that even patterns that tend to be bidirectional in real languages do not need to be bidirectional for learners to successfully acquire them. Learners can acquire a unidirectional relationship as long as the closed-class category is predictive. 
of closed-class items determine the behavior of other words in the sentence. This extends beyond the presence of certain open-class categories to their actual positions in the sentence. To illustrate, consider the colloquial French sentence (3.1). The two verbs, one morphologically finite (veux) and the other non-finite (manger), occur in different positions relative to the negative marker (pas). Linguists capture this contingency between finiteness and verb position by positing that finite and non-finite morphemes are represented in different positions in the sentence. If there is finite morphology, there will be a verb and that verb will occur in the "finite" position (pre-negation). In this way, the presence and location of verbs is determined by the kind of morphology that occurs in the sentence.

(3.1) je veux pas manger (Colloquial French)

I want neg to-eat

'I don't want to eat'

Of course, linguists' analyses are intended to be formal models of syntactic knowledge, and not necessarily claims about the psychological representation of sentences. However, this kind of analysis demonstrates an important empirical point: regularities of word order and word form can be stated as restrictions on the distribution of closed-class items. Consider now the problem of distributional learning. One way to begin, given this view from syntactic theory, would be to identify closed-class items based on their salient perceptual properties and then proceed to learn their distribution. Because this distribution is asymmetrical—closed-class categories always predict but are not predicted by open-class categories—-the computations that learners perform could in 
principle also be asymmetrical. Specifically, learners need to find out what a closed-class item predicts—-the presence of other categories, the placement of words, and so on—but they need not expend any effort finding distributional patterns that a closed-class item is predicted by, because there are none. ${ }^{9}$

In this study, we explored the possibility that learners privilege computations in which closed-class items are predictive of open-class items over computations in which they are predicted by open-class items. We exposed adult learners to a miniature language containing a one-way grammatical dependency between two form-class categories, $\mathrm{X}$ and $\mathrm{Y}$. When an $\mathrm{X}$ word was present, a Y word always had to be present as well, but $\mathrm{Y}$ words could occur with or without $\mathrm{X}$ words. $\mathrm{X}$ was the predictive category; $\mathrm{Y}$ was predicted by $\mathrm{X}$. To acquire this dependency, that is, to learn that $\mathrm{X}$ predicts $\mathrm{Y}$, learners must compute the conditional probability of $\mathrm{Y}$ given $\mathrm{X}(\mathrm{p}(\mathrm{Y} \mid \mathrm{X})=1.0)$. In two contrasting experimental conditions, we assigned different types of words to the $\mathrm{X}$ and $\mathrm{Y}$ categories. In one condition the predictive category $(\mathrm{X})$ was a closed class (short monosyllabic and containing only one item) while in the other condition the predictive category was an open class (mono or disyllabic and containing one of three possible lexical items). If learners' computations are unbiased-i.e., if they compute the

${ }^{9}$ Of course, closed-class items do not appear randomly in sentences. Their presence is determined by the semantic meaning that the speaker wishes to express. The learner does eventually need to learn which meanings go with which forms, but this is a separate and somewhat uncorrelated problem. As the comparison between Amharic and English definiteness marking illustrates, learning that a given form means "definite" does not tell the learner where, distributionally, that form occurs, nor does learning the distribution of a form reveal its meaning (e.g., both definite and indefinite articles precede nouns in English). Both learning problems are important, but we are concerned here only with the distributional one. 
probability of closed-class categories given open-class ones as readily as they compute the probability of open-class categories given closed-class ones-it should not matter whether the predictive category is closed-class or open-class. However, if learners privilege the computation that is most relevant for acquiring natural language dependencies, learning should be better when the predictive category is closed-class. Results from Experiment 5 indicate that learners do indeed preferentially acquire dependencies where closed-class items are predictive. In Experiment 6, we demonstrate that learners do not simply prefer dependencies where closed-class items appear first in linear order. Experiment 7 confirms that this is a computational, rather than a prosodic bias. In the Discussion we return to the question of why learners should be biased in this way; we do not mean to suggest that they know in advance about languages in particular, but rather that their computational biases may shape languages to be structured in this way.

3.2. Experiment 5: Predictive dependency language $(X \rightarrow Y)$

3.2.1. Experiment 5 method

\subsubsection{Participants}

Seventeen adults from the Georgetown University community (aged 18-27, mean=20.4) received $\$ 10$ in exchange for participating in this study. Data for one participant was not saved due to a technical issue, leaving 16 participants.

3.2.1.2. Description of the miniature language 
The basic word order of the language was AXYBC, where each letter represents a form-class category. Any word could be omitted from the basic sentence structure, and up to three words could be omitted per sentence. The only fixed and consistent rule was that if X was present, $\mathrm{Y}$ had to be present as well ("if X then Y"). In all, this grammar generates 19 different sentence structures, each between two and five words long. ${ }^{10}$ Because the words always appeared in the same order $(\mathrm{X} \rightarrow \mathrm{Y})$, learners could acquire the dependency by computing the forward transitional probabilities from X to Y.

We created a distinction between closed-class and open-class categories by selecting lexical items with specific prosodic properties from a lab corpus (Table 3.1). The closed-class category contained a single item, $k a$, which had several properties common to closed-class items (it was short, lacked a coda or consonant clusters, and was high frequency relative to the other words in the language by virtue of its being the only member of its form class). In contrast, each open-class category contained multiple words that were a mixture of mono- and bisyllabic forms, all with closed final syllables. All words in the language, including the closed-class item, carried stress (i.e., $k a$ was not prosodically dependent on any other item).

In order to ask whether learners are biased to analyze closed-class items as predictive of open-class ones, we created one variant of the language where the predictive category $(\mathrm{X})$ was closed-class and the predicted category $(\mathrm{Y})$ open-class, and a second variant where the class types were switched. Other than this difference in the lexical

${ }^{10}$ The 19 sentence structures in the language are $A X Y B C, A X Y B, A X Y C, A Y B C, X Y B C, A B C$, AXY, AYB, AYC, XYB, XYC, YBC, AB, AC, AY, BC, XY, YB, and YC. 
items in each class, the two languages are identical. In both languages, acquiring the dependency requires computing exactly three word-level forward transitional probabilities (either $\mathrm{X}_{1}-\mathrm{Y}_{1}, \mathrm{X}_{1}-\mathrm{Y}_{2}, \mathrm{X}_{1}-\mathrm{Y}_{3}$ or $\mathrm{X}_{1}-\mathrm{Y}_{1}, \mathrm{X}_{2}-\mathrm{Y}_{1}, \mathrm{X}_{3}-\mathrm{Y}_{1}$ ). Furthermore, the dependency always involves a closed-class item, so learners in both conditions have an "anchor" for their distributional analyses. Mathematically, these languages are identical; learning outcomes will differ only if learners' computational analyses treat closed-class and open-class items differently.

Table 3.1: Vocabulary of the predictive dependency language used in Experiment 5.

\begin{tabular}{llllll}
\hline Condition & A & X & Y & B & C \\
\hline Closed-Class X & $\begin{array}{l}\text { flairb } \\
\text { daffin } \\
\text { glim }\end{array}$ & ka & $\begin{array}{l}\text { lapal } \\
\text { tombur } \\
\text { zup }\end{array}$ & $\begin{array}{l}\text { flugit } \\
\text { mawg } \\
\text { bleggin }\end{array}$ & $\begin{array}{l}\text { clidam } \\
\text { gentif } \\
\text { spad }\end{array}$ \\
Open- Class X & (same) & $\begin{array}{l}\text { lapal } \\
\text { tombur } \\
\text { zup }\end{array}$ & ka & (same) & (same) \\
& & & &
\end{tabular}

Note. We created a distinction between open classes and closed classes by assigning different lexical items to each category. In the linear control language (Experiment 6), the lexical items were identical but $\mathrm{Y}$ preceded $\mathrm{X}$ in the linear order. In the prosody control language (Experiment 7), the "closed-class" item was daygin instead of $k a$.

\subsubsection{Materials}

We generated a 38-sentence exposure set by selecting two sentence types for each of the 19 structures. Sentence sound files were created by concatenating recordings of the individual words spoken by a female native speaker of English with 50 msec of 
intervening silence between words. The 38-sentence exposure set was shuffled 16 times and presented as part of a 1-back task (see Procedure).

\subsubsection{Procedure}

Participants were exposed to the language in the context of a computer game. Instructions were spoken aloud by a robot named "Bot" who told participants to listen as an alien named Zooma practiced saying sentences in a made-up language spoken by aliens on another planet. After each sentence, participants pressed a key to indicate whether Zooma had just repeated herself (they pressed F for "no" or J for "yes"). This was a 1-back task designed to ensure attention. Once Zooma arrived on the new planet, participants began a $2 \mathrm{AFC}$ test. Bot explained that Zooma would try to say each sentence two times, and participants' job was to decide which sentence was better. The entire experiment lasted approximately 45 minutes.

\subsubsection{Test}

We measured knowledge of the language on a two-alternative forced-choice test. The test was designed in two parts.

Short sentences. In the first part, we tested the shortest possible sentences in the language; these provided maximum control over test item structure. The correct choice on each trial was always a grammatical complete two-word sentence, while the incorrect choice was always a legal two-word sequence in the language but was not necessarily a complete sentence (the only incomplete sentence that occurred on this part of the test was AX, which violates the rule "if $X$ then $Y$ "). Test structures are listed in Table 3.2. Six XY Unit trials served as a constituency test: participants chose between XY, a grammatical 
unit, and another sequence from the basic structure (AX, YB, or $\mathrm{BC}$ ). All of these are legal two-word sequences in the language ( $\mathrm{YB}$ and $\mathrm{BC}$ are also complete sentences), but $\mathrm{X}$ and Y are more tightly related grammatically than the other word pairs. A preference for XY would indicate that participants represented this grammatical relationship. Two XY Dependency trials asked participants to choose between AY and AX. Once again, both choices were legal two-word sequences in the language and in fact had exactly the same forward transitional probability (.36), but only AY is a complete sentence. If participants have learned the predictive direction of the dependency, they should prefer AY over AX. On four Basic Structure trials, participants chose between $\mathrm{AB}$ or $\mathrm{AC}$ and an ungrammatical alternative containing the same words in reverse order. Finally, we included six Filler/YB trials. This allowed us to balance the frequency of different sequences, so that participants could not prefer XY strings simply because they occurred more frequently on the test. These trials also allowed us to test whether learners in the Open-Class X condition had a preference for units containing YB. This would be consistent with a bias to analyze closed-class items as predictive because $\mathrm{Y}$ is the closedclass item in that condition, and B is the open-class item that occurs most predictably after Y. We did find such a preference during piloting on Mechanical Turk, with materials that were less well controlled than the present ones. Therefore, we designed the Filler trials to also test preference for $\mathrm{YB}$ over other grammatical sequences (AY or $\mathrm{BC}$ ), and preference for a grammatical sequence containing B but not $\mathrm{Y}(\mathrm{BC})$ over a sequence containing Y but not B (AY). 
Table 3.2: Test design for Experiments 5-7.

\begin{tabular}{lcc} 
Test item type & $\begin{array}{c}\text { Experiments } 5 \text { and } 7 \\
(\mathrm{AXYBC})\end{array}$ & $\begin{array}{c}\text { Experiment } 6 \\
(\mathrm{AYXBC})\end{array}$ \\
\cline { 2 - 3 } Basic Structure & $\mathrm{AB} /{ }^{*} \mathrm{BA}$ & $\mathrm{AB} /{ }^{*} \mathrm{BA}$ \\
& $\mathrm{AC} /{ }^{*} \mathrm{CA}$ & $\mathrm{AC} /{ }^{*} \mathrm{CA}$ \\
XY Unit & $\mathrm{XY} / \mathrm{AX}$ & $\mathrm{YX} /{ }^{*} \mathrm{AX}$ \\
& $\mathrm{XY} / \mathrm{BC}$ & $\mathrm{YX} / \mathrm{BC}$ \\
& $\mathrm{XY} / \mathrm{YB}$ & $\mathrm{YX} / \mathrm{YB}$ \\
& & $\mathrm{YX} / \mathrm{XB}$ \\
XY Dependency & & $\mathrm{YX} / \mathrm{AY}$ \\
& & $\mathrm{AY} /{ }^{*} \mathrm{AX}$ \\
Filler & & \\
& & $\mathrm{AY} / \mathrm{AX}$ \\
& $\mathrm{YB} / \mathrm{AY}$ & $\mathrm{YB} / \mathrm{BC}$ \\
& $\mathrm{YB} / \mathrm{BC}$ & $\mathrm{BC} / \mathrm{AY}$ \\
& $\mathrm{BC} / \mathrm{AY}$ & $\mathrm{BC} / \mathrm{XB}$ \\
& & $\mathrm{YB} / \mathrm{XB}$ \\
& & $\mathrm{AY} / \mathrm{XB}$
\end{tabular}

Note. The table lists pairs of two-word sequences used in the $2 \mathrm{AFC}$ test. The first sequence in each pair is coded as the "correct" answer, even though in most cases both choices are gramamtical sequences in the language. Note that AX in Experiments 5 and 7 , and $\mathrm{XB}$ in Experiment 6, are grammatical sequences but not grammatical sentences. New controls were needed for the Linear language because additional bigrams were grammatical (e.g., $\mathrm{XB})$.

Longer sentences. For a broader picture of participants' knowledge, the second part of the test contained longer sentences, where it is more difficult to isolate structural properties of the language. For example, if participants are asked to choose between $\mathrm{AYB} / \mathrm{AYC}$ and ${ }^{*} \mathrm{AXB} /{ }^{*} \mathrm{AXC}$, a preference for $\mathrm{AYB}$ could reflect either knowledge of the dependency $\mathrm{X} \rightarrow \mathrm{Y}$ or a preference for the bigrams $\mathrm{YB} / \mathrm{YC}$ over ${ }^{*} \mathrm{XB} /{ }^{*} \mathrm{XC}$. This was 
problematic because if learners are computationally biased in the way we have suggested, the bigrams YB and YC should be particularly salient to learners in the condition with open-class X and closed-class Y. In other words, both groups of learners may prefer the correct item on this test but for different reasons: for learners of the language with closed-class X, it would be because they learned the dependency "if X then Y", while for learners of the language with open-class $\mathrm{X}$ and closed-class $\mathrm{Y}$, it would be because they have started to acquire a dependency along the lines of "if $\mathrm{Y}$ then $\mathrm{B} / \mathrm{C}$ ". For this reason, these longer test items are not as useful as the shorter ones for testing our hypothesis about the computations learners prefer. However, we included them at the end of the test because they do add information about how well each set of learners acquired the language in general. Eight XY Dependency trials contrasted grammatical sentences with Y or XY against sentences containing X but not Y. Twelve Basic Structure trials contrasted a grammatical sentence against one that contained two words from an A, B, or C category (e.g., AAYB) or contained an A, B, or C word in the wrong position (e.g., CXYA).

Collapsing across items with two-word sequences and longer sentences, there were six XY Unit trials, ten $X Y$ Dependency trials, sixteen Basic Structure trials (eight with word-order errors and eight with repeated categories) and six Filler trials.

\subsubsection{Experiment 5 results}

Accuracy on the $2 \mathrm{AFC}$ test was measured as choice of the target sequence (the first item of each pair in Table 3.2). Results are presented in Table 3.3 and Figure 3.1. 
Table 3.3: Results of Experiment 5 (predictive dependency language)

\begin{tabular}{|c|c|c|c|c|}
\hline \multirow[b]{2}{*}{ Test item type } & \multicolumn{2}{|c|}{ Two-word sequences } & \multicolumn{2}{|c|}{ Longer sentences } \\
\hline & $\begin{array}{l}\text { Closed- } \\
\text { Class X }\end{array}$ & $\begin{array}{l}\text { Open- } \\
\text { Class X }\end{array}$ & $\begin{array}{l}\text { Closed- } \\
\text { Class X }\end{array}$ & $\begin{array}{l}\text { Open- } \\
\text { Class X }\end{array}$ \\
\hline Basic Structure & $.94(.12)$ & $.84(.27)$ & $.69(.15)$ & $.66(.17)$ \\
\hline XY Unit & $.77(.09)$ & $.60(.22)$ & & \\
\hline $\begin{array}{l}\text { XY } \\
\text { Dependency }\end{array}$ & $.81(.26)$ & $.56(.42)$ & $.62(.09)$ & $.64(.22)$ \\
\hline Filler & $.50(.20)$ & $.54(.17)$ & & \\
\hline
\end{tabular}

Note. Means (standard deviations) reflect choice of target item on the 2AFC test. The results for two-word sequences are most important (see text). On these items, the Closed-Class X condition performed significantly better than the Open-Class X condition.

\subsubsection{Basic structure}

Our first question was whether participants in either condition acquired basic knowledge of the language. To answer this, we analyzed participants' performance on the Basic Structure items of our 2AFC test. Both groups of learners performed similarly well, strongly preferring the correct choice for shorter sentences (Closed-class X: 94\%, Openclass X: 84\%) as well as longer sentences (Closed-class X: 69\%, Open-class X: 66\%). These results indicate that both groups of learners acquired basic knowledge of the language. 


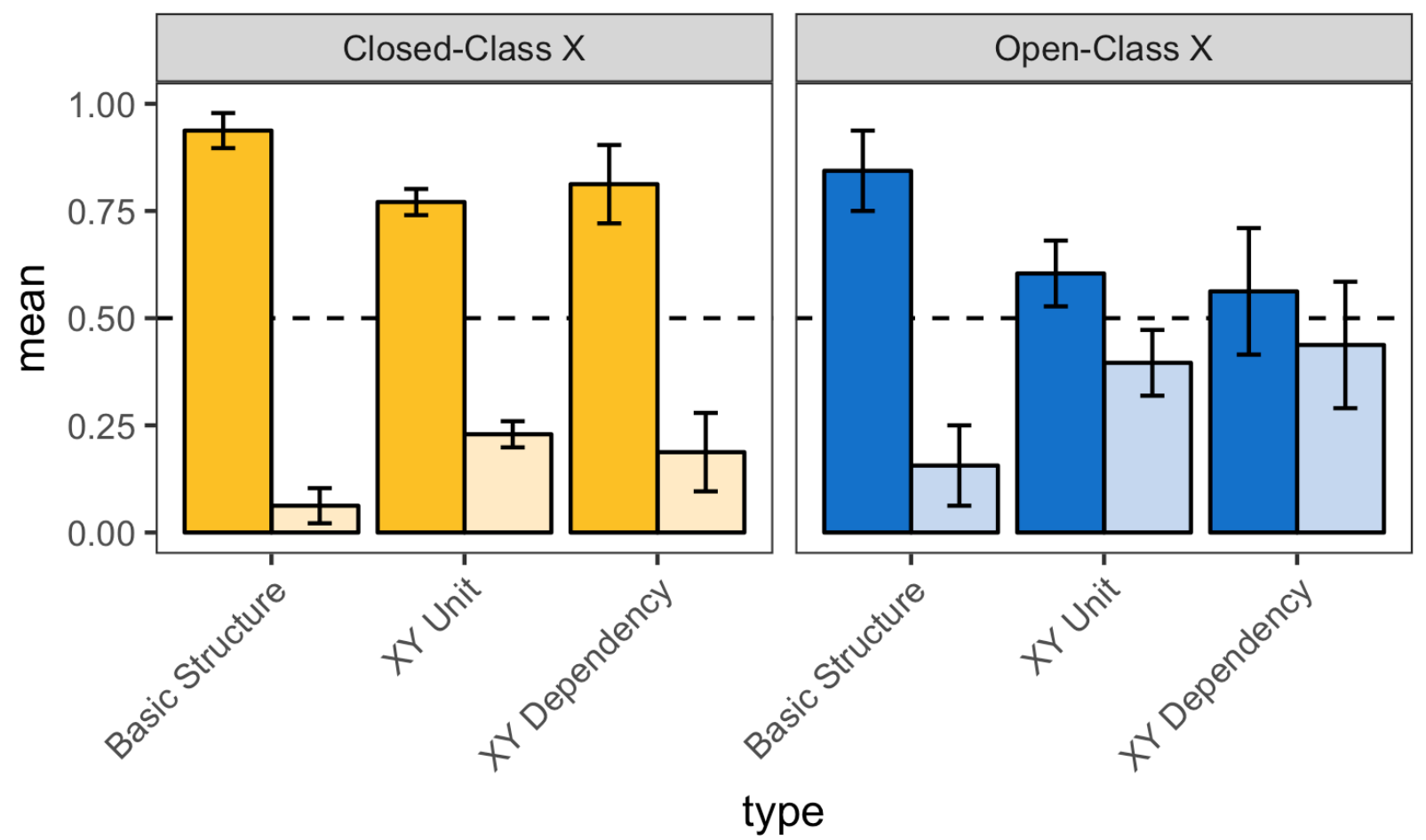

Figure 3.1: Results of Experiment 5 (predictive dependency language). Results of the $2 \mathrm{AFC}$ test are presented for learners of the basic language in the Closed-Class X and Open-Class X conditions. Darker bars indicate the target choice.

\subsubsection{Predictive dependency}

Our most important question was whether the "if X then Y" dependency would be acquired better when the predictive category $(\mathrm{X})$ was closed-class than when it was openclass. We measured knowledge of the dependency on two different types of test items. The XY Unit items measured a preference for XY versus other grammatical, two-word sequences. The XY Dependency items tested knowledge of the predictive direction of the dependency: participants chose between a two-word sequence containing Y but not X (AY) and one containing $\mathrm{X}$ but not $\mathrm{Y}(\mathrm{AX})$. These sequences have the same forward 
transitional probablity, but only AY is a complete sentence, since X cannot occur without Y.

We compared learning in the two conditions in a two-way mixed ANOVA with Condition (Closed-Class X, Open-Class X) as a between-subjects variable and Test Item (XY Unit, XY Dependency) as a within-subjects variable. There was a significant main effect of group, reflecting better performance in the Closed-Class $\mathrm{X}$ condition $(\mathrm{F}(1,14)=$ $6.73, \mathrm{p}=.02)$. There was no main effect of item type $(\mathrm{F}(1,14)=\mathrm{o}, \mathrm{p}=1.0)$ and no interaction between item type and group $(\mathrm{F}(1,14)=.14, \mathrm{P}=.71)$, indicating that participants in the Closed-Class X condition were more accurate than the Open-Class X condition on both types of test items. The grammatical coherence of XY as a unit was identical in these two conditions, since $\mathrm{X}$ always perfectly predicts $\mathrm{Y}$. These results indicate, however, that learners more readily represent dependent words as a unit, and acquire the predictive direction of the dependency, when the predictive category is closed-class.

We also asked participants to choose between longer grammatical sentences with $\mathrm{XY}$ or $\mathrm{Y}$ alone and ungrammatical sentences containing $\mathrm{X}$ but not $\mathrm{Y}$. These are analogous to the shorter XY Dependency items analyzed above. On these longer XY Dependency items, we observed equivalent performance in the two conditions (Closed-Class X: 63\%, Open-Class X: 64\%). These results indicate that each group's knowledge of their language extends to longer sentences. However, the success of learners in the Open-Class X condition does not constitute evidence against our hypothesis. As described in the Materials section, if learners do preferentially analyze closed-class items as predictive, 
both groups of learners will actually prefer the correct item on this test but for different reasons. This confound is why we have emphasized the results for two-word sentences (see above), where learning can result only from acquisition of the dependency "if $\mathrm{X}$ then Y". Overall, the pattern of results in this experiment is strongly consistent with a bias to analyze closed-class items as predictive.

\subsubsection{Experiment 5 discussion}

The results show that when adults are exposed to a grammatical dependency with the structure "if X then Y," learning outcomes depend on whether the predictive category $(\mathrm{X})$ is closed-class or open-class. When $\mathrm{X}$ is closed-class and $\mathrm{Y}$ is open-class, learners easily acquire the dependency. However, in a mathematically identical condition where $\mathrm{X}$ is open-class and Y is closed-class, learning is significantly worse. Learners apparently privilege computations that treat closed-class items as predictive-the same computations that are most relevant for acquiring natural language dependencies.

We emphasize that the statistical evidence for the dependency was the same in the two conditions: $\mathrm{X}$ always perfectly predicted Y. Furthermore, learners were exposed to the same number of lexical items (twelve open-class and one closed-class), sentence structures, and sentence types. To acquire the dependency in both conditions, learners needed to compute exactly three forward transitional probabilities involving four lexical items (one closed-class and three open-class). Yet despite this mathematical equivalence, we saw much better learning in the condition where the predictive category was closedclass. These results indicate that learners are not simply computing all possible pairwise transitional probabilities in the language. Rather, they appear to analyze the distribution 
of closed-class items in certain biased ways, more easily finding patterns in which the closed-class category is predictive of another category than patterns in which it is predicted by another category.

Could our results be explained by our participants' prior knowledge of English, rather than a computational bias? English is a head-initial language, where closed-class items occur before, rather than after, the open-class items they depend on. Perhaps participants simply prefer patterns where closed-class items appear first. We do not generally find strong native-language effects in our artificial language experiments. However, in order to rule out this explanation empirically, we conducted a new experiment in which the linear order of the dependency is reversed (i.e., Y occurs before $\mathrm{X}$ in the sentence but $\mathrm{X}$ still predicts $\mathrm{Y}$ ).

\subsection{Experiment 6: Linear order control language $(\mathrm{Y} \leftarrow \mathrm{X})$}

Experiment 5 established that learners treat closed-class items differently, learning a forwards dependency $\mathrm{X} \rightarrow \mathrm{Y}$ only when $\mathrm{X}$ was closed-class. These results are consistent either with a linear order bias (these learners prefer dependencies in which closed-class items occur first) or with a computational bias (they prefer dependencies in which closedclass items predict open-class ones). In Experiment 6, we changed the word order of the language such that $\mathrm{Y}$ preceded $\mathrm{X}$ in the linear order but $\mathrm{X}$ was still predictive $(\mathrm{Y} \leftarrow \mathrm{X})$. If learners simply prefer patterns where closed-class items appear first, the Open-Class X condition should now succeed in learning the "if X then Y" dependency, even though it is structurally unnatural (since an open-class category predicts a closed-class one). That result would suggest that learners are sensitive to the linear order between closed-class 
and open-class categories, but not to the predictive structure of dependencies involving those categories. However, if learners prefer patterns where closed-class categories predict open-class ones, the Open-Class X condition should again fail to learn the dependency.

In both conditions of Experiment 6, learning the $\mathrm{Y} \leftarrow \mathrm{X}$ dependency requires learners to compute a backwards statistic: the probability that $\mathrm{Y}$ just occurred, given that they now see X. This contrasts with Experiment 5, where learners in both conditions had to compute the forwards probability of $\mathrm{Y}$ occurring next, given that they see X. Most research on statistical learning has focused on forwards transitional probabilities. Two studies have provided preliminary evidence that adults and infants are equally capable of computing backwards transitional probabilities (Pelucchi, Hay, \& Saffran, 20o9; Perruchet \& Desaulty, 2008). However, note that the linear direction of the dependency (backwards vs. forwards) is orthogonal to our design. We are holding the linear order of $\mathrm{X}$ and $\mathrm{Y}$ constant, such that the dependency is either forwards in both conditions (Experiment 5) or backwards in both conditions (Experiment 6); we are manipulating which member of the dependency (X or Y) is closed class. Therefore, between-group differences in each experiment will emerge only if learners analyze closed-class differently from open-class items.

\subsubsection{Experiment 6 methods}

We used the same miniature language as Experiment 5 except that the word order was $A Y X B C$, such that $Y$ preceded $X$ in the linear order but $X$ was still predictive $(Y \leftarrow X)$. The test was modified slightly relative to Experiment 5 (Table 3.2). We added trials 
comparing the sequence XB (which was now grammatical) and YX. If learners acquired the backwards $\mathrm{Y} \leftarrow \mathrm{X}$ dependency, they should prefer $\mathrm{YX}$ to XB even though these two sequences have nearly identical forward transitional probabilities (YX: .53, XB: .50). The addition of this test item makes the XY Unit test more difficult than in Experiment 5, where the forward transitional probability of the target was 1.0 and none of the foils had a forward transitional probability greater than .55 .

3.3.1.1. Materials and procedure

Exposure and test materials were re-synthesized to swap the linear order of $\mathrm{X}$ and Y, and to add the new test trials. The procedure was the same as in Experiment 5 .

\subsubsection{Participants}

Seventeen adults age $18-28$ received $\$ 10$ to participate in this study. For one person, the experiment crashed before the test, so we did not collect any data from that individual.

3.3.2. Experiment 6 results

\subsubsection{Basic structure}

Results are presented in Table 3.4 and Figure 3.2. Again, both groups of learners performed similarly well, strongly preferring the correct choice for shorter sentences (Closed-class X: 88\%, Open-class X: 84\%). Performance on longer sentences was somewhat reduced for the Closed-Class X condition (57\%), though still above chance, while performance in the Closed-Class Y condition was somewhat higher than before (73\%). These results indicate that both groups learned the basic properties of the language, like the learners in Experiment 5. 
Table 3.4: Results of Experiment 6 (predictive dependency language, linear order control).

\begin{tabular}{|c|c|c|c|c|}
\hline \multirow[b]{2}{*}{ Test item type } & \multicolumn{2}{|c|}{ Two-word sequences } & \multicolumn{2}{|c|}{ Longer sentences } \\
\hline & $\begin{array}{l}\text { Closed- } \\
\text { Class X }\end{array}$ & $\begin{array}{l}\text { Open- } \\
\text { Class X }\end{array}$ & $\begin{array}{l}\text { Closed- } \\
\text { Class X }\end{array}$ & $\begin{array}{l}\text { Open- } \\
\text { Class X }\end{array}$ \\
\hline Basic Structure & $.88(.13)$ & $.84(.13)$ & $.57(.17)$ & $.73(.14)$ \\
\hline XY Unit & $.55(.09)$ & $.78(.09)$ & & \\
\hline XY Dependency & $.75(.27)$ & $.31(.37)$ & $.56(.13)$ & $.56(.21)$ \\
\hline Filler & $.56(.19)$ & $.59(.14)$ & & \\
\hline
\end{tabular}

Note. Means (standard deviations) reflect choice of target item on the 2AFC test.

3.3.2.2. Predictive dependency

As in Experiment 5, we analyzed performance on the XY Unit and XY Dependency items (now YX Unit and YX Dependency) with a two-way mixed ANOVA. There was no main effect of Group $(F(1,14)=1.93, p=.19)$, nor of item type $(F(1,14)=2.08, p=.17)$. However, there was a significant interaction between Group and Item Type $(F(1,14)=$ 13.223, $\mathrm{p}=.003)$. To understand this interaction, we compared the two groups directly on each item type with two independent-sample T-tests. On the XY Unit items, the OpenClass X condition did significantly better than the Closed-Class X condition $(t(14)=-4 \cdot 97$, $\mathrm{p}<$.001), while on the XY Dependency items the Closed-Class X condition did significantly better than the Open-Class $X$ condition $(t(14)=2.70, p=.02)$. The OpenClass X condition was numerically below chance on the XY Dependency items, but this did not significantly differ from chance $(t(7)=-1.43, \mathrm{p}=.197)$. 


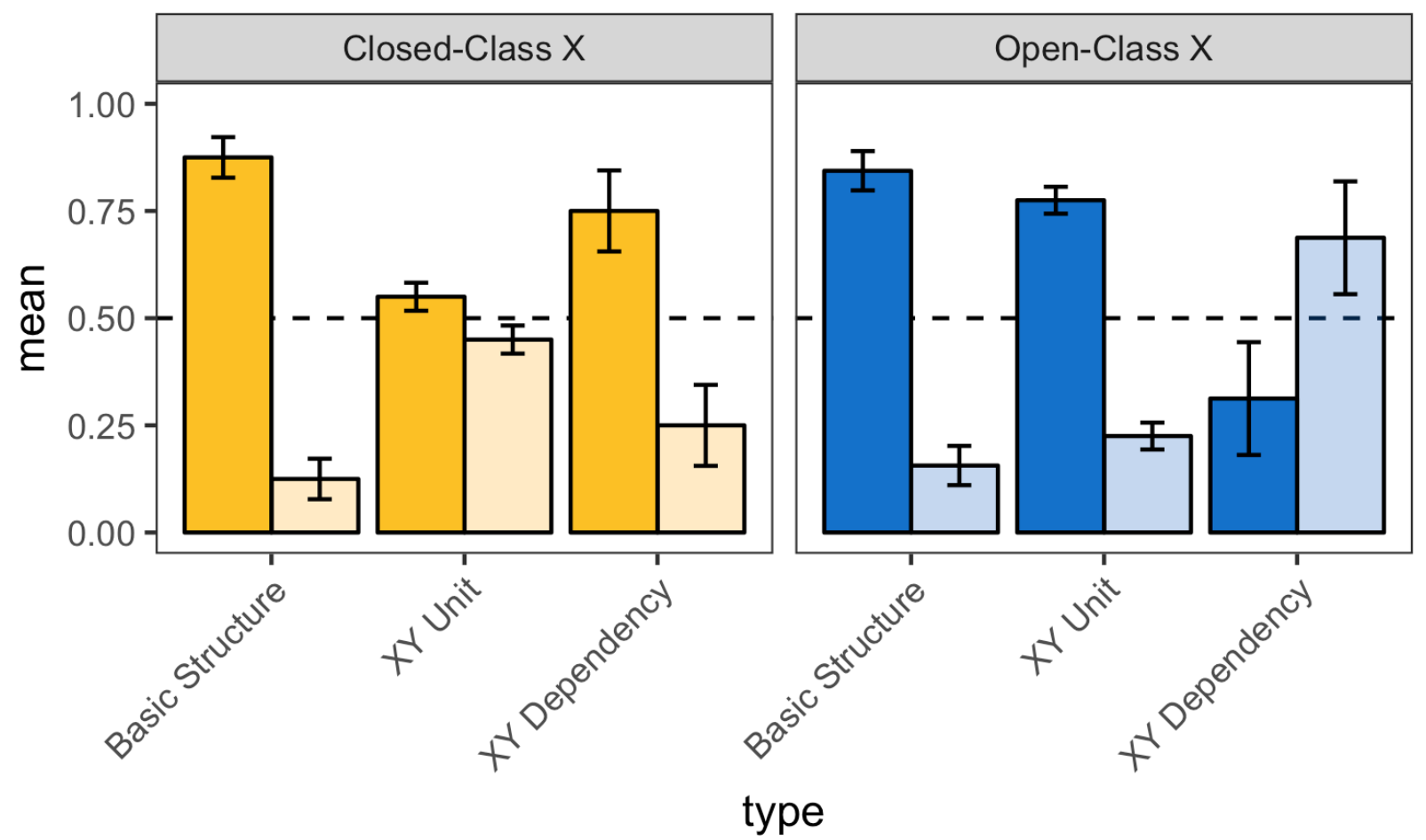

Figure 3.2: Results of Experiment 6 (predictive dependency language, linear order

control). In the linear order control language, $\mathrm{X}$ occurred after $\mathrm{Y}$ in linear order but $\mathrm{X}$ still predicted Y. Darker bars indicate the target choice on a 2AFC test. In the Open-Class X condition, learners did not learn that X predicts Y. Instead, they apparently analyzed Y as predictive of X.

These results provide important information about the nature of the learning bias we are investigating. The aim of this experiment was to find out if the Open-Class X condition would be able to acquire the "if X then Y" dependency when Y (that condition's closed-class item) occurred first. The answer is no: although the Open-Class X condition did represent YX as a grammatical unit, they did not acquire the predictive structure of the dependency, choosing the target item on the YX dependency test (AY) only $31 \%$ of the time. This poor performance is particularly striking given that the alternative (AX) is not even a grammatical sequence in this experiment (since $\mathrm{X}$ must be preceded by $\mathrm{Y}$ ); its 
forward transitional probability is $\mathrm{o}$. It is clear that changing the linear order of $\mathrm{X}$ and $\mathrm{Y}$ did not make the "if X then Y" dependency learnable in the Open-Class X condition. Instead, this change apparently led those learners to analyze $\mathrm{Y}$, not $\mathrm{X}$, as the predictive category.

As in Experiment 5, knowledge of the YX dependency was tested in longer sentences as well. Performance was again equivalent, with both groups scoring $56 \%$ correct. These results indicate that learners' respective knowledge extends to longer sentences, but does not tell what kind of knowledge they have.

\subsubsection{Experiment 6 discussion}

In Experiment 6, we exposed learners to a dependency in which the predictive member of the dependency, $\mathrm{X}$, followed rather than preceded the other category $(\mathrm{Y} \leftarrow \mathrm{X})$. Our main interest was in the Open-Class X condition, where the closed-class member of the dependency $(\mathrm{Y})$ now preceded the open-class one $(\mathrm{X})$, as in English. Would learners be able to learn a structurally unnatural dependency-where an open-class category predicted a closed-class one-under these conditions? The answer is no: learners in the Open-Class X condition did not acquire the $\mathrm{Y} \leftarrow \mathrm{X}$ dependency. Rather, these learners apparently analyzed $\mathrm{Y}$ as predictive of $\mathrm{X}(\mathrm{Y} \rightarrow \mathrm{X})$, despite only weak evidence for such a relationship in their input (Y was followed by X only 53\% of the time). These results provide compelling evidence that learners preferentially acquire dependencies where closed-class items are predictive.

In the Closed-Class X condition, learning appeared to be somewhat reduced in Experiment 6 relative to Experiment 5 (performance was not significantly above chance 
on one of the two relevant subtests). Other studies have shown that learners are as good at computing statistics backwards as they are forwards, so a bias for forward dependencies seems unlikely to explain this result (Pelucchi et al., 2009; Perruchet \& Desaulty, 2008). The somewhat depressed learning outcomes could be attributable to changes in the distribution of $\mathrm{X}$ and $\mathrm{Y}$ that occurred as a consequence of changing their linear order. For example, when the word order is AXYBC, X occurs in an edge position (first) $21 \%$ of the time (out of all occurrences of X). In contrast, when the word order is AYXBC, $\mathrm{X}$ occurs in an edge position (last) only $10.5 \%$ of the time. In any case, learning outcomes for Closed-Class X in Experiment 6 are not directly relevant to the computational bias of interest in this chapter. The point of Experiment 6 was to ask whether learners in the Open-Class $\mathrm{X}$ condition could acquire the $\mathrm{Y} \leftarrow \mathrm{X}$ dependency, which they could not.

The results of Experiments 5 and 6, taken together, provide compelling evidence that learners preferentially acquire dependencies where closed-class items are predictive. Learners do not simply prefer that closed-class items precede open-class ones, since switching the linear order $\mathrm{X}$ and $\mathrm{Y}$ in Experiment 6 did not make the dependency learnable in the Open-Class X condition. We have argued that this evidence points to a computational learning bias. However, our results are also consistent with a simpler prosodic explanation. Perhaps learners expected a closed-class category to depend on an open-class category because this pattern fits an expected prosodic template. We did take measures to guard against this possibility by making our closed-class item $(k a)$ an independent, stress-bearing word rather than a phonological clitic. Closed-class items are 
indeed often prosodically reduced, but we chose to mark closed-class membership in other ways in order to avoid this problem. However, to ensure that this explanation could not account for our results, we ran an additional control experiment.

\subsection{Experiment 7: Prosody control language $(X \rightarrow Y)$}

\subsubsection{Experiment 7 method}

This experiment used the same language as Experiment 5 (in which the predictive category, X, linearly preceded Y) except that we replaced the closed-class item $k a$ with a new word, daygin (Table 3.1). The new "closed-class" word was bisyllabic, carried initial stress, and had a closed final syllable, making it the same phonological weight as openclass words; its only distinguishing property is its high frequency. Without the prosodic cues, this strength of this word as an anchor is substantially reduced, so we did not expect learning to reach the same levels as in Experiment 5. The key question was whether we would still observe a difference in learning outcomes between the Closed-Class X and Open-Class X conditions. If the results of Experiments 1 and 2 are purely the result of a prosodic bias, learning outcomes should not differ between these conditions. However, if learners have a computational bias to analyze salient items (including items salient for their frequency) as predictive, learning should still be better in the Closed-Class X condition.

Exposure and test materials were re-synthesized, replacing ka with daygin. All other details of the design, materials, and procedure were the same as in prior experiments. Sixteen adults age 18-22 each received $\$ 10$ to participate in this study. 


\subsubsection{Experiment 7 results}

\subsubsection{Basic structure}

Results are in Table 3.5 and Figure 3.3. As in Experiments 5 and 6, both groups of learners performed well on tests of the basic structure for shorter sentences (88\% correct for both conditions). Again, performance was somewhat reduced for longer sentences though still above chance (Closed-Class X: 68\%, Open-Class X: 66\%). Thus when prosodic cues are removed, learners can still acquire the basic properties of the language regardless of the structure of grammatical dependencies within the language.

Table 3.5: Results of Experiment 7 (predictive dependency language, prosody control).

\begin{tabular}{|c|c|c|c|c|}
\hline \multirow[b]{2}{*}{ Test item type } & \multicolumn{2}{|c|}{ Two-word sequences } & \multicolumn{2}{|c|}{ Longer sentences } \\
\hline & $\begin{array}{l}\text { Closed- } \\
\text { Class X }\end{array}$ & $\begin{array}{l}\text { Open- } \\
\text { Class X }\end{array}$ & $\begin{array}{l}\text { Closed- } \\
\text { Class X }\end{array}$ & $\begin{array}{l}\text { Open- } \\
\text { Class X }\end{array}$ \\
\hline Basic Structure & $.88(.19)$ & $.88(.19)$ & $.68(.07)$ & $.66(.21)$ \\
\hline XY Unit & $.69(.17)$ & $.56(.20)$ & & \\
\hline XY Dependency & $.56(.32)$ & $.44(.32)$ & $.55(.15)$ & $.55(.29)$ \\
\hline Filler & $.38(.21)$ & $.54(.26)$ & & \\
\hline
\end{tabular}

Note. Means (standard deviations) reflect choice of target item on the $2 \mathrm{AFC}$ test. 


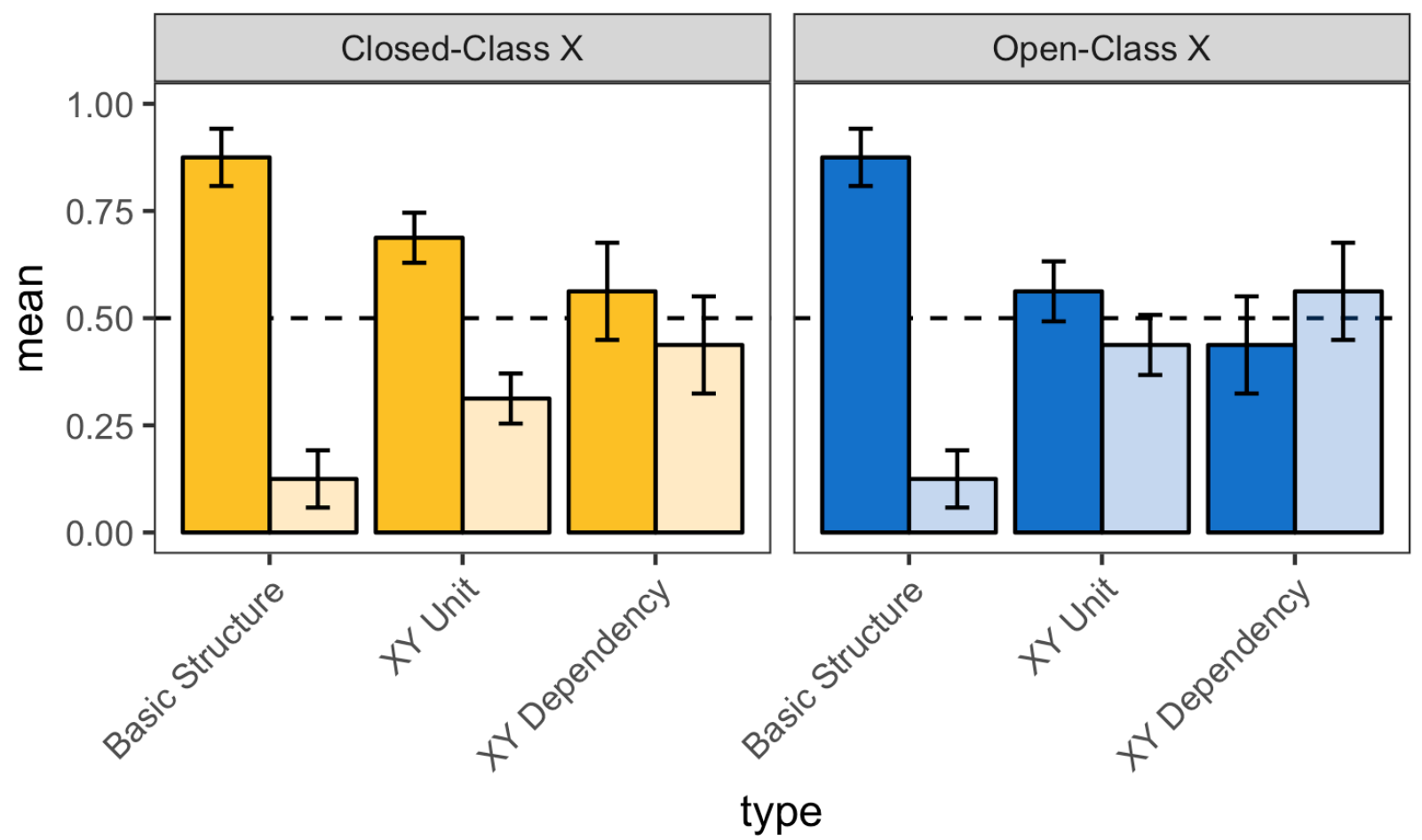

Figure 3.3: Results of Experiment 7 (predictive dependency language, prosody control).

Darker bars indicate the target choice on a 2AFC test. The Closed-Class X condition still outperformed the Open-Class X condition even when prosodic cues were removed, consistent with a computational (rather than prosodic) bias.

3.4.2.2. Predictive dependency

We expected learning of the "if $\mathrm{X}$ then Y" dependency to be reduced relative to Experiment 5, since the salience of the closed-class anchor was significantly reduced. Results were again analyzed with a two-way mixed ANOVA. This time, there was no main effect of group $(\mathrm{F}(1,14)=1.97, \mathrm{p}=.18)$, no main effect of item type $(\mathrm{F}(1,14)=1.73, \mathrm{p}=.21)$, and no interaction $(\mathrm{F}(1,14)=\mathrm{o}, \mathrm{p}=1.0)$. However, the Closed-Class $\mathrm{X}$ condition did perform significantly better than chance overall $(t(7)=2.55, \mathrm{p}=.04)$, while the Open-Class $\mathrm{X}$ condition did not $(\mathrm{t}(7)=.68, \mathrm{p}=.52)$. 


\subsubsection{Experiment 7 Discussion}

As expected, when the only distinguishing feature of the closed-class item was its high frequency, learning in the Closed-Class X condition was reduced relative to Experiment 5. Crucially, however, there is still an advantage in the Closed-Class X condition. The results illuminate the role of prosody in explaining the results of Experiment 5. Prosodic properties of closed-class items do influence how they are analyzed. The results of Experiment 3 demonstrate that the role of these properties is to modulate learners' attention to closed-class items, rather than to lead learners to acquire patterns that fit an expected prosodic template.

\subsection{Discussion}

In three experiments we asked whether learners are biased to analyze closed-class items in certain ways. We showed that learners acquire a predictive dependency $\mathrm{X} \rightarrow \mathrm{Y}$ only when the predictive category, $\mathrm{X}$, is closed-class. In a mathematically identical condition where $\mathrm{X}$ is open-class and $\mathrm{Y}$ is closed-class, learners do not acquire the dependency (Experiment 5). In Experiment 6, we found that this effect interacts with linear order, such that learning is reduced in our native English-speaking subjects when the predictive category precedes the predicted one $(\mathrm{Y} \leftarrow \mathrm{X})$. However, we found additional evidence for a computational bias in the control condition, where $\mathrm{X}$ was open-class and $\mathrm{Y}$ closed-class. Those learners analyzed Y, the closed-class item, as predictive, leading them to acquire a dependency $(\mathrm{Y} \rightarrow \mathrm{X})$ that was not present in their exposure but is structurally like the dependencies between closed-class and open-class categories in natural languages. Finally, in Experiment 7, we showed that learners analyze closed-class items as 
predictive even when prosodic cues to closed-class status are removed, leaving frequency as the only distinguishing factor. Together, these results indicate that learners privileged computations that treat closed-class items as predictive-the same computations that are most relevant for acquiring natural language dependencies.

\subsubsection{Extending the Anchoring Hypothesis}

The original idea of the Anchoring Hypothesis (Valian \& Coulson, 1988) was that, because closed-class items tend to occur at phrase boundaries, focusing on them could help learners acquire the grammatical dependencies inside and among phrases. Our results add a computational component to this approach as well. Learners must analyze the distribution of elements in the language in terms of what they already know. Because closed-class items are noticed first, due to their unique phonological properties and their high frequency, these will be the constant terms in learners' computations; other patterns can then be learned and represented relative to them.

A learning mechanism that operates in this way would eventually represent a broad range of language patterns in terms of the distribution of a small set of closed-class items. As we pointed out in the Introduction, this is increasingly the way that language patterns are analyzed in syntactic theory as well. The results of our experiment suggest that human languages may acquire this structure at least in part as a consequence of computational biases in the human language learner.

\subsubsection{Future directions}

This intriguing possibility points to several areas for further research. First, we must ask whether this computational bias is present in children, the most important 
natural language learners. Our preliminary results in ongoing work with child participants suggest that they do share this bias. Second, if it is true that children organize their language around closed-class items, it is puzzling that they refrain from actually producing these words in their own speech for several years. Future work must be aimed at understanding the reasons for the discrepancy between what children represent and what they produce. Finally, the language in this experiment was unlike natural languages in a variety of ways: for example, the distribution of all of the categories other than $\mathrm{X}$ and $\mathrm{Y}$ was unpredictable, there was only a single grammatical phrase (XY), and none of the words had any meaning. We are in the process of exploring whether learners privilege the same types of computations in the acquisition of languages that are more natural. If so, we can ask what kinds of natural language patterns can be acquired and represented using these privileged computational mechanisms, and to what extent these learning mechanisms explain why these patterns come to exist in languages of the world. 


\section{COMPUTATIONAL MECHANISMS FOR ACQUiRING A COMPLEX MORPHOSYNTACTIC PATTERN}

\subsection{Introduction}

In natural languages, the morphological form of words often correlates with the position that those words occupy in the sentence. For example, in German, the finite verb in main clauses is generally second while non-finite verbs occur last, as in Maxe möchte nur eine Zigarette rauchen ("Max just wants to smoke a cigarette"). ${ }^{11}$ How do language learners determine that these syntactic and morphological patterns are related?

The acquisition of this type of form/position contingency — known as "verb movement" in the linguistics literature-has been the subject of a large body of research (Blom, 2008; Clahsen, Eisenbeiss, \& Penke, 1996; Clahsen, Penke, \& Parodi, 1993; Déprez \& Pierce, 1993; Déprez \& Pierce, 1994; Dye, 2011; Freudenthal, Pine, Aguado-Orea, \& Gobet, 2007; Haan, 1987; Haegeman, 1995; Jordens, 1990; Platzack, 1990, 1996; Poeppel \& Wexler, 1993; Rizzi, 1994; Rohrbacher \& Vainikka, 1994; Verrips \& Weissenborn, 1992; Westergaard, 2008; Wexler, 1998). Much of this literature is concerned with demonstrating that children acquire this type of pattern, and related ones, relatively early (around age 2). Theoretical debate has largely focused on the nature of the representations underlying young children's knowledge. However, in order to represent knowledge that a verb's form is related to its position, children must first learn that this fact is true for a particular language. Our current theories lack mechanistic explanations of how children acquire this type of language-specific knowledge.

\footnotetext{
for details.
}

${ }^{11}$ Certain constructions are exceptions to this generalization. See footnote 4 in Chapter 2 
In a separate literature on statistical learning, there is evidence that humans can extract information about language structure from statistical information present in their input. For example, learners use transition probabilities to find word boundaries (Aslin, Saffran, \& Newport, 1998; Pelucchi, Hay, \& Saffran, 2009; Perruchet \& Desaulty, 2008; Saffran, Aslin, \& Newport, 1996; Saffran, Newport, \& Aslin, 1996) and to group words into grammatical phrases (Thompson \& Newport, 2007). However, this literature has not focused on morphosyntactic patterns such as verb form/position contingencies, which may require a somewhat different computational approach. We aimed to address this gap, asking how learners extract information about a verb form/position contingency from language input.

4.1.1. Computational approaches to acquiring a verb form/position contingency To acquire a verb form/position contingency, children must somehow associate different positions of the verb with certain inflections. There are a variety of ways this might work. One approach would be to do a "Frequency Analysis": learners could encode how frequently a given position/inflection pairing occurs in the sentences they hear. For example, MOSAIC — a model of language acquisition that was designed to account for the acquisition of this type of pattern-builds sentences word-by-word beginning at the end of the sentence, and ultimately ends up storing word sequences that are repeatedly encountered (Freudenthal et al., 2007). To the extent that these sequences contain verbs correctly inflected for their position, the model has "learned" the form/position contingency. The Frequency Analysis as implemented in MOSAIC does capture certain empirical facts about child language acquisition, such as children's use of infinitives 
instead of finite verbs. However, it fails to account for other evidence that children's knowledge of verb placement is rule-governed and is not based on frequent chunks (Westergaard, 2009). Furthermore, learning in a variety of domains is often influenced by conditional probability rather than frequency. This is true in classical conditioning experiments with animals (Rescorla, 1966; Seligman, 1970) as well as modern studies of statistical language learning in humans (Aslin et al., 1998; Thompson \& Newport, 2007). Thus, a model that encodes frequency alone-and cannot analyze the conditional relationships between elements—-seems unlikely to be suitable for natural language learning.

A second approach, one which does involve searching for conditional rules, would be to focus on the words that sound most prominent (Brown, 1973; Gleitman \& Wanner, 1982, 1984; Slobin, 1973). Lexical or open-class categories such as nouns and verbs tend to have these properties: they generally bear stress, are longer, may appear in isolation, and have greater semantic content. Thus, children might acquire a form/position contingency through a "Verb Analysis": they encode the two possible positions for verbs, and then determine what kind of morphology occurs on verbs in each position. Gleitman and Wanner (1984) advocate exactly this approach, arguing that "since the open class, and the structures in which it participates, [appear to be] earlier discovered, we can conclude that the child analyzes the structure of the closed class against whatever structure he has imposed on the open class, and not the other way around" (p. 239). Those authors find empirical support in the evidence that children appear to acquire open-class items first. For example, when children first begin to speak, their sentences overwhelmingly consist 
of open-class words. A similar approach is advocated by Braine (1963) who proposes that children learn the sentence positions of "primary phrases" (such as noun phrases and verb phrases) and then learn the locations of morphemes within these phrases.

However, subsequent research suggested that children actually do represent closed-class items before they begin producing them (Gerken, Landau, \& Remez, 1990; Gerken \& McIntosh, 1993; Gervain, Nespor, Mazuka, Horie, \& Mehler, 2008; Höhle \& Weissenborn, 2003; Shafer, Shucard, Shucard, \& Gerken, 1998). Babies in their first year of life use their knowledge of closed-class items' distributional properties to segment new words and guess their grammatical category (Marquis \& Shi, 2008; Shi, Cutler, Werker, \& Cruickshank, 2006; Shi \& Lepage, 2008). Since learners apparently do perceive and represent closed-class items early on, there is a third approach they could take to acquiring form/position contingencies. Rather than focusing on open-class words, children might start with the "little words" in the sentence-functional or closed-class categories such as determiners and inflectional morphology—and identify the position of these items. Then, having sketched an outline of the sentence using these closed-class items, they might proceed to organize open-class items into this structure. That is, they could learn a form/position contingency through an "Inflection Analysis": they encode the position of closed-class inflectional morphology, and then determine what kind of open-class items occur with that morphology. This is the opposite approach to the one advocated by Gleitman and Wanner (1984) and Braine (1963) but it is equally compatible with the evidence available today. 
In the following section I will review evidence that learners do focus on closedclass items, using them to "anchor" their distributional analyses (Valian \& Coulson, 1988), and I will argue that this approach leads them to do an Inflection Analysis. The important point made in the present section is that although the Frequency Analysis, Verb Analysis, and Inflection Analysis would all lead to similar knowledge, in terms of computation they are mathematically distinct. The Frequency Analysis involves computing the frequency with which a verb occurs in a certain position with a certain inflection. The Verb Analysis involves computing the probability of different inflections, given a verb in a certain position. Finally, the Inflection Analysis involves computing the probability of different open-class categories, given an inflection in a certain position. Thus, these analyses differ in the types of statistics that learners compute, the nature of the elements whose position is encoded, and which elements are the "given" terms in learners' computations.

4.1.2. Function words as anchors for distributional analysis

The computations underlying language learners' distributional analyses are not well understood, but there is some evidence that learners do focus their analyses on specific parts of the sentence. In particular, closed-class items attract learners' attention through their distinctive perceptual properties, namely their short duration, high frequency, light syllable structure, and special phonology (Shi, Morgan, \& Allopenna, 1998). Various researchers have noted that attention to closed-class items would be useful for acquiring grammatical patterns. Braine (1963) suggested that the high frequency of these items could make them useful as a reference point, such that learners could acquire ordering relationships relative to them ("first after X"). Valian and Coulson (1988) 
provided additional evidence for this proposal and termed it the Anchoring Hypothesis. Morgan, Meier and Newport (1987) noted that closed-class items tend to occur at the edges of phrases, forming a potential clue to the hierarchical structure of the sentence, and demonstrated that adult learners take advantage of this clue to learn phrasal dependencies. Similar ideas have been proposed in the literature on the acquisition of form/position contingencies. For example, the Lexical Learning Hypothesis of Clahsen and colleagues posits that morphology somehow "triggers" the acquisition of correlated syntactic patterns (Clahsen et al., 1996; Clahsen \& Penke, 1992). A recent study supports the idea that closed-class morphology helps learners acquire this type of pattern: adults were most successful at learning a verb placement pattern in a miniature language when the verb's position was correlated with prosodically closed-class morphology, compared with control conditions with prosodically open-class morphology or no morphology at all (Chapter 2).

Attention to closed-class items is actually consistent with any of the computational analyses described above. For example, learners who are trying to figure out where verbs can go might use closed-class morphology to look in the right place. This would still be a Verb Analysis if learners are ultimately encoding the position of the verb rather than the position of the inflection. However, recent evidence suggests that there are specific types of computations underlying anchored distributional analysis (Chapter 3). Adults and children age 7-9 listened to sentences from a meaningless miniature language that contained a one-way grammatical dependency between two form-class categories, $\mathrm{X}$ and Y. The dependency was designed to be like the dependencies between determiners and 
nouns in English: if a determiner such as the is present in a sentence, there will also be a noun, but nouns may occur with or without determiners. The important feature of this dependency—like all one-way dependencies between closed-class and open-class categories in natural languages-is that the closed-class category predicts the open-class category and not the other way around. The question in the study was whether learners' computations reflect this asymmetry, that is, whether learners privilege computations in which closed-class items are predictive of (rather than predicted by) open-class items. In the miniature language, when an $\mathrm{X}$ word was present, a Y word had to be present as well, but Y words could occur with or without X words ("if X then Y"). Possible sentences included $\mathrm{AXYBC}, \mathrm{XYC}$, and $\mathrm{YBC}$, but not *XBC (because $\mathrm{X}$ cannot occur without $\mathrm{Y}$, just like determiners cannot occur without nouns). In one condition X was a closed class (short monosyllabic and containing only one high-frequency item) and Y was an open class (mono or disylalbic and containing one of three possible lexical items). In a contrasting condition, $\mathrm{X}$ was an open class and $\mathrm{Y}$ was a closed class. The conditions are mathematically identical: the dependency is always "head-initial" (the predictive category, $\mathrm{X}$, appears first in both conditions) and involves one closed-class and three open-class items. However, learning for adults as well as children was significantly better in the condition with closed-class $\mathrm{X}$, suggesting that learners privilege computations in which closed-class items are the predictive (given) terms.

This recent evidence leads to a prediction for the acquisition of form/position contingencies. Learners who are biased to analyze closed-class items as predictive might be expected to do an Inflection Analysis, encoding the position of closed-class items and 
then asking which types of open-class words are predicted by (occur with) the closedclass item. They would be unlikely to do a Verb Analysis, which would require them to treat an open-class category (Verbs) rather than the closed-class category as the given term in their computation. Note that the dependency in that experiment cannot be acquired via a Frequency Analysis, since storing the chunk XY does not tell the learner whether $\mathrm{X}$ predicts $\mathrm{Y}$ or vice versa.

The computational analyses that learners perform will have consequences for the way that language patterns are ultimately represented. If learners systematically use an Inflection Analysis to acquire language patterns, the presence and position of many different open-class items will end up being encoded in terms of a small set of closedclass items. What the learner could be said to "know" is what happens around each of these closed-class items. Interestingly, this is exactly how linguistic representations are structured in modern syntactic theory. Early work in generative linguistics focused on the role of lexical categories (noun phrases, verb phrases) and how they were arranged in a sentence. Beginning with Abney (1987), linguists have shifted toward analyses in which functional rather than lexical categories shape the structure of a sentence (see Rizzi \& Cinque, 2016 for discussion and historical context). For example, the contingency between verb morphology and verb position in German is captured by positing that finite and non-finite morphology is represented in different positions in the sentence. If there is finite morphology, there will be a verb and that verb will occur in the "finite" position (second in main clauses, in the functional category C). In this way, the presence and location of verbs is determined by the kind of morphology that occurs in the sentence. 
Thus, an important implication of this computational approach to learning is that it ends up building representations structurally like the ones posited by current syntactic theory.

\subsubsection{The current experiment}

Here we asked what computations learners use to extract information about a verb form/position contingency from language input. We designed a miniature language with a form/position contingency: "verbs" could occur first or second, with or without the prefix luh. (We use the label "verb" for convenience; all words were meaningless.) In natural languages, form/position contingencies are generally bidirectional within a given clause type, such that in German main clauses for example, verbs that are $2^{\text {nd }}$ have finite morphology and verbs with that morphology tend to occur $2^{\text {nd }}$. A variety of computational approaches, including a Frequency Analysis, a Verb Analysis or an Inflection Analysis would lead to successful learning of these natural language patterns. In order to tease these analyses apart, we needed to expose learners to a language where only one of these approaches would work. In one condition, verbs in first position always had the prefix luh, but verbs with luh could occur either first $\left(V_{1}\right)$ or second $\left(V_{2}\right)$. Learners would succeed in learning this pattern by doing a Verb Analysis $\left(\mathrm{V}_{1} \rightarrow l u h\right)$ but not an Inflection Analysis. In another condition, verbs with luh always occurred first, but firstposition verbs did not always have luh. In this condition, learners could acquire the pattern by doing an Inflection Analysis $\left(l u h \rightarrow V_{1}\right)$ but not a Verb Analysis. Since a Frequency Analysis does not really involve analyzing language input but rather reproducing frequent chunks, this approach would work equally well in both conditions. Thus, the most informative result would be learning in one condition but not the other, 
because this would rule out the Frequency Analysis and point instead to one of two computationally distinct alternatives.

4.2. Experiment 8: Form/position contingency language

4.2.1. Experiment 8 method

4.2.1.1. Participants

Participants were sixteen native English-speaking children age 7 to 9 (mean 8;2). The experiment took place over two days either at local YMCA aftercare or in our lab. ${ }^{12}$ 4.2.1.2. Description of the miniature language

We created a structured miniature language with two obligatory open-class categories, labeled S and V for convenience. The "verb" occurred either $1^{\text {st }}$ or $2^{\text {nd }}$ (last) with or without the prefix luh (Table 4.1). Children were randomly assigned to learn one of two variants of the language, where the only difference was the predictive direction of relationship between the verb's position and its inflection. One variant of the language followed the rule "if luh then V1": verbs with luh always occurred ist (uninflected verbs could occur $1^{\text {st }}$ or $\left.2^{\text {nd }}\right)$. The other variant followed the rule "if V1 then luh": V1 always had luh (V2 could have luh or be uninflected).

${ }^{12}$ Three additional children were tested but not included in the analysis below because they were not present for the second day of the experiment (2) or because they gave every sentence the same rating at test (1; this participant was in the $\mathrm{V}_{1} \rightarrow$ luh condition). 
Table 4.1: Design of the form/position contingency language used in Experiment 8.

\begin{tabular}{lll} 
Structure & luh $\rightarrow \mathrm{V}_{1}$ & $\mathrm{~V}$ 1 $\rightarrow$ luh \\
\hline luhV-S & $\mathrm{x}$ & $\mathrm{x}$ \\
V-S & $\mathrm{x}$ & \\
S-luhV & & $\mathrm{x}$ \\
S-V & $\mathrm{x}$ & $\mathrm{x}$
\end{tabular}

Note. The distribution of the inflection differed across two variants of the language. Each variant had three sentence types. In one variant, the verb's inflection predicted its position; in the other, the verb's position predicted its inflection.

The predictions for learning are as follows. If learners treat closed-class items as constants in their computations, and look for patterns that are predicted by those items (Inflection Analysis), they should acquire the version of our language where the verb's inflection predicts its position $\left(l u h \rightarrow V_{1}\right)$. This is the condition where we expected the best learning, based on our previous results for an XY dependency. Alternatively, if learners focus on the prosodically prominent words in the language and learn inflection patterns relative to those items (Verb Analysis), they should acquire the version of our language where the verb's position predicts its inflection $\left(\mathrm{V}_{1} \rightarrow l u h\right)$. Finally, if learners acquire this type of pattern by encoding high-frequency chunks (Frequency Analysis), performance should be similar across conditions, since each condition has three equally frequent verb position/inflection pairings.

\subsubsection{Materials}

The two obligatory categories, V and S, each contained three words. Each of these words was bisyllabic, carried initial stress, and had a closed final syllable (S: fluggit, daffin, 
gentif, V: tombur, clidum, bleggin), all properties typical of open-class words in natural languages. The inflection category had contrasting phonological and prosodic properties which were like closed-class categories in natural languages. We used a single monosyllabic, unstressed, phonologically reduced form luh, which formed a prosodic unit with the verb to which it attached as a prefix ("luhTOMbur").

The recordings of the $\mathrm{S}$ and $\mathrm{V}$ words came from a lab corpus of nonsense words recorded in isolation by a female native speaker of American English. The inflection luh was created by splicing off the first, unstressed syllable of the word lapal ("luhPAUL") from the same lab corpus. This ensured that it had the prosodic and phonological characteristics of unstressed syllables in English. We assigned lexical items to the S and V categories such that the $\mathrm{V}$ words sounded natural when concatenated with this inflection. The lexical items were exactly the same in the two conditions.

To create the exposure sets, we selected three sentence types (out of nine possible types) for each of the three sentence structures that were grammatical in that language, making nine sentences total. For the sentence structures that were grammatical in both variants of the language (luhV-S and S-V), we used the same exact sentence types in both exposure sets. The frequency of the $\mathrm{S}$ and $\mathrm{V}$ words was balanced within each exposure set. Across the two exposure sets, the relative frequency of the inflection luh was different due to the sentence types that were exposed (sentence types were selected as described above). In the luh $\rightarrow V_{1}$ condition, where luh occurred in only 1 of the 3 sentence types, luh had the same individual frequency as the other lexical items. In the $\mathrm{V}_{1} \rightarrow l u h$ condition, luh occurred in two of the three sentence types and therefore occurred twice as 
frequently as every other lexical item. This frequency imbalance makes luh more distinctive (relative to the open-class categories) in the condition where we predicted worse learning. In both conditions, of course, luh retained its distinctive properties as a phonologically reduced, prosodically weak suffix.

\subsubsection{Procedure}

Participants were exposed to the language in the context of a computer game. Instructions were spoken aloud by a robot named "Bot" who told participants to listen as an alien named Zooma practiced saying sentences in a made-up language spoken by aliens on another planet. First, a brief Practice phase was designed to familiarize children with the rating scale by demonstrating how it worked with English sentences. Participants listened as Zooma said several different English sentences. Then Bot explained that Zooma was going to say another sentence and participants were supposed to indicate whether Zooma had said that English sentence when she was practicing. Bot instructed participants to click "Yes" if they were definitely sure they had heard Zooma say that sentence; "Maybe" if they were unsure if they heard Zooma say that sentence; and "No" if they were definitely sure they did not hear Zooma say the sentence. The rating scale appeared on the screen and the experimenter repeated Bot's instructions while clicking the appropriate points on the scale to demonstrate how it worked. At this point the experimenter also explained that participants could also click between Maybe and Yes or between Maybe and No.

After this English practice phase, Zooma began saying SillySpeak sentences and flying across the screen. Children were told that Zooma would sometimes get a little 
confused and repeat the same sentence she just said, and that they could help Zooma by clicking on her when this happened. This was a 1-back task designed to ensure attention. Each time they clicked on Zooma they saw a star light up on the screen. After 10 stars, a picture on the bottom of the screen showed Zooma's rocket moving closer to the new planet, and Zooma's background image changed such that she appeared to be traveling from Earth through different galaxies and to the new planet. There were four blocks of exposure each day (each containing 10 1-backs), and the entire exposure phase took 20 minutes.

On Day 1, the experiment concluded after the 20-minute exposure phase. On Day 2, participants repeated English practice and the Silly Speak exposure phase. At the end of Day 2, Zooma was shown on the new planet and participants continued on to the SillySpeak rating test. The entire experiment lasted approximately 30 minutes on Day 2.

\subsubsection{Test}

The test was designed to ask whether participants acquired the inflection pattern of each language. Participants rated each of the four sentence structures in Table 4.1 as either grammatical or ungrammatical. They also rated one additional structure, ungrammatical in both conditions, where luh was attached as a prefix to the Subject instead of the Verb but still occurred first, as is grammatical in both conditions ( $\left.{ }^{*} l u h S-V\right)$.

There were four trials for each sentence structure ( 20 trials total). The test contained the same 12 grammatical and 8 ungrammatical sentences for all participants, but the exact sentence structures that were grammatical or ungrammatical differed across conditions according to the structure of the language to which they were exposed. All test 
sentences were novel. Test sentences were selected such that different lexical items from the same category occurred with equal frequency and overlapped to the same extent with other categories, as in the exposure corpus. Sentences were presented in the same pseudo-random order for each participant. No structure was tested twice in a row.

\subsubsection{Experiment 8 results}

Learners in the two conditions received quite similar exposure; the only difference concerned the mathematical relationship between the verb's position and its inflection. Thus, our first question was whether this subtle mathematical difference was perceptible to learners, as measured by differences across the two groups in how learners rated various sentence types. Mean ratings for all five sentence structures are presented in Table 4.2. Ratings were analyzed with a two-way mixed ANOVA with Condition $\left(\mathrm{V}_{1} \rightarrow \mathrm{luh}\right.$, $\left.\mathrm{luh} \rightarrow \mathrm{V}_{1}\right)$ as a between-subjects variable and Structure (luhV-S, V-S, S-luhV, S-V, luhS-V) as a within-subjects variable. There was no main effect of Condition $(F(1,14)=.022, \mathrm{p}=$ $.885)$, no main effect of Structure $(F(1,4)=1.146, \mathrm{p}=.344)$, and a significant interaction between Condition and Structure $(F(1,4)=8.920, \mathrm{p}<.001))$. This indicates that participants rated structures differently depending on the exposure that they received, demonstrating that learners are sensitive to the mathematical relationship between the verb's position and its inflection.

The next and most important question was whether the inflection pattern was equally learnable in the two conditions. This would reveal the types of computations that learners perform. To answer this question, we did two within-group analyses in which we directly compared ratings for two sentence structures in each language: the sentence 
structure that violates each language's inflection pattern (the blank cells in Table 4.1) versus the sentence structure that corrects the error (in both conditions, this was the structure luhV-S). Results are presented in Figure 4.1. In the luh $\rightarrow V_{1}$ condition, the violation sentence had luh in the wrong position $\left({ }^{*} \mathrm{~S}-\mathrm{luhV}\right)$. Participants rated these violation sentences significantly lower than sentences with luh in the correct position (mean rating of luhV-S $=4.12,{ }^{*} \mathrm{~S}-\mathrm{luhV}=2.72, \mathrm{t}(13)=3.94, \mathrm{p}=.002$ ), indicating knowledge that luh can occur only on $\mathrm{V}_{1}$. In the $\mathrm{V}_{1} \rightarrow$ luh condition, the violation sentence had $\mathrm{V}_{1}$ without luh. Participants rated those violation sentences no higher than sentences where $\mathrm{V}_{1}$ did have luh (mean rating of luhV-S $\left.=3.28,{ }^{*} \mathrm{~V}-\mathrm{S}=3.63, \mathrm{t}(13)=-.75, \mathrm{p}=.467\right)$, indicating that they did not acquire the inflection pattern of their language. 
Table 4.2: Results of Experiment 8 (form/position contingency language).

\begin{tabular}{lll} 
& luh $\rightarrow \mathrm{V}_{1}$ & $\mathrm{~V}_{1} \rightarrow \mathrm{luh}$ \\
\cline { 2 - 3 } luhV-S & $4.19(\mathrm{o.66})$ & $3.28(0.96)$ \\
V-S & $3.53(0.59)$ & $3.62(0.88)$ \\
S-luhV & $2.72(0.82)$ & $4.31(0.46)$ \\
S-V & $3.47(0.62)$ & $3.19(1.09)$ \\
luhS-V & $3.66(0.42)$ & $2.97(0.99)$
\end{tabular}

Note. Mean ratings for five different sentence structures. Shaded boxes indicate the sentences that violate the inflection pattern in each condition. The crucial comparison is the within-group contrast between the violation structure-where either the inflection is in the wrong place $\left({ }^{*} \mathrm{~S}\right.$-luhV in $\left.l u h \rightarrow \mathrm{V}_{1}\right)$ or the verb is incorrectly inflected $\left({ }^{*} \mathrm{~V}-\mathrm{S}\right.$ in $\left.\mathrm{V}_{1} \rightarrow l u h\right)$ - versus the structure where the inflection is correctly placed and the verb is correctly inflected (luhV-S).

This result-that participants readily acquired the rule "if luh then $\mathrm{V}_{1}$ ", but not the rule "if $V_{1}$ then luh"-is consistent with a bias to analyze closed-class items as predictive of other language patterns. Computationally, learners treat closed-class items as the "given" terms in their analyses, leading other patterns to be encoded relative to those items. 


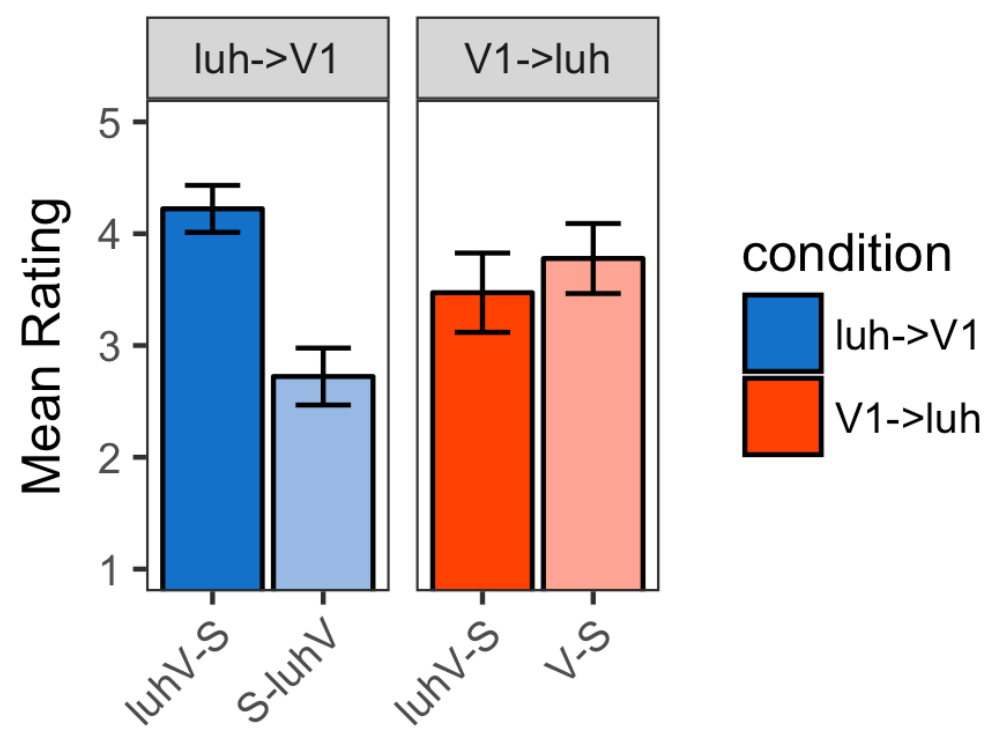

Figure 4.1: Results of Experiment 8 (form/position contingency language). Mean ratings for the sentence structure where $V_{1}$ has luh (darker bars) and for the violation sentence structure in each language (lighter bars). In the $l u h \rightarrow V_{1}$ condition, the violation structure has luh in the wrong position. In the $\mathrm{V}_{1} \rightarrow l u h$ condition, the violation structure has $\mathrm{V}_{1}$ without luh.

The robustness of this effect is also evident in an analysis of individual subjects. We converted each individual's ratings to Z-scores and computed a difference score for the sentence types represented in Figure 4.1: luhV-S versus the violation sentence in each language. The difference scores are plotted in Figure 4.2. Seven of the 8 children in the $l u h \rightarrow V_{1}$ condition have positive difference scores, indicating a preference for luhV-S over ${ }^{*} \mathrm{~S}-\mathrm{luhV}$. For five of these children, the difference score is greater than 1 , indicating that they rated luhV-S a full standard deviation higher than ${ }^{*}$ S-luhV. In contrast, difference scores in the $\mathrm{V}_{\mathbf{1}} \rightarrow l u h$ condition are distributed around $\mathrm{o}$, indicating no preference. 


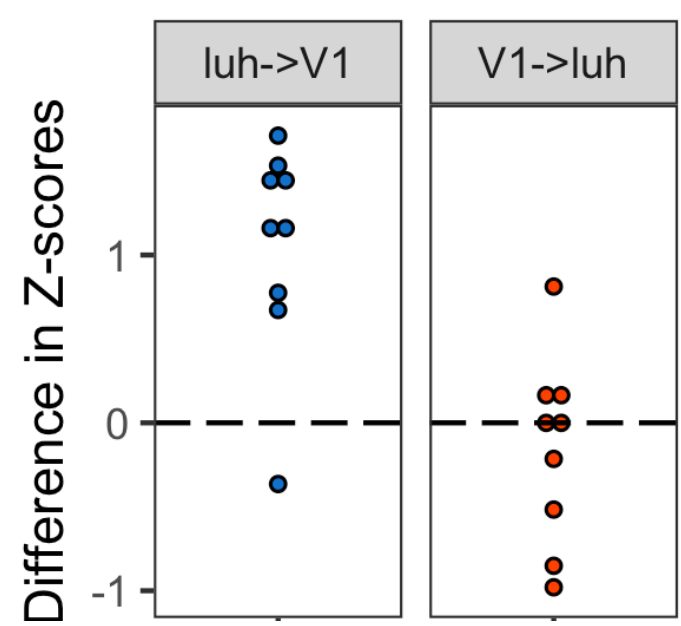

Figure 4.2: Individual results for Experiment 8 (form/position contingency language). The Y-axis represents difference in Z-scores for luhV-S versus the sentence that violated each language's inflection patterns (S-luhV for $l u h \rightarrow \mathrm{V}_{1}$, and VS for $\mathrm{V}_{1} \rightarrow l u h$ ). Positive difference scores reflect a preference for the grammatical structure, luhV-S.

Our ratings test was also designed to test a separate issue: whether participants learned that luh occurs as a suffix on Verbs and not on Subjects. To find out, we compared ratings within each group for two sentence structures: luhV-S, where luh is a prefix on the Verb, and *luhS-V, where luh is a prefix on the Subject. We chose these two structures because luh occurs in the same position in both. In the $l u h \rightarrow \mathrm{V}_{1}$ condition, luhV-S was rated higher than *luhS-V, though this difference did not reach significance $(t(14)=-1.91, \mathrm{p}=.08)$. In the $\mathrm{V}_{1} \rightarrow$ luh condition, mean ratings for these structures were not even marginally significantly different $(t(14)=-.64, \mathrm{p}=.53)$. This result suggests that learners have not yet grouped the $\mathrm{S}$ and $\mathrm{V}$ words into their respective categories. This is not particularly surprising; the word order in this language was variable, and no words had any meaning, so the only cue to category membership was the inflection, which 
occurred in only $1 / 3$ of sentences in the luh $\rightarrow \mathrm{V}_{1}$ condition and $2 / 3$ of sentences in the $\mathrm{V}_{1} \rightarrow l u h$ condition. This result is consistent with the way we have described the Inflection Analysis, where learners encode the position of closed-class items and then learn which open-class words occur with that item. Learners in the $l u h \rightarrow V_{1}$ condition have clearly encoded the position of luh as demonstrated by the previous analysis, but they have not yet completed the process of determining which types of open-class words may occur with luh. We consider this result in more detail in the Discussion.

\subsection{Discussion}

\subsubsection{Summary of results}

We asked how children age 7-9 learn a contingency between the position of a meaningless "verb" and the presence of a verbal inflection luh in a miniature language. We created two mathematically distinct exposure conditions in order to distinguish two types of analyses that learners might perform. In one condition, inflected verbs were always in a certain position, such that learners could acquire the pattern by tracking the position of the verb relative to the inflection luh. In the other condition, verbs in a certain position were always inflected, such that learners could acquire the pattern by tracking the presence of the inflection luh relative to the position of the verb. Children learned only in the former condition, where the inflection luh served as the "given" term in their computation ("if luh, then the verb is 1st"). Thus, a subtle mathematical distinction had important consequences for learning. The results suggest that learners analyze language 
input in certain biased ways, privileging analyses in which closed-class items are predictive of other patterns.

4.3.2. Learners encode the stable position of closed-class items

An alternative way of stating our results is that children in the $l u h \rightarrow V_{1}$ condition simply learned that luh always occurred first. In the control condition, luh did not have a stable position, and perhaps this is why children struggled to learn that variant. This is exactly the point. Children analyze the position of closed-class items, thus they acquire patterns in which closed-class items have a stable position. Note that there was also a stable positional pattern in the $\mathrm{V}_{1} \rightarrow l u h$ condition: verbs without luh were always second (this follows from the language's rule that verbs in first position must have luh, since there were only two possible positions for the verb). In the $\mathrm{V}_{1} \rightarrow$ luh condition, it was an open-class item which had a stable position. Thus, if children simply learned any and all stable positional patterns, they would have done equally well in the two conditions (modulo any differences between first and second/last position, but since these are both edge positions, both should have been salient to learners (Endress, Nespor, \& Mehler, 2009)). But they did not; children learned only the language where the closed-class item had a stable position. This, we argue, is because learners begin acquiring language by encoding the position of closed-class items, and then organize open-class items around those positions.

\subsubsection{Anchored distributional learning with versus without meaning}

In this experiment, none of the words had any meaning. This was by design: our goal was to determine what type of distributional information was necessary for learning 
a particular pattern, so we needed to ensure that participants could not learn the pattern by attending to some other type of information. However, one might argue that this situation was unlike natural language acquisition, where words do have meaning. Perhaps our learners focused on learning the distribution of closed-class items only because none of the words were meaningful. If so, this would cast doubt on the relevance in natural language acquisition of the learning mechanism we have proposed. In our view, the situation of natural language acquisition is more similar to our experiments than one might think. Initially, learners of real languages do not know what any of the words mean, hence they are not in a position to focus on the ones that are meaningful. In contrast, even newborns can distinguish between closed-class and open-class words based on perceptual cues (Shi, Werker, \& Morgan, 1999). Once babies do begin representing the meanings of some words at around 6-9 months (Bergelson \& Swingley, 2012), they are still likely to encounter many sentences where all of the content words are unfamiliar. Closed-class items, because of their high frequency, will often be the only familiar forms in the sentence, which is one reason why these items have been seen as potentially useful 'anchors' or 'marker points' in early language acquisition. If learners acquire grammatical patterns by analyzing the distribution of closed-class items, then even these sentences with unfamiliar content words will be informative since they contain information about the position and co-occurrence patterns of closed-class items. Focusing on closed-class items would therefore allow learners to acquire grammatical patterns earlier than focusing on lower-frequency words whose meaning they already know. 
Of course learners will use many sources of information, including meaning, when acquiring a real language. We are in the process of designing an experiment to ask how learners' analyses do change when semantic meaning is available. However, for the reasons outlined above, we do not expect the availability to meaning to substantially change the nature of our results.

\subsubsection{Implications for theories of children's representations}

We have shown how learners can acquire a form/position contingency through a simple and straightforward mechanism: encoding the position of a closed-class item. Once learners determine which open-class words go with that prefix, they will have full knowledge of the form/position contingency. They will not produce open-class words with that prefix in the wrong sentence position, since the correct sentence position of the inflection was one of the very first things they learned about it.

Many researchers-particularly those working in frameworks motivated by linguistic theory-have interpreted children's knowledge of form/position contingencies as evidence for highly abstract and innate knowledge. For example, Poeppel and Wexler (1993), having presented evidence that a two-year-old child named Andreas was strikingly systematic in his placement of finite and non-finite verbs, believe "it is extremely difficult to see how such complex syntactic computations [i.e., the relationship between verb form and position] could be learned" and conclude that Andreas represents various abstract, adultlike functional categories as well as an innate notion of "verb movement". However, if children are equipped with a mechanism that allows them to encode the position of closed-class items, it is not at all surprising that their placement of closed-class items is 
strikingly target-like and systematic. Nor is it surprising that they sometimes appear to know the distribution of forms before they know what those forms mean (e.g. Legendre, Barrière, Goyet, \& Nazzi, 2010). This would also explain why children sometimes incorrectly generalize over position, mapping closed-class items to sentence positions rather than grammatical roles (Chung, 1994; Hakuta, 1982) or failing to learn the placement of closed-class forms whose position is variable (Neokleous, 2015). A computational bias to encode the position of closed-class items can account for all of these findings.

\subsubsection{Computational underpinnings of anchored distributional analysis}

The idea that learners anchor distributional analysis to closed-class items is not new; many researchers have proposed versions of this idea (Braine, 1963; Clahsen \& Penke, 1992; Gerken et al., 1990; Morgan et al., 1987; Valian \& Coulson, 1988). But there are several ways that anchoring might work computationally. Do learners use closed-class items as "pointers" to the open-class patterns that they need to analyze? Or do learners actually analyze closed-class items themselves? Our results suggest the latter. Closedclass items play a central role in learners' computations, serving as the given terms relative to which other patterns are learned and represented. Morphology helps learners acquire syntactic patterns not only because this morphology draws attention to the behavior of open-class items, but because learners are actually organizing knowledge of the patterning of open-class items with respect to that morphology.

Why are learners' computations biased in this way? The answer need not be that learners know in advance that closed-class items are "special" or that they have innate 
linguistic representations in which functional categories form the basis of the linguistic tree. Rather, this bias may be a consequence of the fact that learners must analyze the language in terms of what they already know. Closed-class items draw learners' attention first because of these items' distinctive perceptual properties, so these items form the terms in learners' subsequent computations.

\subsubsection{Learning effects on language structure}

Linguistic theory has demonstrated that adults' linguistic representations have certain fundamental features: they are abstract, hierarchically structured, and-if modern syntactic theory is correct-centered on functional or closed-class items. Linguistically motivated theories of language acquisition often attribute these structural properties to an innate Universal Grammar. An alternative-supported by the results of this chapteris that one or more of these structural properties may arise as a consequence of the way in which learners organize language input. That is, perhaps what is innate is a propensity to search for systematic patterns in one's environment and to attend to certain perceptual properties over others. The extent to which these general learning biases can explain structural properties of natural languages remains an exciting question for further research. 


\section{CONCLUSION}

5.1. Summary of the dissertation

The goal of this research was to ask how learners extract information about morphosyntactic dependencies from language input. I began by addressing concerns that morphosyntactic patterns are too complex to learn distributionally without the support of full linguistic representations. Experiment 1 demonstrated that learners can in fact acquire the morphosyntactic patterns of a miniature $V_{2}$ language without representing the language's generative rules. Experiments 2-4 demonstrated that the language's V2 patterns were learned best when there was a correlated morphological pattern. These results are consistent with the Anchoring Hypothesis (Valian \& Coulson, 1988), which proposes that learners constrain distributional analysis by focusing on perceptually distinctive closed-class items.

In Experiment 5, I began to ask what computational mechanisms underlie anchored distributional analysis. In natural languages, closed-class items predict openclass items but not the other way around: for example, if there is a determiner there will be a noun, but nouns can occur with or without determiners. I asked whether learners' computations reflect this asymmetry. I designed a new miniature language with the oneway dependency $\mathrm{X} \longrightarrow \mathrm{Y}$ : if $\mathrm{X}$ was present $\mathrm{Y}$ was always also present, but $\mathrm{Y}$ could occur without X ("if X then Y"). Learners easily acquired this dependency when the predictive category, X, was closed-class, but not in a mathematically identical version where X was open-class and Y was closed-class. Follow-up experiments demonstrated that this effect results from a computational bias to analyze closed-class items as predictive of other 
language patterns, rather than a preference for certain linear orderings of closed-class and open-class items (Experiment 6) or preferences for certain prosodic patterns (Experiment 7).

Experiment 8 was designed to ask whether the computational mechanism discovered in Experiments 5-7 could account for the acquisition of the more complex patterns investigated in Experiments 1-4, and to extend these results to child learners. I created a third miniature language in which there was a contingency between the position of meaningless "verbs" and the presence of a verbal prefix luh. I designed two exposure sets where the mathematical relationship between the verb's form and its position was slightly different, allowing us to ask which mathematical relationships are computable by language learners. In one condition, inflected verbs were always first, such that learners could acquire the pattern by tracking the position of the verb relative to the presence of luh ("if luh then V1"). In the other condition, verbs in first position were always inflected, such that learners could acquire the pattern by tracking the presence of luh relative to verbs in each position ("if $V_{1}$ then luh"). Children age 7-9 learned only in the former condition, where the inflection luh predicted the verb's position. Thus, a subtle mathematical distinction had important consequences for learning, and learners again demonstrated a bias to use closed-class items as the predictive (given) terms in their computations. 
5.2. Implications for theories of language acquisition

5.2.1. Mechanisms of morphosyntax acquisition

Taken together, the results of this dissertation form the outline of a mechanistic learning theory for the acquisition of morphosyntactic contingencies. Learners notice closed-class items first, due to their distinctive perceptual properties and high frequency, so they try to figure out where those items occur. In German, this would mean encoding the position of finite and non-finite morphology (“-te goes second and -en goes last"). As learners analyze closed-class items by searching their context, they learn that certain other words always occur nearby (e.g., both -te and -en attach to a group of words that will turn out to be verbs). By gradually acquiring knowledge about the predictable context of different closed-class items, learners can build an early representation of the sentence.

If this hypothesis is correct, and children really do use this mechanism to acquire their natural languages, then of course their sentences will contain the right patterns (cf. Chapter 2). Knowledge of the patterning of closed-class items is the main content of children's early morphosyntactic representations.

\subsubsection{Expanding the Anchoring Hypothesis}

These results add a computational component to the Anchoring Hypothesis (Valian \& Coulson, 1988; Morgan et al., 1987; Braine, 1963). The original idea of that hypothesis was that closed-class items, because they are distinctive, draw learners' attention to grammatically important parts of the sentence, essentially telling learners where to look for patterns. The experiments in this dissertation showed, however, that 
closed-class items are more than simply flags. Rather, they are the elements whose distribution learners analyze as they search for additional patterns. This learning bias constrains distributional analysis even further than the Anchoring Hypothesis had assumed, preparing learners to acquire exactly the kinds of dependencies that exist in natural languages.

\subsubsection{The special status of closed-class items}

The mental representations acquired through this learning procedure would have at least one important feature in common with representations posited by syntactic theory: closed-class items will have a special status. The reason, however, would not be because children know innately that there exists such a thing as a functional category and that they must use it to organize other language patterns. In my view, it is more simply the case that closed-class items have a cluster of properties that make them highly noticeable. They are high frequency, and they are prosodically and phonologically different from the open-class words around them. This draws attention, making closedclass items easily learned and therefore available to learners as units around which to organize their knowledge of sentences. In other words, the privileged status of closedclass items in our mental representations of language may arise in part from the way young learners analyze language input.

\subsubsection{Origin of abstract knowledge}

What, then, is the role of the hierarchical tree structure that is posited by syntactic theory? According to traditional generative theories of language acquisition, this tree structure is innate, which explains why children acquire language so easily and also why 
all languages seem to have a similar abstract hierarchcial structure. I agree that adults' knowledge of language is abstract and hierarchical. Where I disagree with traditional generative theories is on the issue of where these trees come from. Hierarchical trees may not need to be innate. Learners might be able to build up such representations, with the right fundamental properties, by analyzing the distribution of closed-class items in the way I have shown.

The result, of course, would not look exactly like the tree that Poeppel and Wexler (1993) and others had in mind. On this alternative view, there would not be a universal structure common to all languages, since the exact structure would depend in part on the closed-class items of a particular language. Interestingly, an increasingly popular hypothesis, known as the Borer-Chomsky Conjecture (Borer 1984; Chomsky 1995), suggests that the differences in the syntax of different languages come from differences in the features of functional heads. In syntax, the features of an item are what determines where it goes in the sentence, so one can think of features as summaries of an item's permitted context. From this perspective, the Borer-Chomsky Conjecture can be re-stated as saying that languages differ because their functional items have different contexts (different features). This is exactly the kind of variation that the present approach would predict.

Does this mean that nothing further is innate? No. At minimum one must say that humans have an innate attentional bias which leads them to focus on things that occur frequently and have certain other perceptual properties; and they must also have the innate ability to perceive the properties that make closed-class items distinctive. One 
might also want to say that humans are innately biased to attend to the relative temporal (and spatial) ordering of different units in order to account for why position is learned so early (cf. Slobin 1966). I have also posited one particular type of computational ability that is likely innate; and others who have worked on statistical learning have posited other such computational abilities. Finally, there may of course be other properties, perceptual biases, and computations that come into play as more complex distributional analyses of syntactic structure occur. An open question for the future concerns which of these constitutes innate knowledge of language and which are more general biases about learning and processing.

\subsection{Predictions for cross-linguistic variation}

In the Introduction, I pointed out that all languages-including Chinese-have at least some closed-class items. However, languages vary in how many of these items are present. The learning mechanism posited here will clearly play a larger role in languages that include more closed-class items. These are the same languages in which the mechanism is most needed, since it is meant to be a mechanism for acquiring morphosyntactic patterns (which by definition are present only in languages with morphology). Interestingly, however, the results of Experiments 1-4 suggest that analyzing closed-class items can also be used to acquire patterns that are technically just syntactic and not morphological, such as V2 word order. ${ }^{13}$ When adults were exposed to a

${ }^{13}$ In this pattern, characteristic of many Germanic and Scandinavian languages, main clauses have verbs second and a subject, object, or other constituent first, while subordinate clauses generally have verbs last and subjects first. This pattern can be stated (and in principle 
miniature V2 language, they readily acquired the V2 word order pattern when the language contained verbal morphology, but not when the language lacked such morphology, even though the syntactic pattern (the relative order of open-class words across constructions) was identical. These results suggest that certain syntactic patterns can only be learned when there are closed-class items nearby. My prediction, then, is that these syntactic patterns will always be marked with closed-class morphology. This is supported by typological evidence that, for example, languages with V2 word order always have some kind of verbal morphology (minimally, a finite affix on the $V_{2}$ item).

Others have also argued that the acquisition of certain syntactic patterns will depend on morphology, and that there will be corresponding typological effects. These arguments are based in syntactic theories about the formal relationship between syntactic and morphological patterns. For example, Rohrbacher (1999) has argued that rich ${ }^{14}$ morphology is the cause of "verb movement" (a pattern in which the verb occurs in multiple positions, as in German). On this theory, which Bobaljik (2002) terms the Rich Agreement Hypothesis, all languages with verb movement must also have rich morphology. Furthermore, it is hypothesized, children will acquire verb movement only once they have already acquired multiple cells of the morphological paradigm. There is

could be learned) without reference to the verb's morphology, making it technically a syntactic rather than morphosyntactic pattern. The verb's morphology also correlates with its position (generally: finite when second in main clauses, non-finite when last), but this is analyzed in syntax as a separate pattern. See Chapter 2 for more details.

${ }^{14}$ What kind of morphology counts as "rich" depends on the author. In general, and for Rohrbacher (1999), morphology is considered relatively "rich" when it encodes many different values of person or number (i.e., when there is morphological agreement) and relatively "poor" when there is a single form for all persons/numbers within a tense (i.e., when there is morphology but not agreement). 
some evidence that the acquisition of agreement morphology does precede the acquisition of verb movement (Clahsen \& Penke, 1992; Clahsen, Eisenbeiss, \& Penke, 1996), though in other cases these two patterns appear to be acquired roughly simultaneously (Pierce, 1992). However, a number of authors have pointed out that Rohrbacher's typological generalization does not hold, since there exist languages like Norwegian, with verb movement but relatively poor morphology (Bobaljik, 2002; Alexiadou \& Fanselow, 2002; Bentzen, 2004). Bentzen (2004) suggests that children learning these languages must be using syntactic rather than morphological cues to acquire verb movement. Note, however, that the exceptional languages all do have verbal morphology; they simply do not have morphological agreement (in Norwegian, for example, there is a single present-tense form for all person/number combinations in a given verb class). That is, these languages all do contain a closed-class anchor that in principle could be used by children to acquire the verb placement pattern. So while these languages are problematic for the Rich Agreement Hypothesis, they are not problematic for my hypothesis.

Taking into account languages like Norwegian, the correct typological generalization seems to be that if there is rich morphology, then there is verb movement (Bobaljik, 2002). It is not yet clear why this generalization holds. It could result from some aspect of language acquisition. The results of Chapter 4 suggest that position is one of the first patterns that learners acquire when analyzing closed-class items. In Experiment 8, children learned the sentence position of a closed-class verbal prefix luh even before learning what kinds of open-class words luh occurred with (see section 
4.2.1.5). This initial tendency to analyze closed-class items in a stable position could be related to the typological patterns described above.

\subsection{Outstanding questions}

The results of this dissertation raise a number of important questions for future research, Some of these questions concern anchored distributional analysis more generally, while others arise specifically from my approach.

5.4.1. Questions about anchored distributional analysis

\section{If learners focus so intently on closed-class items, why don't they say them?} This question applies to the Anchoring Hypothesis more generally, and not only the version I have proposed. It cannot be that children do not know that these items exist; the important research by Louann Gerken, Rushen Shi, and colleagues that was reviewed in the Introduction demonstrates that they do. The explanation most convincingly suggested in previous literature concerns their prosody. The likelihood that an element will be included in children's productions seems to be affected quite a bit by whether the element bears stress (Gerken, Landau, \& Remez, 1991; Slobin, 1966; Demuth \& McCullough, 2009; Boom, 1970), and less by the item's meaning or its grammatical function. For example, children have been reported to produce items that are linguistically closed-class when they are prosodically prominent (Slobin, 1966).

The answer may be that children rely on prosodic templates for language production, resulting in the omission of closed-class items in their speech (Gerken, 1991; Demuth \& McCullough, 2009). Younger children may rely more heavily on these 
templates than older children, as part of a general strategy for reducing the complexity of their utterances (L. Bloom, 1970; P. Bloom, 1990; Valian, 1991; Valian \& Aubry, 2005; Valian, 2016). Miniature language experiments may provide a methodology for exploring this issue further. We have done several pilot experiments in which children speak some of the miniature languages used in this dissertation. In these pilot studies, children do treat closed-class items in miniature languages as they treat closed-class items in real languages, that is, they often omit them. We have also seen children initially producing a single form of a verb that occurs with multiple inflections and using that form every time they produce the verb, similar to the use of 'default' forms observed in the acquisition of pronouns and verbal morphology. In ongoing work we are continuing these studies in order to better understand the relationship between children's use of closed-class items as anchors and their production of these items.

\section{Why does the acquisition of closed-class items vary across languages?}

Children begin producing closed-class items at somewhat different times, depending on the language. For example, there are reports that Turkish-learning children produce morphology and use it productively much earlier than English-learning children (Slobin \& Bever, 1982; Aksu-Koç \& Slobin, 1985; Batman-Ratyosyan, 1999). There are probably multiple reasons for this difference. One factor that has generally not been investigated, but which deserves more attention, is the nature of the quantitative evidence for the morphological pattern in children's input. By quantitative evidence I do not mean just raw frequency; I mean the precise mathematical distribution of the closed-class item, such as the probability with which it occurs in a certain position, the probability with which it 
predicts other elements, the extent to which its presence is correlated with other closedclass items, and so on. These mathematical properties are rarely considered as the source of children's success or failure to acquire a particular linguistic element, but the results of this dissertation (and other statistical learning literature) suggest that these types of properties do matter quite a bit. We need more research on the computational mechanisms that learners use to analyze language input and on the mathematical relationships that learners are and are not sensitive to. New findings on this topic could yield further insights into the mechanisms of morphosyntax acquisition and could also help to explain cross-linguistic differences in acquisition.

\section{What properties must a closed-class item have to be analyzed this way?}

Across languages, closed-class items have a cluster of properties that make them highly noticeable (Shi et al., 1998): they tend to be very high frequency, prosodically weak, and have central or reduced vowels and open syllable structure. How many of these properties must an item have to be distinctive? Or is it the correlation among multiple propertiesrather than the presence of any individual property—-that is critical? Sensitivity to correlated cues has been argued to be relevant in a number of other domains, including for detecting the end of phrases (Morgan, Meier, \& Newport, 1987), acquiring grammatical gender (Maratsos \& Chalkley, 1980), and in non-linguistic domains such as concept formation (Caramazza \& Mahon, 2003). In Experiment 7, we showed that learners do analyze a high-frequency form as predictive of other forms even when there are no other cues to closed-class membership. However, more research is needed to 
understand how the various distributional and perceptual properties of closed-class items work together to make these items distinctive.

A related issue is that the specific formal properties of closed-class items vary from language to language. For example, verb stems in Hebrew (like other Semitic languages) consist of a three-consonant frame or root plus a set of vowels which represent the inflection. In American Sign Language, aspect is expressed through movements of the hand through space, while the shape of the hand being moved is part of the verb stem. These types of closed-class forms-discontinuous sets of vowels or movement trajectories-structurally depend on open-class items in the same way that closed-class items depend on open-class items in other languages. That is, if a verbal inflection is present, then a verb will also be present, whether the inflection is a suffix (English), a set of vowels (Hebrew) or a movement trajectory (ASL). Thus, the hypothesized learning mechanism would in principle be just as useful in these languages as in languages like English. However, in these languages, the perceptual identification of the closed class items may be quite different. Do learners indeed attend to closed-class forms in languages like ASL and Hebrew based on their distinctive properties, and then analyze these forms as predictive of other language patterns-despite superficial differences in the form of these items compared to English function words and morphology?

\subsubsection{Questions for my approach}

What about functional categories that behave differently? The hypothesis is that learners analyze closed-class items as predictive of open-class items, and that this approach is useful because it matches the direction of grammatical dependencies in 
natural languages. In real languages, functional categories do generally depend on lexical ones, but the functional/lexical distinction does not map perfectly to the closedclass/open-class one. For example, numerals are analyzed as a functional category in syntax even though the class of numerals is techncially open. On the other hand, prepositions are often analyzed as a lexical category despite being a closed class and containing words with closed-class-like phonological properties. Furthermore, certain functional categories may not necessarily depend on open-class categories: for example, pronouns—analyzed as Determiners—usually occur with a verb (i.e., they are rarely produced in isolation), but these do not structurally depend on the verb in the same way that a verbal inflection does. These theoretical nuances are problematic for any theory where learners must deterministically categorize items as functional or lexical based on universally available and externally observable properties. For example, on the theory that children acquire language by mapping surface forms like 'the' to innate representations like 'Determiner' (i.e., the standard generative account), one has to identify the specific property by which the learner accomplishes this mapping. For my theory, however, the exceptional properties of certain functional categories are in principle not a problem, since the hypothesized learning mechanism does not need to know the category of an element in order to analyze it. Any item that sounds distinctive-whether it has the theoretical status of a functional category or not—should draw learners' attention and be analyzed as hypothesized. If the results of this analysis reveal a predictive dependencyas they usually will—-the learner will encode that pattern. If not, the learner has discovered an exception and will need to analyze the input differently in order to learn 
the exceptional item's distribution. But she only needs to do these additional analyses for closed-class items that are exceptional. ${ }^{15}$ If children follow this learning strategy, the acquisition of exceptional closed-class items such as pronouns should, all else being equal, have a somewhat different trajectory than the acquisition of (for example) determiners. Further research on how learners analyze different types of closed-class items, including items like pronouns, would be valuable for continuing to develop and refine the current proposal.

\section{How detailed must learners' representations of closed-class items be for}

this learning mechanism to work? As shown in work reviewed in the Introduction, children recognize some closed-class items from their language early on. This demonstrates that children must have some minimal representation of these items at this stage. The content of those representations, however, is not at all clear. This issue is worthy of future research in general in addition to being relevant for developing the current proposal. I have claimed that children analyze closed-class items in a particular way because children represent them early, such that the representations are available to learners as units around which to organize other language patterns. But how complete are children's representations at this stage, and is this enough to allow for the learning procedure I have proposed? Evidence from a separate literature on children's use of 'filler syllables' suggests that children initially represent many different closed-class items as a

${ }^{15}$ It is interesting to note that pronouns, the main exception to the generalization that functional categories depend on lexical ones, are special in other ways as well. So the learner needs to pay special attention to them anyway, but it is not clear what would is not clear what would ordinarily tell them this. 
single collapsed category, which often manifests in their speech simply as a schwa

(Bloom, 1970; Peters, 2001). Are children analyzing this underspecified, collapsed category as predictive of other language patterns? Or do they begin doing such analyses only after differentiating closed-class items from one another? This question is particularly important in view of the fact that, in many languages, children produce so much speech before they start using closed-class items. If children can only use closed-class items to organize their knowledge of language after they fully represent each item's phonological content, it is a great mystery why they begin saying closed-class items so late. But if children can use closed-class items in their distributional analyses before knowing exactly what the items are, the mechanism will be much more valuable. This is an important issue for future research.

\section{Do children use this mechanism to acquire the morphosyntactic patterns of} real languages? This is a difficult question to answer using data from natural languages (see Introduction), which is why the work reported here relies on the methodology of miniature language learning. However, it is possible to provide converging evidence for the hypothesized mechanism from natural language acquisition by examining children's error patterns. In Chapter 2 (Section 2.4.1), I pointed out that children learning V2 languages have been observed to make the same kinds of errors as the adult learners in our experiments. Unfortunately, many studies of children's spontaneous speech do not include quantitative data, making it difficult to evaluate how often certain errors occur relative to others. In an ongoing project, we are examining the quantitative analyses of 
children's spontaneous speech that are available, asking whether the distribution of errors is what the hypothesis would predict.

Another way of addressing this question would be to take a comparative approach, asking which closed-class items within a particular language are acquired earlier or later than others, and also comparing the acquisition of closed-class items across languages. This information could then be compared with the quantitative distribution of the closed-class items in children's input; see Why does the acquisition of closed-class items vary across languages? above.

What kinds of patterns can be acquired with this mechanism? I have shown that analyzing closed-class items can yield information about phrasal dependencies such as the ones between determiners and nouns, and about positional contingencies such as the relationship between verb position and verb inflection. Is anchored distributional analysis effective only for patterns that are immediately adjacent to closed-class items, or can this mechanism be used to acquire dependencies across longer distances? Previous studies have suggested that humans struggle to compute statistical relationships between certain types of non-adjacent elements (Newport \& Aslin, 2004); if learners have closedclass items to anchor to, can they learn outside these limits?

How do learners acquire the hierarchical arrangement of closed-class items in a sentence? I have suggested that children start with representations of individual closed-class items and their predictable contexts. These representations could be similar in structure to the pieces of grammatical structure posited in cue-based models of acquisition, (Fodor, 1998; Lightfoot, 2017; Westergaard, 2008), with the important 
difference that my learner's representations would initially be encoded in terms of specific lexical items and superficial surface patterns instead of innate, language-universal categories. These item-based representations would become increasingly detailed as learners (i) generalize across specific lexical items to form grammatical categories such as 'Determiner' and 'Verb' and (ii) acquire more information about the distribution of the closed-class category.

The next step depends on what is innate. If there are innate categories and/or features, this is the point at which children might in principle link these innate representations with their representations of the patterning of particular closed-class items in a language. This transition would mark a discrete change in children's representations, after which these representations could be viewed as consisting of the same types of symbols as those of adults. If such categories are not innate-and, as mentioned above, my own position at present is that they may not need to be-the transition to adultlike representations would be more gradual. Children would build up such representations by continuing to search for patterns that a closed-class item predicts. The patterns that a learner notices will be increasingly abstract, eventually including higher-level properties of the sentence and properties of the discourse context (in order to learn that a particular closed-class category predicts definiteness or contrastive focus). Feature-based approaches to syntax, including modern Minimalist approaches (Chomsky, 1995; Borer, 1984), provide a straightforward formalism for describing these representations since each distributional pattern can be represented as a feature of the closed-class category (the functional head). In accounts of acquisition 
within the feature-assembly framework (Hegarty, 2005; Lardiere 2000, 2008, 2009; Stringer, 2012), language acquisition is a viewed as a process of acquiring the individual functional features of a particular language and determining how those features are grouped onto individual functional heads. The present research can be seen as providing a mechanism for feature-assembly approaches to acquisition, as well as a non-nativist explanation for why syntactic features are automatically assembled onto functional rather than lexical heads (because closed-class items, not open-class items, are the ones whose context is being analyzed).

These are only ideas to be fleshed out in the future. At present, this is not yet a proposal for exactly how learners acquire the hierarchical arrangement of different closed-class items in a sentence, and whether innate knowledge of grammatical categories and/or features plays a role in this process. Further study of this issue will be critical for continuing to connect this mechanistic theory of morphosyntax acquisition to the representations posited by modern syntactic theory. 


\section{REFERENCES}

Abney, S. P. (1987). The English noun phrase in its sentential aspect (Doctoral dissertation). Available from ProQuest Dissertations \& Theses Global. (303643642)

Alexiadou, A., \& Fanselow, G. (2002). On the correlation between morphology and syntax. In Studies in Comparative Germanic Syntax: Proceedings from the 15th Workshop on Comparative Germanic Syntax (Vol. 53, pp. 219-242). Groningen: John Benjamins.

Ambridge, B., \& Lieven, E. V. M. (2011). Child language acquisition: Contrasting theoretical approaches. Cambridge, UK: Cambridge University Press.

Ambridge, B., \& Lieven, E. (2015). A Constructivist account of child language acquisition.

In B. MacWhinney \& W. O’Grady (Eds.), Handbook of Language Emergence (pp. 478-510). Hoboken, NJ: Wiley Blackwell.

Ambridge, B., Pine, J. M., \& Lieven, E. V. M. (2014). Child language acquisition: Why universal grammar doesn't help. Language, 9o(3), e53-e9o.

Aslin, R. N., Saffran, J. R., \& Newport, E. L. (1998). Computation of conditional probability statistics by 8-month-old infants. Psychological Science, 9(4), 321-324.

Austin, A. C. (2010). When children learn more than what they are taught: Regularization in child and adult learners (Doctoral dissertation). Available from ProQuest Dissertations \& Theses Global. (3430798)

Bannard, C., Lieven, E., \& Tomasello, M. (2009). Modeling children's early grammatical knowledge. Proceedings of the National Academy of Sciences of the United States of America, 106(41), 17284-17289.

Batman-Ratyosyan, N. (2003). The acquisition of word order and morphology in Turkish 
(Doctoral Dissertation). Available from ProQuest Dissertations \& Theses Global. (305314909)

Bentzen, K. (2004). V-to-I Movement in the absence of morphological cues: Evidence from adult and child Northern Norwegian. Nordlyd, 31(3).

Bergelson, E., \& Swingley, D. (2012). At 6-9 months, human infants know the meanings of many common nouns. Proceedings of the National Academy of Sciences of the United States of America, 109(9), 3253-3258.

Blom, E. (2008). The acquisition of finiteness. Berlin: De Gruyter.

Bloom, L. (1970). Language development: Form and function in emerging grammars. Cambridge: MIT Press.

Bloom, P. (1990). Subjectless sentences in child language. Linguistic Inquiry, 21(4), 491504 .

Bobaljik, J. D. (2002). Realizing germanic inflection: Why morphology does not drive syntax. The Journal of Comparative Germanic Linguistics, 6(2), 129-167.

Bowerman, M. (1978). Structural relationships in children's utterances: Syntactic or semantic? In L. Bloom (Ed.), Readings in language development (pp. 197-213). New York: Wiley.

Borer, H., \& Wexler, K. (1987). The maturation of syntax. In T. Roeper \& E. Williams (Eds.), Parameter Setting (pp. 123-172). Dordrecht: Springer Netherlands.

Braine, M. D. (1963). On learning the grammatical order of words. Psychological Review, 70, 323-348

Braine, M. D. (1976). Children's first word combinations. Monographs of the Society for 
Research in Child Development, 41(1), 1-104.

Brown, R. (1973). A first language: The early stages. Cambridge, MA: Harvard U. Press.

Chung, G. N. (1994). Case and its acquisition in Korean (Doctoral dissertation). Available from ProQuest Dissertations \& Theses Global. (304138672)

Clahsen, H., Eisenbeiss, S., \& Penke, M. (1996). Lexical learning in early syntactic development. In H. Clahsen (Ed.), Generative perspectives on language acquisition (Vol. 14, p. 129-159). Amsterdam: John Benjamins.

Clahsen, H., \& Penke, M. (1992). The acquisition of agreement morphology and its syntactic consequences: New evidence on German child language from the Simone corpus. In J. M. Meisel (Ed.), The Acquisition of Verb Placement (pp. 181-223). Springer Netherlands.

Clahsen, H., Penke, M., \& Parodi, T. (1993). Functional categories in early child German. Language Acquisition, 3(4), 395-429.

Clark, H. H., \& Clark, E. V. (1977). Psychology and language: An introduction to psycholinguists. New York: Harcourt Brace Jovanovich.

Crain, S., \& Nakayama, M. (1987). Structure dependence in grammar formation. Language, 63(3), 522-543.

Crain, S., \& Thornton, R. (1998). Investigations in Universal Grammar: A guide to experiments on the acquisition of syntax and semantics. Cambridge, MA: The MIT Press.

Culbertson, J., \& Newport, E. L. (2015). Harmonic biases in child learners: in support of language universals. Cognition, 139, 71-82. 
Culbertson, J., \& Newport, E. L. (2017). Innovation of word order harmony across development. Open Mind, 1(2), 91-100.

Demuth, K., \& McCullough, E. (2009). The prosodic (re)organization of children's early English articles. Journal of Child Language, 36(1), 173-200.

Déprez, V., \& Pierce, A. (1993). Negation and functional projections in early grammar. Linguistic Inquiry , 24(1), 25-67.

Déprez, V., \& Pierce, A. (1994). Crosslinguistic evidence for functional projections in early child grammar. In T. Hoekstra \& B. D. Schwartz (Eds.), Language Acquisition Studies in Generative Grammar (p. 57-84). Amsterdam: John Benjamins.

Dye, C. D. (2011). Reduced auxiliaries in early child language: Converging observational and experimental evidence from French. Journal of Linguistics, 47(2), 301-339.

Endress, A. D., Nespor, M., \& Mehler, J. (2009). Perceptual and memory constraints on language acquisition. Trends in Cognitive Sciences, 13(8), 348-353.

Fisher, C. (2002). The role of abstract syntactic knowledge in language acquisition: a reply to Tomasello (2000). Cognition, 82(3), 259-278.

Fodor, J. D. (1998). Parsing to learn. Journal of Psycholinguistic Research, 27(3), 339-374.

Freudenthal, D., Pine, J. M., Aguado-Orea, J., \& Gobet, F. (2007). Modeling the developmental patterning of finiteness marking in English, Dutch, German, and Spanish using MOSAIC. Cognitive Science, 31(2), 311-341.

Gerken, L., Landau, B., \& Remez, R. E. (1990). Function morphemes in young children's speech perception and production. Developmental Psychology, 26(2), 204-216.

Gerken, L., \& McIntosh, B. J. (1993). Interplay of function morphemes and prosody in 
early language. Developmental Psychology, 29(3), 448-457.

Gervain, J., Nespor, M., Mazuka, R., Horie, R., \& Mehler, J. (2008). Bootstrapping word order in prelexical infants: A Japanese-Italian cross-linguistic study. Cognitive Psychology, 57(1), 56-74.

Getz, H. (2018). Acquiring wanna: Beyond Universal Grammar. Language Acquisition.

Gleitman, L. (1990). The structural sources of verb meanings. Language Acquisition, 1(1), $3-55$

Gleitman, L. R., \& Wanner, E. (1982). The state of the art of the state of the art. In E. Wanner \& L. R. Gleitman (Eds.), Language acquisition: The state of the art. Cambridge: Cambridge University Press.

Gleitman, L. R., \& Wanner, E. (1984). Richly specified input to language learning. In O. G. Selfridge, E. L. Rissland, \& M. A. Arbib (Eds.), Adaptive Control of Ill-Defined Systems (pp. 227-249). Boston, MA: Springer US.

Goldin-Meadow, S. (1979). Structure in a manual communication system developed without a conventional language model: Language without a helping hand. In $\mathrm{H}$. Whitaker \& H. Whitaker (Eds.), Studies in Neurolinguistics (Vol. 4, pp. 125-209). New York: Academic Press.

Guilfoyle, E., \& Noonan, M. (1992). Functional categories and language acquisition. Canadian Journal of Linguistics-Revue Canadienne de Linguistique, 37(2), 241-272.

Haan, G. R. de. (1987). A theory-bound approach to the acquisition of verb placement in Dutch. In G. de Haan \& W. Zonneveld (Eds.), Formal parameters of generative grammar, Yearbook III (pp. 15-30).Utrecht: University of Utrecht. 
Haegeman, L. (1995). Root infinitives, tense, and truncated structures in Dutch. Language Acquisition, 4(3), 205-255.

Hakuta, K. (1982). Interaction between particles and word order in the comprehension and production of simple sentences in Japanese children. Developmental Psychology, 18(1), 62-76.

Hegarty, M. (2005). A feature-based syntax of functional categories: the structure, acquisition and specific impairment of functional systems (Vol. 79). Berlin: Mouton de Gruyter.

Höhle, B., \& Weissenborn, J. (2003). German-learning infants' ability to detect unstressed closed-class elements in continuous speech. Developmental Science, 6(2), 122-127.

Hudson Kam, C. L., \& Newport, E. L. (2005). Regularizing unpredictable variation: The roles of adult and child learners in language formation and change. Language Learning and Development, 1(2), 151-195.

Hudson Kam, C. L., \& Newport, E. L. (2009). Getting it right by getting it wrong: when learners change languages. Cognitive Psychology, 59(1), 30-66.

Hyams, N. (1994). V2, null arguments and COMP projections. In T. Hoekstra \& B. D. Schwartz (Eds.), Language Acquisition Studies in Generative Grammar (pp. 21-55).

Hyams, N. (1996). The underspecification of functional categories in early grammar. In H. Clahsen (Ed.), Generative perspectives on language acquisition (Vol. 14, pp. 91-128). Amsterdam: John Benjamins.

Jordens, P. (1990). The acquisition of verb placement in Dutch and German. Linguistics and Philosophy, 28(6), 1407-1448. 
Kimball, J. (1973). Seven principles of surface structure parsing in natural language. Cognition, 2(1), 15-47.

Kramer, R. (2010). The Amharic definite marker and the syntax-morphology interface. Syntax , 13(3), 196-240.

Lardiere, D. (2000). Mapping features to forms in second language acquisition. In J. Archibald (Ed.), Second language acquisition and linguistic theory (pp. 102-129). Malden, MA: Blackwell.

Lardiere, D. (2008). Feature assembly in second language acquisition. In J. M. Liceras, H. Zobl, \& H. Goodluck (Eds.), The role of formal features in second language acquisition (pp. 106-140). Mahwah, NJ: Lawrence Erlbaum Associates.

Lardiere, D. (2009). Some thoughts on the contrastive analysis of features in second language acquisition. Second Language Research, 25(2), 173-227.

Legendre, G., Barrière, I., Goyet, L., \& Nazzi, T. (2010). Comprehension of infrequent subject-verb agreement forms: Evidence from French-learning children. Child Development, 81(6), 1859-1875.

Lightfoot, D. (1995). Why UG needs a learning theory: triggering verb movement. In A.

Battye \& I. Roberts (Eds.), Clause structure and language change (pp. 31-52). Oxford: Oxford University Press.

Lightfoot, D. W. (2017). Discovering new variable properties without parameters. In Parameters. Linguistic Analysis, 41(3-4), special edition, edited by Massimo PiattelliPalmarini and Simin Karimi, 409-444.

MacWhinney, B. (200o). The CHILDES project: The database. Mahwah, NJ: Lawrence 


\section{Erlbaum.}

Maratsos, M., \& Chalkley, M. (1980). The internal language of children's syntax: The ontogenesis and representation of syntactic categories. In K. Nelson (Ed.), Children's language: Volume 2 (pp. 127-214).

Marquis, A., \& Shi, R. (2008). Segmentation of verb forms in preverbal infants. The Journal of the Acoustical Society of America, 123(4), EL105-EL110.

Marquis, A., \& Shi, R. (2012). Initial morphological learning in preverbal infants. Cognition, 122(1), 61-66.

Miller, M. (1979). The Logic of Language Development in Early Childhood. Berlin: SpringerVerlag.

Morgan, J. L., Meier, R. P., \& Newport, E. L. (1987). Structural packaging in the input to language learning: contributions of prosodic and morphological marking of phrases to the acquisition of language. Cognitive Psychology, 19(4), 498-550.

Nazzi, T., Barrière, I., Goyet, L., Kresh, S., \& Legendre, G. (2011). Tracking irregular morphophonological dependencies in natural language: evidence from the acquisition of subject-verb agreement in French. Cognition, 120(1), 119-135.

Neokleous, T. (2015). The L1 acquisition of clitic placement in Cypriot Greek. Lingua. International Review of General Linguistics. Revue Internationale de Linguistique Generale, 161, 27-47.

Newport, E. L. (1990). Maturational constraints on language learning. Cognitive Science, $14,11-28$.

Newport, E. L., \& Aslin, R. N. (2004). Learning at a distance I. Statistical learning of non- 
adjacent dependencies. Cognitive Psychology, 48(2), 127-162.

Pelucchi, B., Hay, J. F., \& Saffran, J. R. (2009). Learning in reverse: eight-month-old infants track backward transitional probabilities. Cognition, 113(2), 244-247.

Peters, A. M. (2001). Filler syllables: what is their status in emerging grammar? Journal of Child Language, 28(1), 229-242; discussion 254-256, 269-274.

Perruchet, P., \& Desaulty, S. (2008). A role for backward transitional probabilities in word segmentation? Memory \& Cognition, 36(7), 1299-1305.

Pierce, A. E. (1992). Language acquisition and syntactic theory: A comparative analysis of French and English child grammars. Dordrecht: Springer Science \& Business Media.

Pinker, S. (1984). Language learnability and language development. Cambridge, MA: Harvard University Press.

Platzack, C. (1990). A grammar without functional categories: A syntactic study of early Swedish child language. Nordic Journal of Linguistics, 13(02), 107.

Platzack, C. (1996). The initial hypothesis of syntax. In H. Clahsen (Ed.), Generative perspectives on language acquisition (pp. 369-414). Amsterdam: John Benjamins.

Poeppel, D., \& Wexler, K. (1993). The full competence hypothesis of clause structure in early German. Language, 69(1), 1-33.

Radford, A. (1990). Syntactic theory and the acquisition of English syntax: The nature of early child grammars of English. Oxford: Blackwell.

Reeder, P. A., Newport, E. L., \& Aslin, R. N. (2013). From shared contexts to syntactic categories: the role of distributional information in learning linguistic form-classes. Cognitive Psychology, 66(1), 30-54. 
Rescorla, R. A. (1966). Predictability and number of pairings in Pavlovian fear conditioning. Psychonomic Science, 4(11), 383-384.

Rizzi, L. (1994). Early null subjects and root null subjects. In T. Hoekstra \& B. D. Schwartz (Eds.), Language Acquisition Studies in Generative Grammar (pp. 151-176).

Rizzi, L., \& Cinque, G. (2016). Functional categories and syntactic theory. Annual Review of Linguistics, 2(1), 139-163.

Rohrbacher, B. W. (1999). Morphology-driven syntax: A theory of V to I raising and prodrop. Amsterdam: John Benjamins.

Rohrbacher, B., \& Vainikka, A. (1994). On German verb syntax under age 2. In Proceedings of the 19th Annual Boston University Conference on Language Development (Vol. 2, p. 170). Somerville, MA: Cascadilla.

Rohrbacher, B., \& Vainikka, A. (1994). On German verb syntax under age 2. In IRCS Tech. Rep. No. 94-24. Philadelphia: University of Pennsylvania.

Saffran, J. R. (2001). The use of predictive dependencies in language learning. Journal of Memory and Language, 44(4), 493-515.

Saffran, J. R., Aslin, R. N., \& Newport, E. L. (1996). Statistical learning by 8-month-old infants. Science, 274(5294), 1926-1928.

Saffran, J. R., Newport, E. L., \& Aslin, R. N. (1996). Word segmentation: The role of distributional cues. Journal of Memory and Language, 35(4), 606-621.

Santelmann, L. M., \& Jusczyk, P. W. (1998). Sensitivity to discontinuous dependencies in language learners: evidence for limitations in processing space. Cognition, 69(2), 105134 . 
Santelmann, L., Berk, S., Austin, J., Somashekar, S., \& Lust, B. (2002). Continuity and development in the acquisition of inversion in yes/no questions: dissociating movement and inflection. Journal of Child Language, 29(4), 813-842.

Schuler, K. (2017). The acquisition of productive rules in child and adult language learners (Doctoral dissertation). Available from ProQuest Dissertations \& Theses Global. $(1958956127)$

Schuler, K. D., Reeder, P. A., Newport, E. L., \& Aslin, R. N. (2017). The effect of Zipfian frequency variations on category formation in adult artificial language learning. Language Learning and Development, 13(4), 357-374.

Schuler, K., Yang, C., \& Newport, E. (2016). Testing the Tolerance Principle: Children form productive rules when it is more computationally efficient to do so. In Proceedings of the 38th Annual Conference of the Cognitive Science Society (pp. 2321-2326). Austin, TX: Cognitive Science Society.

Seligman, M. E. (1970). On the generality of the laws of learning. Psychological Review, 77(5), 406-418.

Shafer, V. L., Shucard, D. W., Shucard, J. L., \& Gerken, L. (1998). An electrophysiological study of infants' sensitivity to the sound patterns of English speech. Journal of Speech, Language, and Hearing Research:JSLHR, 41(4), 874-886.

Shi, R., Cutler, A., Werker, J., \& Cruickshank, M. (2006). Frequency and form as determinants of functor sensitivity in English-acquiring infants. The Journal of the Acoustical Society of America, 119(6), EL61-EL67.

Shi, R., \& Lepage, M. (2008). The effect of functional morphemes on word segmentation 
in preverbal infants. Developmental Science, 11(3), 407-413.

Shi, R., Morgan, J. L., \& Allopenna, P. (1998). Phonological and acoustic bases for earliest grammatical category assignment: a cross-linguistic perspective. Journal of Child Language, 25(1), 169-201.

Shi, R., Werker, J. F., \& Morgan, J. L. (1999). Newborn infants' sensitivity to perceptual cues to lexical and grammatical words. Cognition, 72(2), B11-B21.

Slobin, D. I. (1966). The acquisition of Russian as a native language. In F. Smith \& G. A. Miller (Eds.), The genesis of language (pp. 129-135). Cambridge: MIT Press.

Slobin, D. I. (1973). Cognitive prerequisites for the development of grammar. In C. A. Ferguson \& D. I. Slobin (Eds.), Studies of child language development (pp. 175-208). New York: Holt, Rinehart \& Winston.

Soderstrom, M., White, K. S., Conwell, E., \& Morgan, J. L. (2007). Receptive grammatical knowledge of familiar content words and inflection in 16-month-olds. Infancy, 12(1), $1-29$.

Stringer, D. (2012). Spatial feature assembly in first and second language acquisition. Spatial Cognition and Computation, 12(4), 252-274.

Thompson, S. P., \& Newport, E. L. (2007). Statistical learning of syntax: The role of transitional probability. Language Learning and Development, 3(1), 1-42.

Tomasello, M. (2000). Do young children have adult syntactic competence? Cognition, 74(3), 209-253.

Vainikka, A. (1993). Case in the development of English syntax. Language Acquisition, 3(3), $257-325$ 
Valian, V. (1986). Syntactic categories in the speech of young children. Developmental Psychology, 22(4), 562-579.

Valian, V. (1991). Syntactic subjects in the early speech of American and Italian children. Cognition, 40(1-2), 21-81.

Valian, V. (2016). When children don't say what they know: Syntax acquisition and executive function. In D. Barner \& A. S. Baron (Eds.), Core Knowledge and Conceptual Change. Oxford: Oxford University Press.

Valian, V., \& Aubry, S. (2005). When opportunity knocks twice: two-year-olds' repetition of sentence subjects. Journal of Child Language, 32(3), 617-641.

Valian, V., \& Coulson, S. (1988). Anchor points in language learning: The role of marker frequency. Journal of Memory and Language, 27(1), 71-86.

Valian, V., Solt, S., \& Stewart, J. (2009). Abstract categories or limited-scope formulae? The case of children's determiners. Journal of Child Language, 36(4), 743-778.

Verrips, M., \& Weissenborn, J. (1992). Routes to verb placement in early German and French: The independence of finiteness and agreement. In J. M. Meisel (Ed.), The Acquisition of Verb Placement (pp. 283-331). Springer Netherlands.

Westergaard, M. (2008). Verb movement and subject placement in the acquisition of word order. In P. G. Fuentes, M. P. Larrañaga, \& J. Clibbins (Eds.), First language acquisition of morphology and syntax: Perspectives across languages and learners. Amsterdam: John Benjamins.

Westergaard, M. (2009). Usage-based vs. rule-based learning: the acquisition of word order in wh-questions in English and Norwegian. Journal of Child Language, 36(5), 
$1023-1051$.

Wexler, K. (1994). Optional infinitives, head movement and the economy of derivations. In D. Lightfoot \& N. Hornstein (Eds.), Verb movement (pp. 305-350). Cambridge University Press.

Wexler, K. (1998). Very early parameter setting and the unique checking constraint: A new explanation of the optional infinitive stage. Lingua, 106(1), 23-79.

Wonnacott, E., Newport, E. L., \& Tanenhaus, M. K. (2008). Acquiring and processing verb argument structure: distributional learning in a miniature language. Cognitive Psychology, 56(3), 165-209.

Yang, C. (2013). Ontogeny and phylogeny of language. Proceedings of the National Academy of Sciences of the United States of America, 110(16), 6324-6327.

Zhang, Z., Shi, R., \& Li, A. (2015). Grammatical categorization in Mandarin-Chineselearning infants. Language Acquisition, 22(1), 104-115. 